Florida International University

FIU Digital Commons

3-18-2019

\title{
Toward a Better Understanding of the Roles of Social Exchanges and Psychological Safety on Followers' Change-Oriented Behaviors
}

Cynthia Saldanha Halliday

Florida International University, chall061@fiu.edu

Follow this and additional works at: https://digitalcommons.fiu.edu/etd

Part of the Business Administration, Management, and Operations Commons, Management Sciences and Quantitative Methods Commons, and the Organizational Behavior and Theory Commons

\section{Recommended Citation}

Halliday, Cynthia Saldanha, "Toward a Better Understanding of the Roles of Social Exchanges and Psychological Safety on Followers' Change-Oriented Behaviors" (2019). FIU Electronic Theses and Dissertations. 3959.

https://digitalcommons.fiu.edu/etd/3959

This work is brought to you for free and open access by the University Graduate School at FIU Digital Commons. It has been accepted for inclusion in FIU Electronic Theses and Dissertations by an authorized administrator of FIU Digital Commons. For more information, please contact dcc@fiu.edu. 


\section{FLORIDA INTERNATIONAL UNIVERSITY}

Miami, Florida

TOWARD A BETTER UNDERSTANDING OF THE ROLES OF

SOCIAL EXCHANGES AND PSYCHOLOGICAL SAFETY

ON FOLLOWERS' CHANGE-ORIENTED BEHAVIORS

A dissertation submitted in partial fulfillment of the

requirements for the degree of

DOCTOR OF PHILOSOPHY

in

BUSINESS ADMINISTRATION

by

Cynthia Saldanha Halliday

2019 
To: Dean Joanne Li

College of Business

This dissertation, written by Cynthia Saldanha Halliday, and entitled Toward a Better Understanding of the Roles of Social Exchanges and Psychological Safety on Followers' Change-Oriented Behaviors, having been approved in respect to style and intellectual content, is referred to you for judgment.

We have read this dissertation and recommend that it be approved.

Samantha Paustian-Underdahl

Chockalingam Viswesvaran

Stav Fainshmidt

Nathan J. Hiller

Hock-Peng Sin, Major Professor

Date of Defense: March 18, 2019

The dissertation of Cynthia Saldanha Halliday is approved.

Dean Joanne Li

College of Business

Andrés G. Gil

Vice President for Research and Economic Development and Dean of the University Graduate School

Florida International University, 2019 
(C) Copyright 2019 by Cynthia Saldanha Halliday

All rights reserved. 


\section{DEDICATION}

I dedicate this dissertation to

my husband, children, and parents. 


\section{ACKNOWLEDGMENTS}

I would like to acknowledge those who contributed to the completion of my dissertation and doctoral degree.

Family - To my husband and children: You endured so much during my doctoral studies. I am eternally grateful for your love, understanding, support, patience, encouragement, and selfless sacrifice. To my mother (in memory), father, and sister: You paved the way from the beginning of my life to allow me to complete the highest level of education. I appreciate your love, trust and confidence in me.

Dissertation Committee - To my committee chair and advisor, Dr. Hock-Peng Sin: Thank you for accepting this role and encouraging me to explore my research interests. I appreciate your guidance and wisdom throughout the process. To Dr. Sam Paustian-Underdahl and Dr. Stav Fainshmidt: I am deeply grateful for the research and learning opportunities your generously offered me while working with you in the past several years. I appreciate your friendship and mentorship. To Dr. Nathan J. Hiller and Dr. Chockalingam Viswesvaran: Your knowledge inspires me to continuously develop myself. Thank you for your time and insightful feedback. To my entire committee: I appreciate your example of how to become a successful scholar.

Mentors - To Dr. Lee Radebaugh: I am profoundly grateful for your friendship. You showed me through your example that academia can be fun. Thank you for your leadership, dedication, hard work, and mentorship. I have always enjoyed working with you. To Dr. Kristie Seawright: I am thankful for your guidance and friendship when I was contemplating a doctoral degree. To Dr. Brooke Derr: You opened the door to 
academia for me, which instilled in me the desire to eventually pursue a doctoral degree; and for that, I will be always indebted to you.

GLAM and IB Faculty - To Dr. Mary Ann Von Glinow: You pushed me from the very beginning to write and publish; and I feel honored to have your name in my first research publication. I will remember your kind invitations for dinner in the best restaurants in Miami. To Dr. William Newburry and Dr. Juan Sanchez: Thank you for your generosity and teaching opportunities. You made it financially possible for me to present at academic conferences and complete my doctoral studies. To all other faculty members: Thank you for the lessons you taught me.

Other College of Business and FIU Personnel - To Dr. George Marakas, Yasemin Shirazi, Rosa Cellutti, Janite Grooms, and Stefannie Aguilar: You made a big difference in my life as a graduate student, thank you. To the University Graduate School and the Graduate and Professional Student Committee: I express my gratitude for the Dissertation Year Fellowship and several financial grants that allowed me to travel to conferences and graduate. Your generosity is sincerely appreciated.

Ph.D. Students - To Ajay Ponnapalli, Chen Wang, Eve Misati, Lucas Wenger, Mohan Song, Sibel Ozgen, and Yue Zhao: Your friendship, humor and enthusiasm were the cherry on the top of the ice-cream. I enjoyed the stimulating discussions that we had throughout the program and appreciate the encouragement and emotional support when times were challenging. These moments will be forever cherished.

Organizations - I express gratitude to the leaders and employees of four organizations located in the United States, who willingly participated in the collection of the data for this dissertation and made this work possible. 


\author{
ABSTRACT OF THE DISSERTATION \\ TOWARD A BETTER UNDERSTANDING OF THE ROLES OF \\ SOCIAL EXCHANGES AND PSYCHOLOGICAL SAFETY \\ ON FOLLOWERS' CHANGE-ORIENTED BEHAVIORS
}

by

Cynthia Saldanha Halliday

Florida International University, 2019

Miami, Florida

Professor Hock-Peng Sin, Major Professor

Organizational change and innovation are critical for business survival and more likely to occur when employees engage in change-oriented behaviors. Previous studies have examined the direct effects of workplace social exchanges on employees' changeoriented behaviors; however, less attention has been given to the combined effects of these exchanges and the mechanisms by which these relationships occur. In this study, I look at the combined effects of leader-member exchange, trust in team members, and perceived organizational support on voice, innovative, and learning behaviors via psychological safety. In addition, based on the understanding that psychological safety is not always present in the work environment, I look at the conditions under which these workplace social exchanges lead to the aforementioned behaviors even when psychological safety is low or absent. Therefore, the purpose of this dissertation is threefold: (1) to explore the combined effects of leader-member exchange, trust in team members, and perceived organizational support in improving followers' psychological safety within the organization, (2) to investigate the mediating role of psychological 
safety on the relationships between workplace social exchanges and followers' changeoriented behaviors, and (3) to expand on previous findings and examine the conditions under which these social exchanges and psychological safety lead to followers' changeoriented behaviors. Specifically, I propose and test a theoretical model derived from social exchange theory to examine conditional indirect effects of leader-member exchange, trust in team members, and perceived organizational support on voice, innovative, and learning behaviors through psychological safety within the organization, and to examine the role of proactive personality, political skill, perceived team social integration, perceived support for innovation and perceived organizational justice as second stage moderating variables that may compensate for low psychological safety within the organization. My theoretical model was tested using lagged data collected from leader-follower dyads representing 174 followers and 85 leaders from four organizations located in the United States. To test this theoretical model, I used a quantitative non-experimental research design, a survey method, and multilevel analytical procedures. 


\section{TABLE OF CONTENTS}

CHAPTER

PAGE

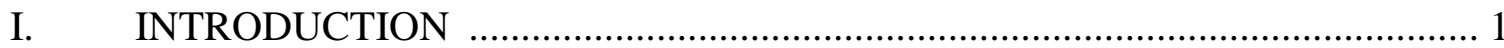

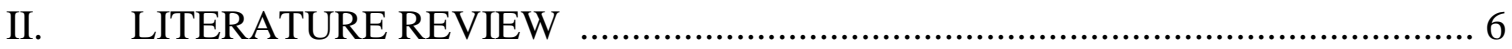

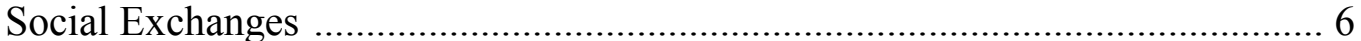

Psychological Safety Within the Organization ............................................ 13

Psychological Safety Within the Organization as a Mediator of the Relationships

Between Leader-Member Exchange, Trust in Team Members, and Perceived

Organizational Support, and Followers' Change-Oriented

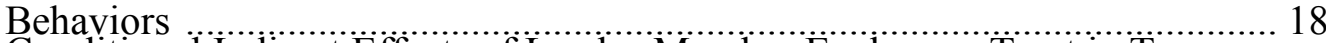

Conditional Indirect Effects of Leader-Member Exchange, Trust in Team

Members, and Perceived Organizational Support on Followers' Change-

Oriented Behaviors via Psychological Safety Within the Organization ........... 25

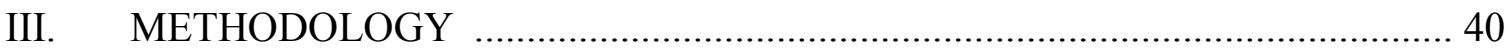

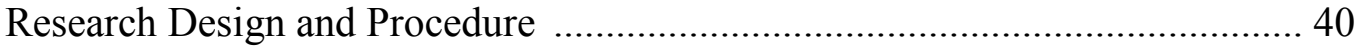

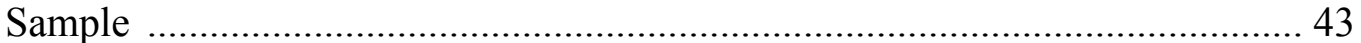

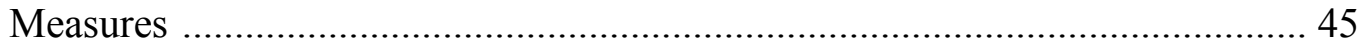

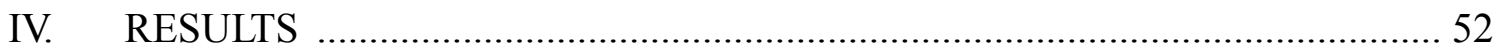

Preliminary Data Analyses .................................................................... 52

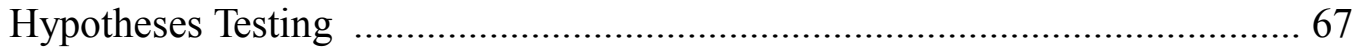

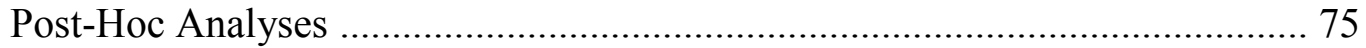

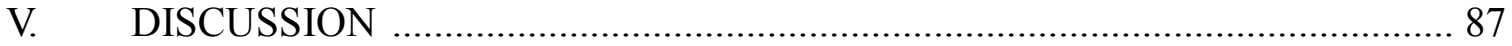

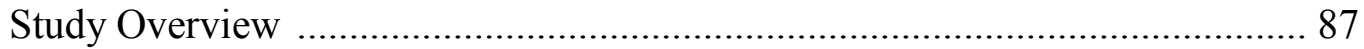

Implications for Theory and Practice ......................................................... 88

Limitations and Future Research .............................................................. 96

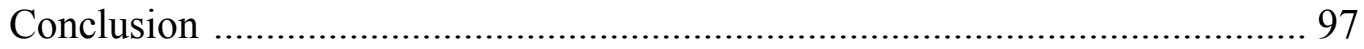

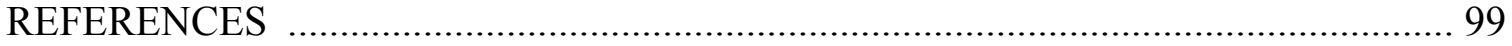

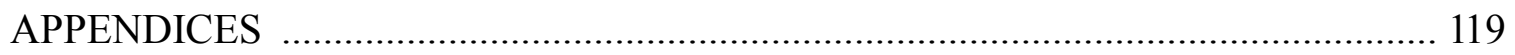

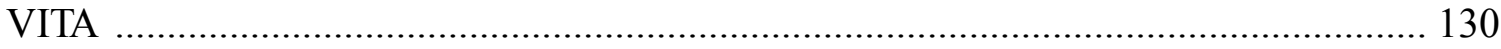




\section{LIST OF TABLES}

TABLE

PAGE

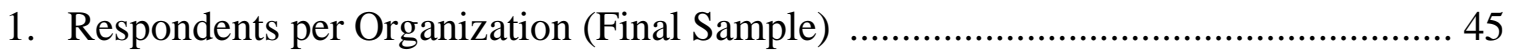

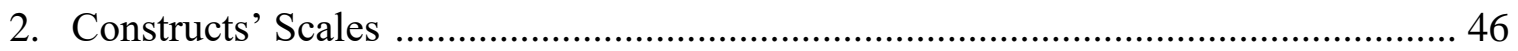

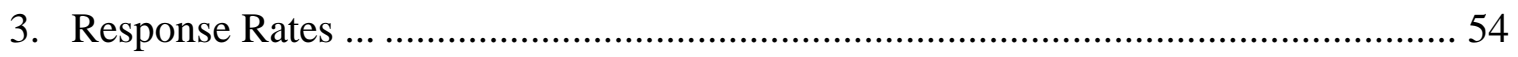

4. Confirmatory Factor Analysis for Independent and Mediator Variables .................. 58

5. Confirmatory Factor Analysis for Dependent Variables ..................................... 59

6. Descriptive Statistics, Inter-Correlations, and Reliabilities of Study Variables ........ 62

7. Skewness and Kurtosis Statistics of Psychological Safety Within the Organization, Voice Behavior, Innovative Behavior, and Learning Behavior

8. Direct Effects of Leader-Member Exchange, Trust in Team Members, and Perceived Organizational Support on Psychological Safety Within the Organization 68

9. Direct Effects of Psychological Safety Within the Organization on Voice Behavior, Innovative Behavior, and Learning Behavior

10. Indirect Effects of Leader-Member Exchange, Trust in Team Members, and Perceived Organizational Support on Voice Behavior via Psychological Safety Within the Organization

11. Indirect Effects of Leader-Member Exchange, Trust in Team Members, and Perceived Organizational Support on Innovative Behavior via Psychological Safety Within the Organization

12. Indirect Effects of Leader-Member Exchange, Trust in Team Members, and Perceived Organizational Support on Learning Behavior via Psychological Safety Within the Organization

13. Conditional Indirect Effects of Leader-Member Exchange, Trust in Team Members, and Perceived Organizational Support on Voice Behavior, Innovative Behavior, and Learning Behavior via Psychological Safety Within the Organization X Proactive Personality

14. Conditional Indirect Effects of Leader-Member Exchange, Trust in Team Members, and Perceived Organizational Support on Voice Behavior, Innovative Behavior, and Learning Behavior via Psychological Safety Within the Organization X Political Skill 
15. Conditional Indirect Effects of Leader-Member Exchange, Trust in Team Members, and Perceived Organizational Support on Voice Behavior, Innovative Behavior, and Learning Behavior via Psychological Safety Within the Organization X Perceived Team Social Integration

16. Conditional Indirect Effects of Leader-Member Exchange, Trust in Team Members, and Perceived Organizational Support on Voice Behavior, Innovative Behavior, and Learning Behavior via Psychological Safety Within the Organization X Perceived Support for Innovation

17. Conditional Indirect Effects of Leader-Member Exchange, Trust in Team Members, and Perceived Organizational Support on Voice Behavior, Innovative Behavior, and Learning Behavior via Psychological Safety Within the Organization X Perceived Distributive Justice

18. Conditional Indirect Effects of Leader-Member Exchange, Trust in Team Members, and Perceived Organizational Support on Voice Behavior, Innovative Behavior, and Learning Behavior via Psychological Safety Within the Organization X Perceived Procedural Justice

19. Direct Effects of Psychological Safety Within the Organization on Promotive Voice Behavior and Prohibitive Voice Behavior 76

20. Indirect Effects of Leader-Member Exchange, Trust in Team Members, and Perceived Organizational Support on Promotive Voice Behavior and Prohibitive Voice Behavior via Psychological Safety Within the Organization

21. Conditional Indirect Effects of Leader-Member Exchange, Trust in Team Members, and Perceived Organizational Support on Promotive Voice Behavior and Prohibitive Voice Behavior via Psychological Safety Within the Organization ..79

22. Direct Effects of Psychological Safety Within the Organization on Idea Generation, Idea Promotion, and Idea Realization

23. Indirect Effects of Leader-Member Exchange, Trust in Team Members, and Perceived Organizational Support on Idea Generation, Idea Promotion, and Idea Realization, via Psychological Safety Within the Organization

24. Conditional Indirect Effects of Leader-Member Exchange, Trust in Team Members, and Perceived Organizational Support on Idea Generation, Idea Realization, and Idea Promotion, via Psychological Safety Within the Organization 82

25. Summary of the Hypotheses 84 


\section{CHAPTER I}

\section{INTRODUCTION}

"When you're finished changing, you're finished."

— Benjamin Franklin

Due to the dynamics of the global market, organizations must embrace continuous change and innovation to remain competitive and realize their long-term goals. Indeed, several once thriving organizations, such as Blockbuster, Borders, Circuit City, Kodak, and Radio Shack, did not survive the pressures of the competitive market due to the lack of change and innovation (Bosman \& de la Merced, 2011; de la Merced, 2010; Jacobs, 2008; McCarty \& Jinks, 2012; Rizzo \& Fitzgerald, 2017). Organizational change and innovation are more likely to occur when employees engage in change-oriented behaviors. Indeed, studies have shown that change-oriented behaviors, such as voice, innovative, and learning behaviors, are often regarded as key factors that lead to organizational success (Carson, Tesluk, \& Marrone, 2007; Edmondson, 1999; Maurer \& Tarulli, 1994; Morrison \& Milliken, 2000; Stern, Katz-Navon, \& Naveh, 2008). Thus, with the increasing pressure and fast-paced evolution of the competitive world, it is important to understand how organizations and leaders can foster employee behaviors that lead to change and innovation.

Researchers have examined the role of workplace social exchanges on several employees' behaviors, such as voice, innovative, and learning behaviors (Loi, Ao, \& Xu, 2014; Van Dyne, Kamdar, \& Joirernan, 2008; Walumbwa, Cropanzano, \& Hartnell, 2009; Wang, Fang, Qureshi, \& Janssen, 2015; Young, 2012). Despite the increasing number of studies investigating the relationships between social exchanges and change- 
oriented behaviors, these studies usually look at one social exchange in a single relationship at a time; yet, a social exchange does not happen in isolation in the workplace. As Blau (1964) suggested, in order to have a better understanding of how social exchanges affect employees' outcomes, it is important to take into consideration other relationships (i.e., at the individual, group, and organizational levels) in the same context of the focal relationship being studied. Thus, I examine the combined effects of leader-member exchange, trust in team members, and perceived organizational support on the several relationships being investigated in this dissertation.

In addition, less attention has been given to the mechanisms by which these relationships occur, although evidence has emerged of the presence of such mechanisms (e.g., Burris, Detert, \& Chiaburu, 2008; Schermuly, Meyer, \& Dämmer, 2013; Wang, Gan, \& Wu, 2016). In an in-house study conducted by Google Inc., psychological safety was found to be a critical ingredient for team success (Duhigg, 2016). Acknowledging its benefits prior to the aforementioned study, researchers have been exploring the conditions that may create a feeling of psychological safety (Nembhard \& Edmondson, 2006; for a meta-analysis, see Frazier, Fainshmidt, Klinger, Pezeshkan, and Vracheva, 2017). Yet, the role of social exchanges on followers' perceptions of psychological safety within the organization has received minimal attention. Drawing from social exchange theory (Blau, 1964), I propose that psychological safety within the organization may be an important mechanism through which social exchange factors lead to change-oriented behaviors. Psychological safety is the belief that one is safe to speak up about new ideas, concerns or mistakes with no negative consequences (Edmondson, 1999), and there is growing evidence suggesting that psychological safety is associated with several 
behaviors that lead to change (Edmondson, 2004; Leung, Deng, Wang, \& Zhou, 2015;

Liu, Tangirala, Lam, Chen, Jia, \& Huang, 2015; Nembhard \& Edmondson, 2006). Thus, I explore the instrumental value of leader-member exchange, trust in team members, and perceived organizational support in improving followers' psychological safety within the organization, which in turn leads to voice, innovative, and learning behaviors.

Moreover, when followers perceive to be in a psychologically unsafe environment, I propose that there are other factors at the individual, team, and organizational levels that may compensate for the absence or low levels of psychological safety within the organization, such that the positive relationships between psychological safety and voice, innovative, and learning behaviors are stronger when these factors are low, and psychological safety becomes less important when these factors are high. In fact, these boundary elements have also been related to several change-oriented behaviors. For example, proactive personality, political skill, and perceived organizational justice have been associated with learning behavior (Sun \& van Emmerik, 2015; Walumbwa et al., 2009) and proactive personality and perceived support for innovation have been related to innovative behavior (Gong, Cheung, Wang, \& Huang, 2012; Scott \& Bruce, 1994). Furthermore, van der Vegt, Bunderson and Kuipers (2010) found that social integration was positively related to learning behavior and Takeuchi, Chen, and Cheung (2012) found that both distributive and procedural justice were related to voice behavior. Thus, I investigate the moderating effects of proactive personality, political skill, perceived team social integration, perceived support for innovation, and perceived organizational justice on the relationships between psychological safety within the organization and voice, innovative, and learning behaviors. 
This study aims to make several important contributions to the literature on social exchanges and change-oriented behaviors. First, by investigating the combined effects of leader-member exchange, trust in team members, and perceived organizational support, I examine the factors that are more likely to lead to psychological safety within the organization. This is important because one social exchange is embedded in several other workplace social exchanges that may affect each other, a condition that is often overlooked when investigating workplace relationships. Second, I study one mechanism by which these social exchanges may lead to change-oriented behaviors and propose that psychological safety within the organization may play an important role in these relationships. Thus, I contribute to the literature by further examining how several workplace social exchanges lead to change-oriented behaviors. Third, based on the knowledge that not all employees feel psychologically safe in their work environment, I explore five conditions that may lead to change-oriented behaviors even when psychological safety is low or absent. Indeed, Hayes (2013) states that "research that establishes the mechanism or mechanisms by which effects operate or the conditions that facilitate and inhibit such effects deepens our understanding of the phenomena scientists study" (p. 3). Therefore, I draw from social exchange theory to expand on previous findings and enhance our understanding of the roles of three workplace social exchanges and psychological safety within the organization on followers' behaviors that lead to change, and of the boundary conditions that may shape these relationships. I do so by proposing and testing the theoretical moderated mediation model shown in Figure 1.

To test this model, I used a quantitative non-experimental research design and multilevel path analyses. To reduce issues and problems associated with common method 
variance, the variables used in this dissertation were measured at three points in time and the data were collected from both leaders and followers (Hiller, DeChurch, Murase, \& Doty, 2011; Podsakoff, MacKenzie, Lee, \& Podsakoff, 2003). The final sample consisted of 174 leader-follower dyads from four organizations located in the United States.

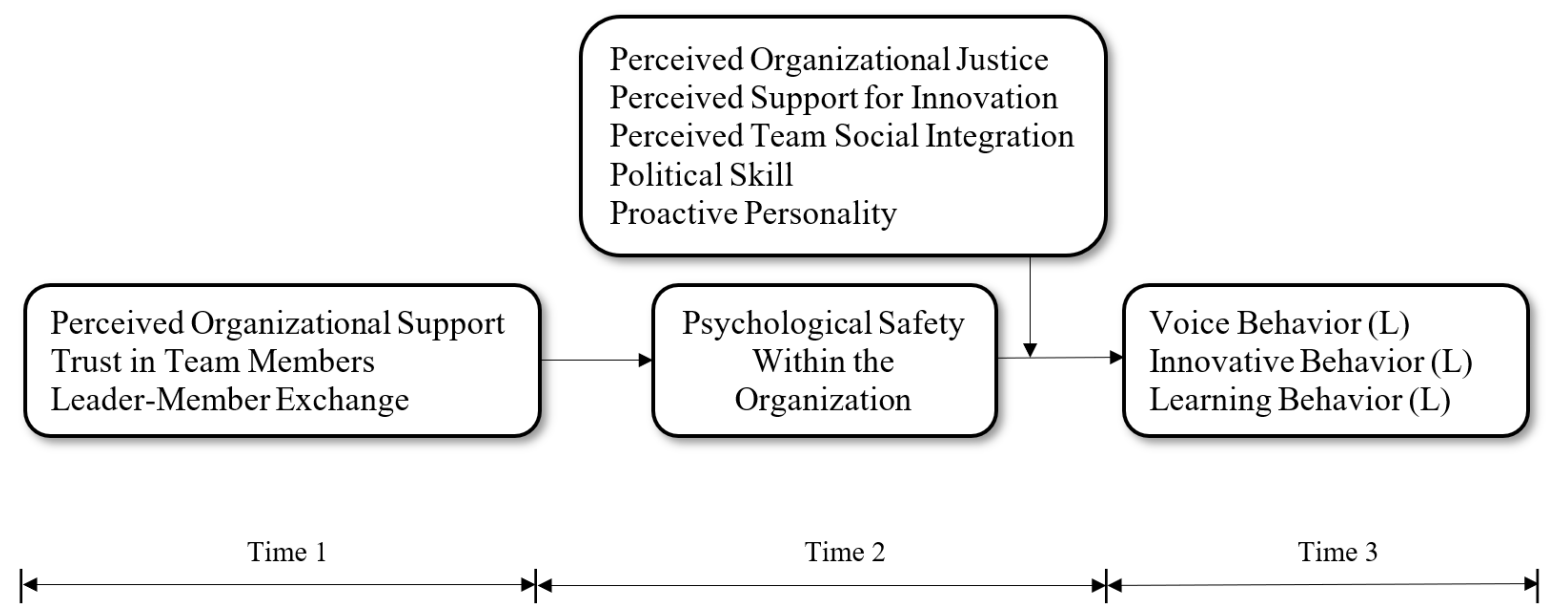

Figure 1. Proposed Moderated Mediation Model. L = rated by the leader.

This dissertation is organized in the following way. In chapter two, I review the literature relevant to the proposed model, including definitions and theoretical deliberations of the relationships among leader-member exchange, trust in team members, perceived organizational support, psychological safety within the organization, voice behavior, innovative behavior, learning behavior, and five moderators; I also develop and introduce the hypotheses predicting the relationships between the study variables. In chapter three, I outline the methodology that I used to gather the data and test the proposed hypotheses. In chapter four, I present the results of my analyses. In chapter five, I discuss the study's findings, practical and theoretical implications, limitations, and recommendations for future research. Lastly, I present the references used in this dissertation, followed by the appendices. 


\section{CHAPTER II}

\section{LITERATURE REVIEW}

Chapter two begins with an introduction to three social exchanges (i.e., leader-member exchange, trust in team members, and perceived organizational support) and psychological safety within the organization. Then, I develop the dissertation hypotheses aimed to increase our understanding of the mechanisms and boundary relationships among the focal and other related constructs.

\section{Social Exchanges}

Social exchange theory (SET) comes from the fields of anthropology, economics, social psychology, and sociology (e.g., Blau, 1964; Homans, 1958; Thibaut \& Kelley, 1959). In his classical 1964 work, Blau describes the similarities and differences between social and economic exchanges. While economic exchanges are characterized by transactions, specific contracts, and expected returns, social exchanges are characterized by trust, respect, and commitment that develop overtime (i.e., through a series of interactions) among individuals, leaders, peers, and organizations and that create a sense of reciprocity and mutual, unspecified obligations (Blau, 1964; Cropanzano \& Mitchell, 2005; Gouldner, 1960). A social exchange relationship is thus considered the "basic unit of analysis" (Emerson, 1976, p. 345). According to SET (Blau, 1964; Cook, 1990), individuals are involved in multiple relationships within the organization, and one social exchange can be affected by others in the same work context. Thus, as Blau (1964) has suggested, when studying the outcomes of certain social exchanges, other social exchanges embedded in the same environment should also be considered. In this dissertation, I take this perspective of interdependent social exchange relationships to 
provide the theoretical rationale behind the relationships between leader-member exchange, trust in team members, and perceived organizational support, and several outcomes.

Leader-member exchange. Research on leader-member exchange (LMX) dates back to the mid-1970s when Dansereau, Graen and Haga (1975) introduced the concept of Vertical Dyad Linkage (VDL), although its fundamental idea can be traced to the late 1950s (Homans, 1958) as LMX has drawn conceptually from the theory of social exchange. As such, it has received significant attention from scholars from several academic fields such as communication, education, health care, management, psychology, and sociology (e.g., Erdogan, Kraimer, \& Liden, 2004; Hunt, 2014; Madlock, Martin, Bogdan, \& Ervin, 2007; Paustian-Underdahl \& Halbesleben, 2014; Runhaar, Konermann, \& Sanders, 2013; Sin, Nahrgang, \& Morgeson, 2009). Indeed, a Google Scholar search using the term leader-member exchange generates over a million results. Thus, it is not surprising that scholars have published over 20 reviews and metaanalyses on LMX as the focal construct (e.g., Banks, Batchelor, Seers, O’Boyle, Pollack, \& Gower, 2014; Dulebohn, Bommer, Liden, Brouer, \& Ferris, 2012; Gerstner \& Day, 1997; Graen \& Uhl-Bien, 1995; Ilies, Nahrgang, \& Morgeson, 2007; Martin, Guillaume, Thomas, Lee, \& Epitropaki, 2016; Rockstuhl, Dulebohn, Ang, \& Shore, 2012; Schriesheim, Castro, \& Cogliser, 1999; Sin et al., 2009).

The theory of leader-member exchange, a component of SET focused on the sole relationship between leaders and followers, is based on the premises that leaders treat their employees differently according to the relationship quality that can be developed and sustained overtime (Liden \& Graen, 1980; Liden, Sparrowe, \& Wayne, 1997). Graen 
and Uhl-Bien (1995) suggest that the process of relationship development has three sequential stages: stranger, acquaintance, and partner, with stranger and partner depending more on transactional and social exchanges, respectively, and acquaintance laying somewhere in between. As such, leader-member exchange is conceptualized as the quality of a dyadic (i.e., one-on-one) relationship between a leader and his/her immediate follower (Dansereau et al., 1975; Dienesch \& Liden, 1986), and such relationship may vary from low- to high-quality.

From this perspective, high-quality LMX is characterized by mutual respect, liking, trust, and resource exchanges (Blau, 1964; Graen \& Uhl-Bien, 1995). Leaders in high-quality relationships provide their in-group followers (i.e., those whom the leaders identify themselves with) superior treatment by spending time with them, inviting and valuing their input and contributions, and giving them feedback (Dansereau et al., 1975; Graen \& Scandura, 1987). Furthermore, leaders in high-quality LMX provide followers with opportunities to grow and develop by assigning their followers challenging and interesting projects, offering them valuable advice on how to accomplish their goals, and giving them latitude to make decisions at work (Erdogan \& Liden, 2002). Likewise, according to the fundamental principle of SET, when followers perceive themselves to be part of their leaders' in-group, they feel obligated, yet pleased, to reciprocate (Blau, 1964; Emerson, 1976; Graen \& Uhl-Bien, 1995; Wilson, Sin, \& Conlon, 2010). Followers will respond to the preferential treatment by putting extra effort at work and performing above their leaders' expectations, by sharing valuable information with and ultimately showing commitment and loyalty to their leaders (Liden et al., 1997). Conversely, a low-quality relationship is impersonal and formal, characterized by exchanges that are structured and 
limited to work related matters (Graen \& Uhl-Bien, 1995). Low-quality relationships are contractual in nature, meaning that leaders and followers know their responsibilities, and followers' compensation and benefits are contingent on their own performance (Blau, 1964). Furthermore, in low-quality LMX, leaders offer less support to their out-group followers and the latter are, accordingly, less loyal to their leaders (Dansereau et al., 1975).

Indeed, there is plenty of evidence that leader-member exchange shapes the work environment and influences employees' outcomes. For example, in seeking to understand the role of leadership on employees' creativity, several researchers (Tierney, Farmer, \& Graen, 1999) studied a group of R\&D employees and found that the quality of the relationship between leaders and followers related to employee creativity, an initial and necessary step of innovative behavior. While integrating the theories of social network and leader-member exchange to better understand innovative behaviors, Wang and colleagues (2015) found that leader-member exchange was positively related to employees' innovative behavior, consistent with previous findings (e.g., Yuan \& Woodman, 2010). Furthermore, using a sample of about 400 employees and 40 immediate supervisors from an automobile leadership organization, Walumbwa and colleagues (2009) found that leader-member exchange was positively related to voluntary learning behavior. Smothers (2012) also found that leader-member exchange was significantly related to learning strategies of working adults.

Trust in team members. Trust has been the focus of an extensive amount of research and, perhaps, one of the most cited conceptualizations of trust is the definition of trust as "the willingness of a party to be vulnerable to the actions of another party based 
on the expectations that the other will perform a particular action important to the trustor, irrespective of the ability to monitor or control that other party" (Mayer, Davis, \& Schoorman, 1995, p. 712). Several authors, including Mayer and colleagues (1995), have also stated that trust is a multidimensional construct that captures a cognitive dimension (e.g., confidence in the other party's expertise) and an affect-based dimension (e.g., positive feelings or emotions towards the other party). Other researchers have also looked at trust in team settings, where the party component of the trust definition usually refers to team members (De Jong \& Elfring, 2010). De Jong and Elfring (2010) define trust in team members as the "shared generalized perceptions of trust that team members have in their fellow teammates" (p. 536). From this perspective, trust in team members can be referred to as the "willingness of a [team member] to be vulnerable to the actions of [the other team members]" (Mayer et al., 1995).

Trust in team members is characterized by open communication, cooperation, knowledge sharing, and tolerance for different opinions (Ashforth \& Mael, 1989; Calton \& Lad, 1995; Costa, 2003; Jones \& George, 1998; McAllister, 1995; Strutton, Pelton, \& Lumpkin, 1993). When team members trust each other, they are more accepting of different opinions that may arise from their colleagues and are also more likely to give differing suggestions because they are not afraid of taking risks and making themselves more vulnerable (Edmondson, 1999, 2004). Furthermore, because they communicate openly and are not afraid of sharing knowledge and personal resources, they are more likely to improve their decision-making effectiveness, overall performance, and reach their team goals (Alge, Wiethoff, \& Klein, 2003; Carmeli, Tishler, \& Edmondson, 2012; Larson \& LaFasto, 1989; Palanski, Kahai, \& Yammarino, 2011; Smith \& Barclay, 1997). 
And when employees feel supported by their colleagues, they are more likely to feel committed to their team and organization and less likely to turnover (Ferres, Connell, \& Travaglione, 2004; Ladebo, 2006).

Indeed, trust in team members has been associated with several positive outcomes. For instance, in a study of 194 research scientists, scholars found that team trust was positively associated with knowledge creation (Chung \& Jackson, 2011). Furthermore, using a sample of 112 teams located in The Netherlands, researchers found that trust within teams was also positively related to perceived task performance and team satisfaction (Costa, Roe, \& Taillieu, 2001). Likewise, in Schiller and colleagues' (2014) study, team trust led to team satisfaction when using a sample of 282 members of virtual teams. Trust in team members has also been shown to be related to team effectiveness (DeOrtentiis, Summers, Ammeter, Douglas, \& Ferris, 2013), and in a study of 151 project teams, team trust was positively related to collaboration and project success (Bond-Barnard, Fletcher, \& Steyn, 2018).

Perceived organizational support. Organizational support theory (Eisenberger, Huntington, Hutchison, \& Sowa, 1986), a subset of SET, suggests that employees are also embedded in social exchanges with their organizations that are developed overtime. Scholars have also suggested that employees personify the organization and ascribe it humanlike attributes such as caring, supportive, and appreciative (Eisenberger et al., 1986; Levinson, 1965). Perceived organizational support (POS) is defined as employees' "global beliefs concerning the extent to which the organization values their contributions and cares about their well-being" (Eisenberger et al., 1986, p. 501). 
High POS occurs when employees feel that the organization respects them, recognizes and appreciates their efforts and contributions, and rewards them accordingly (Eisenberger et al., 1986; Rhoades \& Eisenberger, 2002; Wayne, Shore, Bommer, \& Tetrick, 2002). Furthermore, high POS occurs when employees believe the organization cares for their well-being and satisfies their social-emotional needs (Eisenberger et al., 1986). Consistent with the principle of reciprocity, because employees feel respected, appreciated, and cared by the organization and believe to have high approval from their organization, they feel obligated to increase their performance and help the organization achieve its goals (Aselage \& Eisenberger, 2003; Blau, 1964; Eisenberger, Armeli, Rexwinkel, Lynch, \& Rhoades, 2001; Gouldner, 1960; Levinson, 1965). When employees perceive the organization to be supportive, they also expect the organization to reward them according to their contributions and overall performance (Eisenberger et al., 1986). Because employees develop a sense of obligation towards the organization and believe their performance will lead to greater rewards, they will increase their work effort and be more engaged in positive behaviors that will improve organizational functioning (Eisenberger et al., 1986; Rhoades, Eisenberger, \& Armeli, 2001).

Conversely, employees may ascribe low POS when the organization does not provide them with developmental opportunities, resources, job flexibility, or autonomy (Rhoades \& Eisenberger, 2002; Wayne, Shore, \& Liden, 1997). Under these circumstances, employees will feel less cared by and less obligated to the organization (Gouldner, 1960; Levinson, 1965). Accordingly, employees will feel less satisfied with the organization and will decrease their output. They will also be less committed to the organization and more likely to turnover (Rhoades, Eisenberger, \& Amerli, 2001). 
In fact, perceived organizational support has been linked to several positive outcomes such as task performance, turnover intentions, job satisfaction, and helping behaviors (Guchait, Lee, Wang, \& Abbott, 2016; Riggle, Edmondson, \& Hansen, 2009). For example, using a sample of manufacturing hourly employees and managers, researchers found indication that perceived organizational support leads to affective attachment and helping behavior (Eisenberger, Fasolo, \& Davis-LaMastro, 1990). In a meta-analysis of over 70 studies, Rhoades and Eisenberger (2002) also found that when employees felt that the organization cared about them, they tended to reciprocate by increasing their organizational commitment and improving their overall performance.

\section{Psychological Safety Within the Organization}

Kahn (1990) defined psychological safety as a "sense of being able to show and employ self without fear of negative consequences to self-image, status, or career" (p. 705). In an investigation of learning behaviors among members of work teams in a manufacturing firm, Edmondson (1999) reintroduced the concept and expanded the original conceptualization of psychological safety to a sense of safety for "interpersonal risk taking." Although this latter conceptualization was based on the team level, subsequent studies also used the construct at the individual and organizational levels (e.g., Carmeli \& Gittell, 2009). In this case, when individuals have a sense of psychological safety in their work environments, they are more likely to take interpersonal risks without the fear of being embarrassed or penalized for their actions (Edmondson, 1999).

Although trust and psychological safety share some similarities such as the vulnerability of risk taking, psychological safety differs conceptually from trust in at least 
two points (Mayer et al., 1995; Rousseau, Sitkin, Burt, \& Camerer, 1998). First, trust refers to "the willingness of a party to be vulnerable to the actions of another party" (Mayer et al., 1995). As clearly explained by Chughtai and Buckley (2013), "trust involves giving other people the benefit of the doubt. ... in contrast, the focus of psychological safety is on the self. That is, in case of psychological safety, the question is whether or not other people will give you the benefit of the doubt" (p. 403). Second, Carmeli and Gittell (2009) state that another difference between trust and psychological safety is that the consequences of lack of trust can range in time from short- to long-term, whereas the consequences of lack of psychological safety are immediate or short-term.

Indeed, psychological safety has been related to several positive outcomes such as asking for help (Cauwelier, Ribière, \& Bennet, 2016), engagement (Nembhard \& Edmondson, 2006), team satisfaction (Mayfield, Tombaugh, \& Lee, 2016), and organizational performance (Baer \& Frese, 2003). Furthermore, researchers show that an increase in psychological safety decreases emotional exhaustion and psychological distress (Idris, Dollard, Coward, \& Dormann, 2012).

\section{Leader-member exchange and psychological safety within the organization.}

Researchers suggest that psychological safety is lower in contexts where status difference exists (Bunderson \& Boumgarden, 2010), thus it is likely that leader-member exchange impacts followers' psychological safety. In these contexts of status difference, those in higher positions (e.g., leaders) are less concerned about being rejected or penalized; on the other hand, those in lower positions (e.g., followers) are more cautious when addressing those in higher positions as they fear negative ramifications (Kahn, 1990). 
I propose that the quality of the leader-member-exchange will influence how followers perceive the gap between theirs and their leaders' status. As such, as LMX quality increases, followers may perceive the leader-follower status gap to be narrower, and thus follower will feel safer to express themselves. High-quality LMX is characterized by a relationship of mutual respect and interpersonal trust (Graen \& UhlBien, 1995). Leaders in high-quality LMX relationships support and make themselves available to their followers (Liden, Wayne, \& Sparrowe, 2000). Because supportive leaders welcome questions, invite solutions for organizational challenges, encourage new ideas, and appreciates followers' efforts to improve organizational processes and functioning (Kahn, 1990), followers in a high-quality LMX will feel safe taking interpersonal risks such as by expressing themselves, giving suggestions for improvements and discussing concerns or mistakes with their leaders without negative consequences (Edmondson, 1999). Thus, supportive and trusting leaders will foster followers' feelings of psychological safety within the organization (Kahn, 1990).

In fact, some studies have found that certain characteristics of high-quality LMX lead to higher psychological safety. For example, in a study of neonatal intensive care professionals, Nembhard and Edmondson (2006) found that when physicians encouraged initiative and input from nurses and respiratory therapists, and valued opinions of others equally, psychological safety was perceived to be higher. Conversely, as LMX quality decreases, followers may perceive the leader-follower status gap to be wider. Moreover, in low-quality LMX, unsupportive and disinterested leaders will send cues to followers, who will in turn feel psychologically unsafe to bring issues, concerns, or suggestions to 
their leaders' attentions due to the fear of being reprimanded (Nembhard \& Edmondson, 2006). Thus, I propose the following:

Hypothesis 1a. Leader-member exchange is positively related to followers' psychological safety within the organization.

\section{Trust in team members and psychological safety within the organization.}

Jones and George (1998) propose that team trust fosters high confidence in others and communal relationships, leading to interpersonal cooperation and teamwork, based on the principles of reciprocation (Blau, 1964). They argue that trust in team members creates an environment of respect, open communication, and collaboration. Because team members are likely to collaborate (Carmeli et al., 2009), they may feel more comfortable to propose ideas and speak up about concerns and mistakes without feeling embarrassed. Individuals who trust their teams may also feel safe to express themselves without the fear of negative consequences because they may perceive their team members to be more tolerant and accepting, and they are confident that their team members will support them (Barczak, Lassk, \& Mulki, 2010). Furthermore, because individuals who trust in their teams feel that their team members have faith in their skills and capabilities (Edmondson, 2004), they are more likely to bring up ideas and concerns to their leaders and team members, which may lead them to speak up and express themselves without the fear of negative consequences. Conversely, if individuals do not trust their team members, they are less likely to try new things, take risks, ask questions, speak up or express themselves because they assume that their peers will judge and reject them if they fail, and thus their reputation will be compromised (Kahn, 1990). 
Indeed, Edmondson (2004) describe a Harvard research that she participated where teams with members that had good relationships with one another were more likely to report and discuss mistakes without fear of being reprimanded due to a strong sense of psychological safety. Moreover, using a sample of research scientists from several Irish research centers, Chughtai and Buckley (2013) found that trust in team members was positively associated with team psychological safety. Thus, I propose that followers perceive high psychological safety within the organization when they trust their co-workers or team members.

Hypothesis $1 b$. Trust in team members is positively related to followers' psychological safety within the organization.

\section{Perceived organizational support and psychological safety within the}

organization. Followers' psychological safety is more likely to develop in supportive environments, such as in organizations that value and appreciate employees' contributions, care for employees' well-being, and respect and fairly reward their employees (Edmondson, 1999; Eisenberger et al., 1986). When employees believe the organization values their contributions and provides them with resources and information to fulfill their job responsibilities, they are more likely to ask questions and propose ideas to help the organization achieve their goals (Edmondson, 2004). When employees believe the organization cares about their well-being, they may feel more comfortable being themselves, asking for help, or reporting mistakes, because they are not afraid that the organization will mistreat them (Edmondson, 1999). Likewise, when followers perceive that the organization appreciates their contributions and rewards them according to their achievements, they feel safe to take risks to achieve organizational goals without the fear 
of embarrassment (Edmondson, 1999). Conversely, when followers do not perceive to be valued, cared, or trusted, they will feel unsafe to contribute to the organization or take risks to improve organizational functioning, because they may fear negative consequences (Edmondson, 2004).

Indeed, scholars have suggested that supportive work environments foster psychological safety (Carmeli \& Gittell, 2009; Carmeli \& Zisu, 2009; Edmondson, 2004; Newman, Donohue, \& Eva, 2017). For example, using a sample of full-time and parttime workers from hotels and restaurants, Guchait and colleagues (2016) found that perceived organizational support was positively related to psychological safety. In a meta-analysis of the antecedents and outcomes of psychological safety, supportive work context was also positively associated with psychological safety (Frazier et al., 2017). Thus, when employees perceive to have support from their organizations, they will feel psychologically safe to express themselves without the fear of negative consequences. Hypothesis 1c. Perceived organizational support is positively related to followers' psychological safety within the organization.

\section{Psychological Safety Within the Organization as a Mediator of the Relationships Between Leader-Member Exchange, Trust in Team Members, and Perceived Organizational Support, and Followers' Change-Oriented Behaviors}

While previous studies have investigated the effects of leader-member exchange, trust in team members, and perceived organizational support on the aforementioned followers' change-oriented behaviors, it is also important to understand the mechanisms by which these effects operate (Hayes, 2013). In this dissertation, I argue that psychological safety within the organization is one vital mechanism through which 
leader-member exchange, trust in team members, and perceived organizational support lead to followers' change-oriented behaviors.

In fact, other previously tested models show that certain aspects of social exchanges in general are related to followers' behaviors through psychological safety. For example, using a sample of full-time employees from a variety of organizations in Israel, Carmeli and Gittell (2009) found that the association between high quality relationships among employees and learning from failures was partially mediated by psychological safety. Detert and Burris (2007) found that restaurant chain managers' openness (i.e., followers' perceptions that their leader "listens to them, is interested in their ideas, gives fair consideration to the ideas presented" (p. 871)) was positively related to employees' voice behavior, and that this relationship was mediated by perceptions of psychological safety. Psychological safety has also been found to mediate the relationship between leader-member exchange and knowledge sharing in a study of Dutch and Romanian employees (van den Berg, 2010). Furthermore, using a sample of 165 employees and co-workers, Singh and colleagues (2018) found that psychological safety mediated the positive relationships between perceived organizational support, perceived supervisory support and perceived co-workers support, and organizational embeddedness - a characteristic that has been shown to predict several positive outcomes, such as innovative behavior (Ng \& Feldman, 2010).

Considering the evidence of the positive relationships between leader-member exchange, trust in team members, and perceived organizational support, and psychological safety, and between psychological safety and voice, innovative, and learning behaviors (as will be discussed next), the mediation argument for psychological 
safety within the organization is theoretically coherent and logical. Thus, building on prior relationships and mediation models, I propose that psychological safety within the organization will mediate the relationship between leader-member exchange, trust in team members, and perceived organizational support, and voice, innovative, and learning behaviors. Psychological safety has been associated to several change-oriented behaviors. Next, I will discuss the arguments that explain the relationships between psychological safety and voice, innovative, and learning behaviors.

Voice behavior. Voice behavior, sometimes referred to as voice, is defined as the constructive expression of ideas, opinions and suggestions aimed to improve or change an organizational process or functioning (Van Dyne \& LePine, 1998). Voice behavior can be expressed toward subordinates, coworkers, or superiors (Burris et al., 2008). The focus of this dissertation will be on voice behavior directed toward leaders.

Voice behavior, which also signifies speaking up, is discretionary and may not always be welcomed, which makes it risky (Takeuchi et al., 2012). When employees perceive an environment to be psychologically safe, they are less fearful of taking interpersonal risks and they believe it is their obligation to speak up about issues related to organizational processes (Tangirala, Kamdar, Venkataramani, \& Parke, 2013). Such environments facilitate promotive voice behavior and employees feel at ease to present ideas and suggestions for improvement without the fear of having their ideas rejected (Detert \& Burris, 2007). Furthermore, employees who feel psychologically safe are comfortable talking about their concerns related to the organizational functioning without the fear of negative consequences. Conversely, when psychological safety is lacking, employees are more cautious and do not freely speak up nor easily express their opinions 
and concerns, fearing that doing so will damage their reputation and personal image (Zhao \& Olivera, 2006). For example, in a longitudinal study of matched leaders and followers in a retail firm in China, researchers found that psychological safety leads to both promotive and prohibitive voice behaviors (Liang, Farh, \& Farh, 2012). In addition, Liu and colleagues (2015) found that psychological safety was positively related to voice in a study of bank employees. Subordinate perception of psychological safety was also found to be positively related to voice in a study of managers and their subordinates in a restaurant chain company (Detert \& Burris, 2007). Thus, I propose:

Hypothesis 2. Psychological safety within the organization is positively related to followers' voice behavior.

Hypothesis 3. The relationships between (a) leader-member exchange, (b) trust in team members, (c) perceived organizational support and voice behavior are mediated by psychological safety within the organization.

Innovative behavior. The concept of innovative behavior can be described as the "intentional generation, and realization of new ideas within a work role, workgroup, or organization" (Janssen \& Van Yperen, 2004, p. 370; see also West \& Farr, 1989). Unlike creativity, which refers to the intentional task of generating novel and useful ideas (e.g., new products, processes, methods, technologies, etc.) (Amabile, Conti, Coon, Lazenby, \& Herron, 1996), innovative behavior is a complex, multidimensional process that includes idea generation as well as idea promotion (i.e., securing support and resources needed) and idea realization or implementation (Kanter, 1988; Scott \& Bruce, 1994). These dimensions of the innovation process are not necessarily performed in a sequential 
order (Kanter, 1988); in fact, an individual exhibiting innovative behavior may be involved in one or more dimensions simultaneously.

Due to the uncertainty about its outcome and a high chance of failure, the process of innovation is risky (Holmstrom, 1989), yet firms need to innovate continuously to remain competitive. As such, before engaging in innovative behavior, employees will likely assess the environment to ensure it is receptive to creative actions and thus considered safe to take risks (Ford, 1996). In such environments where employees feel psychologically safe, they are more likely to collaborate with their colleagues to exchange ideas, provide divergent perspectives, and generate more refined ideas, all of which are necessary steps that lead to innovation (Lubart, 2001). Employees are also more likely to promote their creative ideas when they feel psychologically safe because they do not fear being ridiculed or rejected by their leader and peers (Edmondson, 2003; Kark \& Carmeli, 2009). Moreover, even when there are risks of failure, psychologically safe employees may still implement their ideas without the fear of blame. In fact, there is empirical evidence linking psychological safety to innovative behavior. For example, using a sample of R\&D employees engaged in the development of advanced technological products, Carmeli, Reiter-Palmon and Ziv (2010) found a positive relationship between psychological safety and creative work, an initial stage of innovative behavior. Leung and colleagues' (2015) study of full-time employees in China found that psychological safety was positively related to innovative behavior. Thus, I suggest that:

Hypothesis 4. Psychological safety within the organization is positively related to followers' innovative behavior. 
Hypothesis 5. The relationships between (a) leader-member exchange, (b) trust in team members, (c) perceived organizational support and innovative behavior are mediated by psychological safety within the organization.

Learning behavior. One of the earliest studies on learning behavior is Edmondson's (1996) investigation of the causes of variations of unit error rate within hospitals, in which nurses' learning behaviors were deliberated. Edmondson (1999) conceptualizes the term learning behavior as a process of "behaviors through which such outcomes as adaptation to change, greater understanding, or improved performance" ( $p$. 343) can be achieved. Learning behavior is an on-going process that involves steps such as experimenting new ideas or procedures, asking questions to and seeking feedback from leaders and co-workers, reflecting on results, openly discussing errors or unexpected outcomes, and persisting until hindrances or complications are overcome (Oeij, Dhondt, Gaspersz, \& Vroome, 2016). These steps, which are intended to develop employees' skills and improve individual and organizational performance, occur continuously and not necessarily in a sequential order.

Although Edmondson's original study focuses on team learning behavior, other scholars have also used the term to indicate individual learning behavior (e.g., Walumbwa et al., 2009). Similar terms were also developed in subsequent studies following Edmondson's original conceptualization. For example, Raemdonck, Tillema, de Grip, Valcke, and Segers (2011) define self-learning as "an orientation to take an active and self-starting approach in work-related learning activities and situations, and to persist in overcoming barriers and setbacks to acquiring competence" (p. 139). For the purpose of this dissertation, I will use Edmondson's (1999) definition of learning 
behavior but applied to individuals within the organization rather than individuals within teams (e.g., Walumbwa et al., 2009).

Employees who feel psychologically safe will likely collaborate with each other and offer and experiment new ideas without worrying about making mistakes or receiving undesirable reactions from their leaders and co-workers (Gong et al., 2012). When mistakes are made, employees will comfortably and openly discuss them with their supervisor and colleagues without fearing being blamed or penalized, but instead will likely ask for help and feedback to improve the task or process at hand and to learn from those mistakes (Edmondson, 1999). The fearless feelings and healthy exchanges fostered by a psychologically safe environment will encourage further risk-taking behavior and thus the learning process will continue (Edmondson, Bohmer, \& Pisano, 2001). In fact, there is plenty of evidence that psychological safety promotes learning behavior. For example, in Edmondson's (1999) classical study of manufacturing work teams, psychologically safe teams exhibited more learning behaviors than those who felt less psychologically safe. Employees' feelings of psychological safety were also found to be positively related to learning from failure in a longitudinal study of full-time employees of several organizations located in Israel (Carmeli \& Gittell, 2009). Furthermore, Bresman and Zellmer-Bruhn (2013) found that psychological safety led to both internal and external team learning behaviors of $R \& D$ teams of several pharmaceutical firms. Thus, I propose the following:

Hypothesis 6. Psychological safety within the organization is positively related to followers' learning behavior. 
Hypothesis 7. The relationships between (a) leader-member exchange, (b) trust in team members, (c) perceived organizational support and learning behavior are mediated by psychological safety within the organization.

\section{Conditional Indirect Effects of Leader-Member Exchange, Trust in Team Members, and Perceived Organizational Support on Followers' Change-Oriented Behaviors via Psychological Safety Within the Organization}

While the first purpose of this dissertation is to examine the mediating role of psychological safety within the organization in the relationships between leader-member exchange, trust in team members, and perceived organizational support, and followers' change-oriented behaviors, the second purpose of this dissertation is to establish the boundary conditions under which these indirect effects are observed. More specifically, I am interested in understanding the factors that may compensate for low psychological safety within the organization. As such, I will examine five moderators for the relationships between psychological safety within the organization and voice, innovative, and learning behaviors.

\section{Moderators of Psychological Safety Within the Organization and Followers' Behaviors}

As previously discussed, the positive main effects of psychological safety on voice, innovative, and learning behaviors are somewhat established; however, I propose that there are boundary conditions at the individual, team, and organizational levels that will determine when these positive effects prevail. In this section, I explore the importance of proactive personality, political skill, perceived team social integration, perceived support for innovation, and perceived organizational justice in leading to 
followers' change-oriented behaviors even when psychological safety within the organization is low or absent.

Proactive personality. Bateman and Crant (1993) introduced the concept of proactive personality as "the extent to which [people] take action to influence their environment" and Crant (2000) later added that proactive personality is an individual's behavior of "taking initiative in improving current circumstances or creating new ones; it involves challenging the status quo rather than passively adapting to present conditions." The concept of proactive personality was originated from an interactionists' perspective (Bandura, 1977) which states that there is a dynamic interaction between the person and the environment, with both influencing each other (Bandura, 1986).

Proactive individuals anticipate new events and plan accordingly (Gong et al., 2012). As such, they scan the environment, ask questions and identify new opportunities to make contributions and promote constructive changes in a broad range of situations (Crant, 2000; Edmondson, 1999; Seibert, Kraimer, \& Crant, 2001). Individuals who are proactive not only propose innovative ideas but they also take the initiative to shape and influence the environment in order to implement their ideas and improve organizational functioning (Bateman \& Crant, 1993; Janssen \& Van Yperen, 2004; Kanter, 1988). As such, it is possible that proactive personality has a moderating influence on followers' change-oriented behaviors as those who possess this stable disposition are not intimidated by personal or environmental obstacles or challenges, such as psychologically unsafe environments; instead, they persist until all hurdles are overcome and the desired outcomes are realized (Crant, 2000; Seibert, Crant, \& Kraimer, 1999). Furthermore, the effects of a low psychologically safe environment can be overridden when followers are 
highly proactive because they will not be intimidated by an environment that is not psychologically safe; instead, they will continue to express their ideas and opinions until they reach their goals (Seibert et al., 1999). For such individuals, psychological safety within the organization may not matter much as they will have the confidence to challenge the status quo and take actions to improve the situation even in psychologically unsafe environments (Bateman \& Crant, 1993; Crant, 2000), without the fear of negative consequences.

Furthermore, proactive personality has been linked to several positive outcomes. For example, although proactive personality has been related to four of the Big Five personality factors (i.e., extraversion, openness to experience, conscientiousness, and neuroticism), it has also been related to job performance, task performance and organizational citizenship behavior even when controlling for the Big Five factors (Fuller \& Marler, 2009; Spitzmuller, Sin, Howe, \& Fatimah, 2015). Research has also shown that highly proactive individuals display certain change-oriented behaviors such as voice, innovative, and learning behaviors (Tornau \& Frese, 2013). For example, using a sample of manager-employee dyads from a retail chain store in Taiwan, Gong and colleagues (2012) found that proactive personality was positively related to employees' creativity. Furthermore, Raemdonck, van der Leeden, Vlacke, Segers, and Thijssen (2012) studied low-qualified employees from several organizations in the energy, chemistry, and food industries and found that proactive personality was associated with self-directed learning. Thus, for proactive individuals, I propose that the magnitude of the relationship between psychological safety within the organization and voice, innovative, and learning 
behaviors will become weaker such that proactive individuals will engage in these behaviors even when psychological safety within the organization is low or absent. Hypothesis 8. The relationships between (a) leader-member exchange, (b) trust in team members, (c) perceived organizational support and voice behavior occur indirectly through psychological safety within the organization such that the positive indirect effects on voice behavior are weaker (stronger) for followers with stronger (weaker) proactive personality.

Hypothesis 9. The relationships between (a) leader-member exchange, (b) trust in team members, (c) perceived organizational support and innovative behavior occur indirectly through psychological safety within the organization such that the positive indirect effects on innovative behavior are weaker (stronger) for followers with stronger (weaker) proactive personality.

Hypothesis 10. The relationships between (a) leader-member exchange, (b) trust in team members, (c) perceived organizational support and learning behavior occur indirectly through psychological safety within the organization such that the positive indirect effects on learning behavior are weaker (stronger) for followers with stronger (weaker) proactive personality.

Political skill. Political skill is a personal attribute that refers to "the ability to effectively understand others at work, and to use such knowledge to influence others to act in ways that enhance one's personal and/or organizational objectives" (Ahearn, Ferris, Hochwarter, Douglas, \& Ammeter, 2004, p. 311). Political skill contains four dimensions: social astuteness, which refers to one's aptitude to understand others and to know the best way to respond in order to influence them; interpersonal influence, which 
conveys the capacity to adapt one's behavior to effectively communicate with people, gain their admiration, and make them feel comfortable; networking ability, which denotes one's ability to connect and build relationships with people in a way that will help them (i.e., those with such ability) accomplish their work and reach their goals; and apparent sincerity, which pertains to one's capacity to show sincerity and genuine interest in others (Ferris, Treadway, Kolodisky, Hochwarter, Kacmar, Douglas, \& Frink, 2005).

Political skill has also been associated with several positive outcomes. In a metaanalysis of 130 studies, scholars found that political skill was positively associated with self-efficacy, job satisfaction, organizational commitment, work productivity, task performance, and subjective career satisfaction (Munyon, Summers, Thompson, \& Ferris, 2015). Ferris and colleagues (2007) also suggest that political skill may have "moderating effects on predictor-outcome relationships" due to "comprehensive pattern of social competencies with cognitive, affective, and behavioral manifestations" (Ferris, Treadway, Perrewé, Brouer, Douglas, \& Lux, 2007: 291). Indeed, political skill is critical to help employees adapt and behave effectively in uncertain or hostile environments because politically skilled individuals know how to understand and control dysfunctional environments (Ferris et al., 2007; Perrewé, Zellars, Ferris, Rossi, Kacmar, \& Ralston, 2004).

Individuals with high political skill tend to adjust better to adverse settings, such as those characterized by low psychological safety, in a way that helps them raise questions or concerns, give suggestions for improvements, express themselves without the fear of negative ramifications, and learn from their mistakes (Ferris, Treadway, Brouer, \& Munyon, 2012; Sun \& van Emmerik, 2015). Moreover, because politically 
skilled individuals tend to connect and build relationships with others in the organization, they may more easily obtain resources, earn support from leadership and colleagues, and implement their ideas (Baer, 2012; Ibarra, 1993). Individuals who interact with each other may also naturally create a learning environment, even when psychological safety is low, because they observe and exchange information with each other more frequently (Brown \& Duguid, 1991; Gherardi, Nicolini, \& Odella, 1998; Wenger, 1998). As such, political skill likely interacts with psychological safety within the organization in a way that politically skilled followers may engage in change-oriented behaviors, such as voice, innovative, and learning behaviors, even when they perceive the environment to be psychologically unsafe. Indeed, several political skill dimensions, such as networking ability and interpersonal influence, have been considered essential attributes of employees who engage in change-oriented behaviors (Baer, 2012; Carmeli \& Spreitzer, 2009; Janssen, 2005; Pfeffer, 1992). Thus, I propose that political skill will be even more important for the promotion of voice, innovative, and learning behaviors when followers do not feel psychologically safe within the organization.

Hypothesis 11. The relationships between (a) leader-member exchange, (b) trust in team members, (c) perceived organizational support and voice behavior occur indirectly through psychological safety within the organization such that the positive indirect effects on voice behavior are weaker (stronger) for followers with stronger (weaker) political skill.

Hypothesis 12. The relationships between (a) leader-member exchange, (b) trust in team members, (c) perceived organizational support and innovative behavior occur indirectly through psychological safety within the organization such that 
the positive indirect effects on innovative behavior are weaker (stronger) for followers with stronger (weaker) political skill.

Hypothesis 13. The relationships between (a) leader-member exchange, (b) trust in team members, (c) perceived organizational support and learning behavior occur indirectly through psychological safety within the organization such that the positive indirect effects on learning behavior are weaker (stronger) for followers with stronger (weaker) political skill.

Perceived team social integration. Based on the premise that relationships of different nature (i.e., dyadic, team level, etc.) may affect each other (Blau, 1964), it is possible that perceived team social integration could buffer the negative effects of low psychological safety within the organization on change-oriented behaviors. O'Reilly, Caldwell, and Barnett (1989) define social integration as "the degree to which an individual is psychologically linked to others in a group" (p. 22). Socially integrated group members are attracted to and identify themselves with each other and the group (O'Reilly et al., 1989). Individuals who are socially integrated interact with each other more often, even outside office hours or in non-work-related settings, thus developing interpersonal bonds among themselves (Katz \& Kahn, 1978). In fact, social integration is a key indicator of group cohesiveness (O'Reilly et al., 1989).

As such, socially integrated individuals have a sense of obligation to each other and are more committed to the success of the group (LePine \& Van Dyne, 1998), and thus are more likely to engage in behaviors that will promote the group such as generation and implementation of new ideas. Furthermore, group members who are bonded with each other, such as those in socially integrated groups, find support among 
themselves and are more likely to express their opinions and concerns intended to promote constructive changes rather than to merely complain about the status quo (Van Dyne \& LePine, 1998), even when there are external threats such as those characteristics of psychologically unsafe environments. In fact, researchers suggest that when under negative circumstances, such as when psychological safety is low, members of socially integrated groups will mobilize the resources necessary to accomplish their goals (Gump \& Kulik, 1997; Keltner \& Haidt, 1999; Knight \& Eisenkraft, 2015), and thus are more likely to ask questions and seek feedback. Thus, when employees perceive to be psychologically linked to their groups or co-workers, the effects of low psychological safety on positive work outcomes, such as innovative, voice, and learning behaviors, may not matter as much.

Indeed, social integration has also been linked to positive outcomes at the individual, team, and organizational levels. For example, individuals who belong to socially integrated groups are more satisfied with their group and group members (O'Reilly et al., 1989), which in turn may increase their motivation to express their opinions and engage in voice behavior (LePine \& Va Dyne, 1998). Social integration has also been related to group performance in a meta-analysis of several studies on groups (Knight, \& Eisenkraft, 2015), and in a study of technology-based firms, researchers found that socially integrated top management teams were positively associated to return on investment and sales growth (Smith et al., 1994). Furthermore, in a longitudinal study using a sample of self-managed work teams, scholars found that social integration was positively associated with learning behavior (van der Vegt et al., 2010). Conversely, members of groups that are not socially integrated are less likely to exhibit voice, 
innovation, and learning behaviors, particularly in environments of low psychological safety. I therefore expect that psychological safety within the organization will be less important for voice, innovative, and learning behaviors when followers belong to socially integrated groups or teams.

Hypothesis 14. The relationships between (a) leader-member exchange, (b) trust in team members, (c) perceived organizational support and voice behavior occur indirectly through psychological safety within the organization such that the positive indirect effects on voice behavior are weaker (stronger) for followers who feel more (less) socially integrated with their teams.

Hypothesis 15. The relationships between (a) leader-member exchange, (b) trust in team members, (c) perceived organizational support and innovative behavior occur indirectly through psychological safety within the organization such that the positive indirect effects on innovative behavior are weaker (stronger) for followers who feel more (less) socially integrated with their teams.

Hypothesis 16. The relationships between (a) leader-member exchange, (b) trust in team members, (c) perceived organizational support and learning behavior occur indirectly through psychological safety within the organization such that the positive indirect effects on learning behavior are weaker (stronger) for followers who feel more (less) socially integrated with their teams.

Perceived support for innovation. Probably the most cited definition of support for innovation is the one given by West (1990), who refers to support for innovation as the "expectation, approval and practical support of attempts to introduce new and improved ways of doing things in the work environment" (p. 315). It is the belief that the 
organization encourages change and creativity (Koys \& DeCotiis, 1991) and behaviors and attitudes that are associated with innovation, such as risk-taking, freedom, tolerance for diverse ideas, trust, and openness (Oldham \& Cummings, 1996).

Organizations that support innovation are more open to creative suggestions and more likely to provide the freedom and control over the individuals' work (Oldham \& Cummings, 1996); thus, when employees feel responsible for their jobs, they will more likely engage in change-oriented behaviors even when they do not perceive to be psychologically safe. In other words, the negative effects of an environment of low psychological safety will be buffered by individuals' perception of support for innovation. Furthermore, when individuals perceive the organization to be supportive, they are more likely to take risks (Tidd \& Bessant, 2009) even when do not feel psychologically safe because organizations that support innovation do not usually penalize their employees if some of their ideas are not realized (Anderson, Hardy, \& West, 1992). Conversely, in organizations that are more structured and less flexible, individuals may feel less likely to express their ideas, take risks and experiment new procedures because of fear of failure, particularly when psychological safety within the organization is perceived to be low. Thus, it is possible that perceived support for innovation has a moderating influence in the relationships between psychological safety within the organization and change-oriented behaviors.

Indeed, perceived support for innovation has been associated with and shown to moderate relationships that lead to change-oriented behaviors (Montani, Battistelli, \& Odoardi, 2017). For example, using a sample of engineers, scientists, and technicians, Scott and Bruce (2004) found that support for innovation was a predictor of innovative 
behavior, and Lu, Zhou, and Leung (2011) showed that perceived support for innovation interacted with task conflict leading to stronger innovative and knowledge-sharing behaviors. Kwon Choi, Koo Moon, and Ko (2013) also indicated that perceived support for innovation moderated the positive relationship between organizational ethical climate and innovation, such that the relationship was stronger when support for innovation was high. Furthermore, Hsiao, Chang, and Chen found that support for innovation predicted organizational learning and innovativeness, and Howell and Avolio (1993) found that perceived support for innovation moderated the relationship between transformational leadership and performance using a sample of 78 managers from a large financial institution. Thus, I argue that perceived support for innovation will moderate the relationships between psychological safety within the organization and voice, innovative, and learning behaviors.

Hypothesis 17. The relationships between (a) leader-member exchange, (b) trust in team members, (c) perceived organizational support and voice behavior occur indirectly through psychological safety within the organization such that the positive indirect effects on voice behavior are weaker (stronger) for followers with higher (lower) perceived support for innovation.

Hypothesis 18. The relationships between (a) leader-member exchange, (b) trust in team members, (c) perceived organizational support and innovative behavior occur indirectly through psychological safety within the organization such that the positive indirect effects on innovative behavior are weaker (stronger) for followers with higher (lower) perceived support for innovation. 
Hypothesis 19. The relationships between (a) leader-member exchange, (b) trust in team members, (c) perceived organizational support and learning behavior occur indirectly through psychological safety within the organization such that the positive indirect effects on learning behavior are weaker (stronger) for followers with higher (lower) perceived support for innovation.

Perceived organizational justice. Perceived organizational justice, which indicates employees' perception of fairness in the workplace, was originated by Wendell French in a speech at the 24th Annual Meeting of the Academy of Management (French, 1964) and has received extensive attention from scholars from several fields.

Organizational justice has been categorized into three, and later four, dimensions that are highly correlated yet distinct from each other: distributive, procedural, interactional, with the latter being subsequently split into interpersonal, and informational (Moorman, 1991; Colquitt, Conlon, Wesson, Porter, \& Ng, 2001). In this dissertation, I argue that procedural and distributive justice will moderate the relationships between psychological safety within the organization and voice, innovative, and learning behaviors. Considering the several positive outcomes associated with fairness, consistency, unbiasedness, impartiality, and other factors that characterize it, perceived organizational justice is likely to provide followers with the means to overcome the fear of negative consequences associated with an environment of low psychological safety, and thus leading to changeoriented behaviors.

Distributive justice denotes employees' perception of fairness of their outcome distribution (e.g., compensation, promotions, assignments) (Greenberg, 1987; Karriker \& Williams, 2009). When the organization consistently treats and compensates employees 
solely based on their accomplishments (i.e., distributive justice), followers may be more motivated to engage in innovative activities, even when psychological safety is low, because they expect to be rewarded accordingly (Adams, 1965; Greenberg, 1987; Karriker \& Williams, 2009).

Procedural justice relates to the employees' perceptions of fairness of organizational processes that determine the outcome distributions (e.g., based on the rules of consistency, unbiasedness, accuracy, correctability, representativeness, and ethics) (Leventhal, 1980; Thibaut \& Walker, 1975). For example, when an organization is perceived to be unbiased and ethical (i.e., procedural justice) followers may feel less stressed (Janssen, 2004), even in psychologically unsafe environments, because they know that decisions that affect them will be made based on the principles of justice (e.g., fairness, consistency, and impartiality) (Leventhal, 1980). As such, followers may feel encouraged to focus on accomplishing organizational goals, such as providing constructive suggestions and promoting their ideas aimed to improve organizational functioning, even when psychological safety within the organization is low or absent (Janssen, 2004).

Distributive and procedural justice have also been related to several employees' attitudes and behaviors. For example, meta-analytic reviews of organizational justice showed significant relationships among organizational justice dimensions and outcomes such as job satisfaction, organizational commitment, organizational citizenship behavior, task performance, and productivity (Cohen-Charash \& Spector, 2001; Colquitt, Scott, Rodell, Long, Zapata, Conlon, \& Wesson, 2013; Viswesvaran \& Ones, 2002). Organizational justice has also been associated with voice, innovative, and learning 
behaviors. For instance, using a sample of employees from an automobile dealership, researchers found that the dimensions of organizational justice, such as distributive and procedural justice, were significantly related to learning behavior (Walumbwa et al., 2009). Thus, I argue that employees perceived organizational justice will compensate for low or absent psychological safety within the organization. In other words, when employees perceive the organization to be fair regarding processes and distributive outcomes, employees will more likely demonstrate voice, innovative, and learning behaviors, even when psychological safety within the organization is low or absent. Hypothesis 20. The relationships between (a) leader-member exchange, (b) trust in team members, (c) perceived organizational support and voice behavior occur indirectly through psychological safety within the organization such that the positive indirect effects on voice behavior are weaker (stronger) for followers with higher (lower) distributive justice.

Hypothesis 21. The relationships between (a) leader-member exchange, (b) trust in team members, (c) perceived organizational support and innovative behavior occur indirectly through psychological safety within the organization such that the positive indirect effects on innovative behavior are weaker (stronger) for followers with higher (lower) distributive justice.

Hypothesis 22. The relationships between (a) leader-member exchange, (b) trust in team members, (c) perceived organizational support and learning behavior occur indirectly through psychological safety within the organization such that the positive indirect effects on learning behavior are weaker (stronger) for followers with higher (lower) distributive justice. 
Hypothesis 23. The relationships between (a) leader-member exchange, (b) trust in team members, (c) perceived organizational support and voice behavior occur indirectly through psychological safety within the organization such that the positive indirect effects on voice behavior are weaker (stronger) for followers with higher (lower) procedural justice.

Hypothesis 24. The relationships between (a) leader-member exchange, (b) trust in team members, (c) perceived organizational support and innovative behavior occur indirectly through psychological safety within the organization such that the positive indirect effects on innovative behavior are weaker (stronger) for followers with higher (lower) procedural justice.

Hypothesis 25. The relationships between (a) leader-member exchange, (b) trust in team members, (c) perceived organizational support and learning behavior occur indirectly through psychological safety within the organization such that the positive indirect effects on learning behavior are weaker (stronger) for followers with higher (lower) procedural justice. 


\section{CHAPTER III}

\section{METHODOLOGY}

Chapter three describes the methodology that was used to test the moderated mediation model presented in chapter one (see Figure 1). In this chapter, I explain the research design and data collection procedures, describe the sample, introduce the measures, and explain how I analyzed the data and tested the hypotheses.

\section{Research Design and Procedure}

For this dissertation, I used a quantitative non-experimental research design, the survey method to collect the data, and quantitative analyses to test the hypotheses. The sample was of leader-follower dyads. Dyads are appropriate for this study since leadermember exchange is one of the central variables being tested in multiple relationships, as shown in the proposed model (Figure 1), and because leaders rated followers' behaviors. In addition, multisource data are also methodologically more rigorous. I collected the data from four organizations that were identified through cold calls and located in the United States. Once an organization accepted the invitation to discuss the study, I met with the organization's top leader or HR director (depending on the organization), presented the research proposal and asked permission to conduct the study and collect the data. After the organization reviewed the proposal and agreed to participate in the study, the organization's leader sent me an excel spreadsheet with their employees' contact information and information about each leader-follower dyad. After receiving the original contact list from the organization, I assigned a 5-digit code to each employee and created Qualtrics' contact lists to be used in Time 1, Time 2, and Time 3 surveys. The Qualtrics' contact list for the leaders also included the first name of up to four of the leader's direct 
subordinates, which were randomly selected from the original list submitted by the organization. If there were two or more followers with the same first name reporting to the same leader, I eliminated the followers from the study to avoid confusion. After I created all Qualtrics' contact lists and tested all surveys, the top leader or HR director of the organization sent an email to all employees explaining the purpose of the study, informing their employees of his/her support of the research project, encouraging employees' participation, and assuring them of the confidentiality of their responses. One or two days after the email was sent by the organization, I sent an email containing clear instructions about the study, a unique 5-digit code, and a link to the survey. A copy of the email is presented in Appendix A.

Data collection. I collected the data from two sources (i.e., leaders and followers) and at three points in time to reduce the risk of common method bias (Hiller et al., 2011; Podsakoff et al., 2003). Informed consent from all respondents, which included information about the study and contact information of researchers and of the Institutional Review Board (IRB) office at Florida International University, were obtained before the beginning of Time 1 surveys. Upon giving consent to participate in the study, participants were directed to the survey. At Time 1, followers rated their perceptions of leader-member exchange, trust in team members, and perceived organizational support. In addition, both leaders and followers provided information about their demographics. At Time 2, approximately one month after the completion of Time 1 surveys, followers rated their perceptions of psychological safety within the organization, proactive personality, political skill, team social integration, support for innovation, distributive justice, and procedural justice. At Time 3, approximately one 
month after the completion of Time 2 survey, leaders rated up to four of their direct followers on measures of voice behavior, innovative behavior, and learning behavior. Ostroff, Kinicki, and Clark (2002) have shown that a time lag of one month is enough to reduce concerns related to common method variance. Past studies testing similar models have also used a time lag of one month (e.g., Li \& Tan, 2013; Mitchell, Vogel, \& Folger, 2015). To maximize response rates, two reminder emails were sent about every ten days to individuals who had not completed their surveys (Dillman, 2000).

All surveys were administered online through Qualtrics (www.qualtrics.com), a private research software company. In each survey administration, all participants received an email from myself through Qualtrics with instructions on how to complete the survey, a link to the online survey, and a statement assuring them that their responses would be kept confidential. We ensured confidentiality of responses to decrease survey apprehension and socially desirable responses. In addition, the participants received a unique 5-digit identifier code to allow me to link responses from Time 1, Time 2, and Time 3 surveys, including leader-follower responses. To ensure anonymity, no personal identification was displayed in any of the participants' emails, or any of the followers' surveys. Leaders and followers' emails were similar, except that leaders were also notified that they were going to rate up to four of their employees.

Matching of Time 1, Time 2, and Time 3 surveys. After the data collection was completed, all surveys were matched using the SPSS (IBM SPSS Statistics 20) Data Merge Files and Restructure commands. First, identical surveys from all four organizations were combined using the SPSS adding cases option. Next, Time 3 surveys from leaders were converted into panel data format by restructuring selected variables 
into cases. Lastly, surveys collected from leaders and followers at Time 1, Time 2, and Time 3 were matched using the 5-digit code assigned to each employee and the SPSS adding variables option. Unmatched surveys (i.e., when leaders completed their surveys, but their respective followers did not; or when followers completed their surveys, but their respective leaders did not) were not included in the final data set.

\section{Sample}

Sample characteristics. The final sample consisted of 174 leader-follower dyads, with 174 followers and 85 unique leaders. Among followers, 51.1\% were male, with an average age of 44 years $(S D=11.2)$, and $70.1 \%$ held at an occupational/academic degree. The average tenure with the supervisor and with the organization were 4.4 years $(S D=$ 5.1) and 8.3 years $(S D=7.0)$, respectively. Among followers, $1.7 \%$ were Hispanic, Latino or of Spanish origin. Ethnicity of followers were distributed as $94.3 \%$ White, $1.1 \%$ Native Hawaiian or other Pacific Islander, and $4.6 \%$ with two or more races or unknown. Among leaders, $77.6 \%$ were male, with an average age of 46.5 years $(S D=$ 10.1) ranging from 30 to 70 years, and $76.9 \%$ of the leaders held an occupational/ academic degree or higher. The average tenure with the supervisor and with the organization were 6.4 years $(S D=5.5)$ and 12.1 years $(S D=7.3)$, respectively. Ethnicity of leaders were distributed as $88.2 \%$ White, $1.2 \%$ Native Hawaiian or other Pacific Islander, and $2.4 \%$ with two or more races or unknown. The remaining $8.2 \%$ of leaders did not provide their demographic characteristics.

Sample differences among organizations. Table 1 portrays the distribution of respondents per organization. Overall, the final sample for each of the four organizations consisted of 25, 60, 67, and 107 employees, respectively. A One-Way ANOVA test was 
performed to determine whether there were significant differences in demographics among all four organizations. The One-Way ANOVA test results did not reveal any significant differences among followers from the four organizations based on gender $(F(3,171)=1.3$, n.s. $)$, average age $(F(3,171)=1.6$, n.s. $)$, education $(F(3,171)=0.5$, n.s. $)$, Hispanic, Latino, or Spanish origin $(F(3,171)=0.8, n . s$.$) , or race (F(3,171)=1.2$, n.s.). However, there were statistically significant differences in the followers' average tenure with the supervisor $(F(3,171)=4.0, p<.01)$ and average tenure with the organization $(F(3,171)=4.5, p<.01)$ among the organizations. Post-hoc comparisons using the Tukey HSD test indicated that the mean score for average tenure with the supervisor for organization $1(M=2.1)$ was significantly different from organization 3 ( $M$ $=6.4$ ). In addition, the effect size, calculated using eta square (i.e., sum of squares between groups/total sum of square) is .07 , which is considered a medium effect size (Cohen, 1988). The average tenure with the supervisor for organizations 2 and 4 did not differ significantly from any other organization in the sample. Turkey HSD test also indicated that the mean score for average tenure with the organization for organization 1 $(M=4.2)$ was significantly different than tenure with the organization for organization 3 $(M=10.6)$. The calculated effect size is .07 . The average tenure with the organization for organizations 2 and 4 did not differ significantly from any other organization in the sample. The One-Way ANOVA results suggest that the four individual samples are, for the most part, similar, except for the differences among organizations based on the average tenure with supervisor and the average tenure with the organization. In order to eliminate any concerns regarding the impact of these few differences in the results, a dummy-code was created for each organization and used as a control in each hypothesis 
testing. However, when using multilevel analysis, an error stated that there was no variability between the organizations and thus the organizational dummy-code variable was dropped from the analyses.

Table 1

Respondents per Organization (Final Sample)

\begin{tabular}{lccc}
\hline & Followers & Leaders & Total \\
\hline Organization 1 & 17 & 8 & 25 \\
Organization 2 & 37 & 23 & 60 \\
Organization 3 & 45 & 22 & 67 \\
Organization 4 & 75 & 32 & 107 \\
\hline Total & 174 & 85 & \\
\hline
\end{tabular}

\section{Measures}

The scales used in this study were identified from a broad review of the literature and then selected based on their appropriateness for the study. All scales have been well established in the literature. The scales used in this study are summarized in Table 2 and the survey items are listed in Appendices B-D.

\section{Independent Variables}

Leader-member exchange. I measured leader-member exchange in Time 1 using the follower Graen and Uhl-Bien's (1995) original measures to assess the nature of the leader-follower relationship. Some items include "How well does your leader understand your job problems and needs?" and "How would you characterize your working relationship with your leader?" This scale has been widely used in past research (e.g., Epitropaki, Kapoutsis, Ellen, Ferris, Drivas, Ntotsi, 2016; Huang, Krasikova, \& Liu, 2016). Each item of this 7-item measure has its own 5-point scale, as described in detail in Appendix B. The measure has a Cronbach's (1951) alpha coefficient of .93. 
Table 2

Constructs'Scales

\begin{tabular}{llcc}
\hline \multicolumn{1}{c}{ Scale } & \multicolumn{1}{c}{ Source } & $\begin{array}{c}\text { Number } \\
\text { of Items }\end{array}$ & $\begin{array}{c}\text { Cronbach's } \\
\text { Alpha } \\
\text { Reliability }\end{array}$ \\
\hline $\begin{array}{l}\text { Leader Member Exchange } \\
\text { Trust in Team Members }\end{array}$ & Graen \& Uhl-Bien, 1995 & 7 & .93 \\
Organizational Support & Ee Jong \& Elfring, 2010 & 5 & .88 \\
Psychological Safety & Edmondson, 1999 & 6 & .93 \\
Proactive Personality & Seibert, Crant, \& Kraimer, 1999 & 10 & .86 \\
Political Skill & Ferris, Treadway et al., 2005 & 18 & .89 \\
Team Social Integration & Smith et al., 1994 & 9 & .91 \\
Support for Innovation & Anderson \& West, 1998 & 8 & .88 \\
Distributive Justice & Colquitt, 2001 & 4 & .95 \\
Procedural Justice & Colquitt, 2001 & 7 & .93 \\
Voice Behavior & Liang, Farh, \& Farh, 2012 & 10 & .92 \\
Innovative Behavior & Janssen, 2000 & 9 & .97 \\
Learning Behavior & Edmondson, 1999 & 7 & .79 \\
\hline
\end{tabular}

Note. $N=174$.

Trust in team members. I measured trust in team members in Time 1 using the

De Jong and Elfring's (2010) original 5-item measure and a 5-point Likert type scale (1 = strongly disagree, $5=$ strongly agree). For this measure, which has been used in past research (e.g., De Jong, Bijlsma-Frankema, \& Cardinal, 2014), employees were asked to indicate their level of agreement with statements such as "I trust my team members" and "I can rely on my team members to keep their word." This measure has a Cronbach's alpha coefficient of .88 .

Perceived organizational support. I measured perceived organizational support in Time 1 using six items from the Survey of Perceived Organizational Support (Eisenberger et al., 1986) and a 7-point Likert type scale $(1=$ strongly disagree, $7=$ strongly agree), as previously done in Eisenberger, Armeli, Rexwinkel, Lynch, and Rhoades's (2001) study. Employees were asked to indicate their degree of agreement 
with statements such as "My organization strongly considers my goals and values" and "My organization really cares about my well-being." This measure has a Cronbach's alpha coefficient of .93 .

\section{Mediator}

Psychological safety within the organization. I measured psychological safety within the organization in Time 2 using Edmondson's (1999) 7-item measure and a 7point Likert type scale $(1=$ strongly disagree, $7=$ strongly agree $)$. As done in Tangirala et al. (2013), I modified the items to reflect psychological safety of employees of an organization instead of members of a team. Employees were asked to indicate their degree of agreement with statements such as "It is safe to take a risk in this organization" and "It is difficult to ask other employees in this organization for help" (reverse-coded). This measure has a Cronbach's alpha coefficient of .86.

\section{Moderators}

Proactive personality. I measured proactive personality in Time 2 using Seibert and colleagues' (1999) original 10-item measure and a 7-point Likert type scale $(1=$ strongly disagree, 7 = strongly agree), which has also been used by other researchers (e.g., Sun \& van Emmerik, 2015). Employees were asked to indicate the extent to which they agreed with statements such as "If I see something I don't like, I fix it" and "I excel at identifying opportunities.” This measure has a Cronbach's alpha coefficient of .89.

Political skill. I measured political skill in Time 2 using Ferris, Treadway et al.'s (2005) original 18-item measure, which contains four subscales: networking ability (6 items), interpersonal influence (4 items), social astuteness (5 items), and apparent sincerity ( 3 items). This measure has also been used extensively by other researchers such 
as Sun and van Emmerik (2015), and Wei, Chiang and Wu (2012). Employees were asked to indicate their level of agreement with certain statements using a 7-point Likert type scale $(1=$ strongly disagree, $7=$ strongly agree $)$. Examples of items that were used include the following: "I spend a lot of time and effort at work networking with others" (networking ability), "It is easy for me to develop good rapport with most people" (interpersonal influence), "I understand people very well" (social astuteness), and "I try to show a genuine interest in other people" (apparent sincerity). This measure has a Cronbach's alpha coefficient of .91 .

Perceived team social integration. I measured perceived team social integration in Time 2 using the Smith and colleagues' (1994) 9-item measure and a 7-point Likert type scale $(1=$ strongly disagree, $7=$ strongly agree $)$. The items were adapted to reflect social integration of a team instead of a top management group. Employees were asked to indicate their level of agreement with statements such as "The members of my team get along together very well" and "The members of my team are always ready to cooperate and help each other." This measure has a Cronbach's alpha coefficient of .88.

Perceived support for innovation. I measured perceived support for innovation in Time 2 using Anderson and West's (1998) 8-item measure and a 7-point Likert type scale $(1=$ strongly disagree, $7=$ strongly agree $)$. Employees were asked to indicate their level of agreement with statements such as "This organization is open and responsive to change" and "In this organization we take the time needed to develop new ideas." This measure has a Cronbach's alpha coefficient of .96 .

Perceived organizational justice. I measured perceived organizational justice in Time 2 with Colquitt's (2001) original measures of distributive justice (4 items) and 
procedural justice ( 7 items). These measures have been widely used by other researchers such as Blader and Tyler (2009), Cole, Bernerth, Walter and Holt (2010) and Johnson, Selenta and Lord (2006). I used a 5-point Likert type scale $(1=$ to a small extent, 5 = to a large extent) for both measures. For the distributive justice measure, employees were asked questions related to payments and rewards they receive at work (e.g., "Are your pay and rewards justified, given your performance?”). For the procedural justice measure, employees were asked questions related to the decision-making procedures used at work (e.g., "Have those procedures been free of bias?"). The distributive justice measure has a Cronbach's alpha coefficient of .95 and the procedural justice measure has a Cronbach's alpha coefficient of .93 .

\section{Dependent Variables}

Voice behavior. Followers' voice behavior was assessed in Time 3 by their leaders (i.e., direct supervisors) using the Liang and colleagues' (2012) 10-item measure and a 5-point Likert type scale ( $1=$ strongly disagree, $5=$ strongly agree $)$, which contains two subscales: promotive voice (5 items) and prohibitive voice (5 items). This measure has been used by other researchers, such as Wei, Zhang and Chen (2015) and Kakkar, Tangirala, Srivastava and Kamdar (2016). Leaders were asked to indicate the degree to which they agreed with statements regarding their employees such as "Raise suggestions to improve the unit's working procedure" (promotive voice) and "Proactively report coordination problems in the workplace to the management" (prohibitive voice). This measure has a Cronbach's alpha coefficient of .92 .

Innovative behavior. Leaders assessed their employees' innovative behavior in

Time 3 using the Janssen's (2000) original 9-item measure and a 7-point Likert type scale 
$(1=$ never, $7=$ always $)$. The measure, which has been extensively used by other researchers (e.g., Chen, Li, \& Leung, 2016; Kang, Solomon, \& Choi, 2015), is intended to capture idea generation behaviors ( 3 items), idea promotion behaviors ( 3 items) and idea realization behaviors ( 3 items) of employees. Leaders were asked to rate how often their employees performed certain innovative behaviors such as "Create new ideas for difficult issues" (idea generation), "Acquire approval for innovative ideas" (idea promotion), and "Introduce innovative ideas into the work environment in a systematic way" (idea realization). This measure has a Cronbach's alpha coefficient of .97.

Learning behavior. Leaders assessed their employees' learning behavior in Time 3 using Edmondson's (1999) 7-item measure and a 5-point Likert type scale $(1=$ never, 5 $=$ always), which has been used in past research (e.g., Hirst, Van Knippenberg, \& Zhou, 2009). Items were modified to reflect the employees', instead of the teams', learning behaviors. Leaders were asked to rate how often their employees engaged in certain learning behaviors such as "This person relies on outdated information or ideas" (reversecoded) and "This person actively reviews his/her own progress and performance." This measure has a Cronbach's alpha coefficient of .79.

\section{Control Variables}

Past research has indicated the need to control for certain demographic characteristics that may offer alternative explanations when studying both in-role and extra-role performance. For example, gender has been used as a control in studies of voice behavior (e.g., Detert \& Burris, 2007; Van Dyne \& LePine, 1998) and education has been linked to innovative behavior (e.g., Baer, Oldham, \& Cummings, 2003; Wiersema \& Bantel, 1992). Stamper and Van Dyne (2001) found voice and age to be 
related and results from a meta-analysis showed that performance may increase or decrease with age, depending on the type of performance being measured (e.g., Waldman $\&$ Avolio, 1986). Thus, I controlled for gender $(0=$ female, $1=$ male $)$, age (in years), and education $(1=$ not a high school graduate, $2=$ high school graduate, $3=$ associate's degree, 4 = bachelor's degree, $5=$ master's degree, $6=$ professional degree, $7=$ doctorate degree). In addition, employees who have worked longer in an organization may be more comfortable speaking up than new employees (e.g., Liang et al., 2012; Stamper \& Van Dyne, 2001) and organizational tenure has also been found to be related to innovative behavior (e.g., Carmeli, Meitar \& Weisberg, 2006; Janssen, 2004). Position level has been shown to be associated with creativity (Gilson, Lim, D'Innocenzo \& Moye, 2012). Thus, I controlled for tenure with organization (in years) and position level $(1=$ nonsupervisory $; 2$ = front-line management $; 3=$ middle management $; 4=$ top management). 


\section{CHAPTER IV}

\section{RESULTS}

Chapter four presents the results from the preliminary data analyses (i.e., data screening and preparation, response rate and bias, missing values, reliability of scales, descriptive statistics, multicollinearity, normality, linearity, and outliers), hypotheses testing (i.e., for direct effects, indirect effects, and conditional indirect effects), and post-hoc analyses (i.e., direct effects, indirect effects, and conditional indirect effects using voice behavior and innovative behavior subscales as dependent variables, and power analyses).

\section{Preliminary Data Analysis}

Data screening and preparation. Prior to testing the moderated mediation model, I conducted preliminary screening and data preparation procedures. After merging the files, I examined the data for response rates and biases, and missing values. I also compared respondents, partial respondents and non-respondents based on several key variables and demographic characteristics. Next, I conducted confirmatory factor analyses (CFA) to assess the discriminant validity of the constructs and checked the reliability of the scales. I also reviewed the results from the descriptive statistics and intercorrelations to uncover incorrect values and to identify multicollinearity issues. Lastly, I checked the data for normality, linearity and outliers. Except for CFA, all these preliminary analyses were performed using SPSS Statistics 20. CFA was performed using Mplus v8 (Muthen \& Muthen, 2017).

Response and completion rates. Time 1 survey and Time 2 survey were sent to 748 followers. A total of 384 followers answered Time 1 survey, yielding a response rate of 51.3 percent, and a total of 316 followers completed Time 2 survey, yielding a 
response rate of 42.2 percent and a completion rate of 82.3 percent. Time 1 and Time 2 response rates for all four organizations ranged from 37.7 to 75.4 percent. Time 3 survey was sent to 212 leaders, who rated up to four of their followers. A total of 114 leaders answered Time 3 survey, yielding a response rate of 53.8 percent. Time 3 response rates for all four organizations ranged from 43.4 to 67.8 percent. There were several leaders who rated followers who had not completed Time 1 and/or Time 2 surveys, and there were several followers who completed both Time 1 and Time 2 surveys but whose leaders did not complete Time 3 survey. After matching leader-follower dyad responses from Time 1, Time 2, and Time 3 surveys, the final sample consisted of 174 leaderfollower dyads, representing 174 followers and 85 unique leaders. A breakdown of response rates per organization is presented in Table 3.

Response bias. First, I performed independent-samples t-tests to examine potential differences between followers who completed both Time 1 and Time 2 surveys and those who completed Time 1 survey but failed to complete Time 2 survey, based on their demographics, their Time 1 survey ratings, and their leaders' ratings of followers' voice, innovative, and learning behaviors. Female respondents were more likely to complete both surveys than male respondents $(t(378)=-2.70, p<.01$, two-tailed $)$, however the magnitude of the difference in the means was small (eta squared $=.02$ ). Employees with a graduate degree or higher were also more likely to complete both surveys than those with a college degree or lower $(F(378)=11.84, p<.01$, two-tailed $)$, however the magnitude of the difference in the means was small (eta squared $=.03$ ). There were no statistically significant differences between those who completed both Time 1 and Time 2 surveys and those who only completed Time 1 survey based on age 
$(t(377)=-0.20$, n.s., two-tailed $)$, tenure with supervisor $(t(377)=1.28$, n.s., two-tailed $)$, tenure with organization $(t(377)=0.52, n . s .$, two-tailed $)$, position $(t(377)=-1.77$, n.s., two-tailed $)$, or race $(t(378)=-1.43, n . s$. , two-tailed $)$. In addition, there were no statistically significant differences between the two groups of respondents based on their ratings of leader-member exchange $(t(382)=-0.74$, n.s., two-tailed $)$, trust in team members $(t(380)=0.61, n . s .$, two-tailed $)$, or perceived organizational support $(t(379)=$ 0.20, n.s., two-tailed). Furthermore, there were no statistically significant differences between the two groups of respondents based on their leaders' ratings of followers' voice $(t(201)=-0.47, n . s .$, two-tailed $)$, innovative $(t(201)=-0.60$, n.s., two-tailed $)$, or learning $(t(201)=0.06$, n.s., two-tailed) behaviors.

Table 3

Response Rates

\begin{tabular}{cccc}
\hline Time 1 & Surveys Sent & Surveys Completed & Response Rate \\
\hline Followers Total & 748 & 384 & $51.3 \%$ \\
Organization 1 & 57 & 43 & $75.4 \%$ \\
Organization 2 & 265 & 104 & $39.2 \%$ \\
Organization 3 & 200 & 95 & $47.5 \%$ \\
Organization 4 & 226 & 138 & $61.1 \%$ \\
\hline Time 2 & Surveys Sent & Surveys Completed & Response Rate \\
\hline Followers Total & 748 & 316 & $42.2 \%$ \\
Organization 1 & 57 & 38 & $66.7 \%$ \\
Organization 2 & 265 & 100 & $37.7 \%$ \\
Organization 3 & 203 & 92 & $45.3 \%$ \\
Organization 4 & 223 & 122 & $54.7 \%$ \\
\hline Time 3 & Surveys Sent & Surveys Completed & Response Rate \\
\hline Leaders Total & 212 & 114 & $53.8 \%$ \\
Organization 1 & 17 & 10 & $58.8 \%$ \\
Organization 2 & 83 & 36 & $43.4 \%$ \\
Organization 3 & 53 & 28 & $52.8 \%$ \\
Organization 4 & 59 & 40 & $67.8 \%$ \\
\hline
\end{tabular}

Note. After matching leader-follower dyad responses from Time 1, Time 2, and Time 3, the final sample consisted of 174 leader-follower dyads, representing 174 followers and 85 unique leaders. 
Second, I performed independent-samples t-tests to examine potential differences between respondents and non-respondents of Time 1 survey based on their leaders' ratings of followers' voice, innovative, and learning behaviors. Followers who completed Time 1 survey were rated higher on voice behavior $(M=3.98, S D=.60)$ than nonrespondents $(M=3.76, S D=.67 ; t(348)=-3.24, p<.01$, two-tailed $)$. Followers who completed Time 1 survey were also rated higher on innovative behavior $(M=4.54, S D=$ 1.36) than non-respondents $(M=4.03, S D=1.32 ; t(342)=-3.51, p<.01$, two-tailed $)$. Furthermore, followers who completed Time 1 survey were rated higher on learning behavior $(M=3.66, S D=.54)$ than non-respondents $(M=3.46, S D=.52 ; t(342)=-3.32$, $p<.01$, two-tailed). However, the magnitude of the differences in the means were small (eta square $=.03, .03$, and .03 , respectively). Since I did not have demographic information or Time 1 survey ratings for non-respondents, I was not able to compare Time 1 survey respondents and non-respondents based on their demographic characteristics or Time 1 survey ratings. Based on these analyses, I concluded that there is no (or very little) non-response bias.

Missing values. Among followers who responded both Time 1 and Time 2 surveys, only less than 3 percent missed at least one question, while about 97 percent answered all the questions from both surveys. After further examining the data, I observed that the questions missed by less than 3 percent of the respondents were demographic questions or the last 20 questions of Time 2 survey, which are the items for the social integration, distributive justice, and procedural justice moderators. Time 2 survey was the longest survey in the study, with a total of 63 questions, and thus it is likely that the last 20 questions were missed due to survey fatigue. In addition, one 
respondent missed only the demographic questions but completed all other questions in both T1 and T2 surveys, and thus it is likely that the respondent missed those questions to avoid personal identification. I performed an independent-samples t-test to examine potential differences between followers who answered 100 percent of the questions from both Time 1 and Time 2 surveys and those who completed Time 1 and Time 2 surveys but missed at least one question, based on their demographics and on their leader-member exchange, trust in team members, perceived organizational support, and psychological safety within the organization ratings. Respondents who missed at least one question were more likely to be in lower positions $(M=1.17, S D=0.41)$ than those who answered all the questions $(M=2.04, S D=1.07)$ in both Time 1 and Time 2 surveys $(t(314)=-$ $1.98, p<.05$, two-tailed), however the magnitude of the difference in the means was small (eta squared $=.02$ ). There were no statistically significant differences between those who answered all questions from both Time 1 and Time 2 surveys and those who missed at least one question based on gender $(t(315)=-0.48, n . s .$, two-tailed $)$, age $(t(315)$ $=0.19$, n.s., two-tailed $)$, education $(t(315)=-1.18, n . s .$, two-tailed $)$, tenure with supervisor $(t(315)=0.39, n . s .$, two-tailed $)$, tenure with organization $(t(315)=0.31, n . s$. , two-tailed $)$, or race $(t(315)=-0.37, n . s$. , two-tailed $)$. In addition, there were no statistically significant differences between these two groups of respondents based on their ratings of psychological safety within the organization $(t(315)=-1.37$, n.s., twotailed), leader-member exchange $(t(317)=-1.02$, n.s., two-tailed $)$, trust in team members $(t(316)=-0.20, n . s .$, two-tailed $)$, or perceived organizational support $(t(316)=-0.51, n . s$, two-tailed). Based on these analyses, I concluded that the missing values are mostly missing at random. Full (i.e., no missing items) and partial (i.e., completed all surveys but 
missed at least one item) responses were included in the final dataset. For the calculation of correlations, missing values were excluded using pairwise deletion, and for the confirmatory factor analysis and hypotheses testing, missing values were excluded using listwise deletion.

Confirmatory factor analysis. All scales used in this dissertation have been well established and thus there was no need to conduct exploratory factor analyses. However, Anderson and Gerbing (1988) recommend testing the measurement model prior to testing the causal model. For the measurement model testing, I conducted confirmatory factor analyses using Mplus v8 (Muthen \& Muthen, 2017). CFA determines whether the items used in the survey accurately assess the construct (i.e., the construct validity of my measures) and ensures that my data fit my hypothesized model (i.e., that the constructs in the model are distinct). I used several fit indices to assess the model fit: chi-square $\left(\chi^{2}\right)$, degrees of freedom (df), comparative fit index (CFI), standardized root mean-squared residual (SRMR), and root mean square error of approximation (RMSEA), and TuckerLewis index (TLI).

First, I examined the baseline model (i.e., Model 1, Table 4) with the three measures used as the independent variables (i.e., leader-member exchange, trust in team members, and perceived organizational support) and one measure used as the mediator variable (i.e., psychological safety within the organization) since these items were rated by the same respondent (i.e., follower). The results indicate a good fit model to the data $\left(\chi^{2}=501.67, \mathrm{df}=269, \chi^{2} / \mathrm{df}=1.86, \mathrm{CFI}=.96, \mathrm{SRMR}=.04, \mathrm{RMSEA}=.05, \mathrm{RMSEA}\right.$ $[90 \% \mathrm{CI}]=[.05, .06], \mathrm{TLI}=.95)(\mathrm{Hu} \&$ Bentler, 1999; Kline, 2016). In addition, I examined seven alternative models where I combined two or three independent variables, 
or one independent variable and the mediator. As indicated in Table 4, the baseline model fits the data better than the alternative models.

Table 4

\section{Confirmatory Factor Analysis for Independent and Mediator Variables}

\begin{tabular}{clrcccccc}
\hline Mod & Description & \multicolumn{1}{c}{$\chi^{2}, \mathrm{df}$} & $\Delta \chi^{2}, \Delta \mathrm{df}$ & CFI & SRMR & RMSEA & $90 \%$ CI & TLI \\
\hline 1 & LMX/Team/POS/PsyS & $501.67^{* * *}, 269$ & - & .96 & .04 & .05 & $.05, .06$ & .95 \\
2 & (LMX+POS)/Team/PsyS & $1,253.41^{* * * *}, 272$ & $+751.74^{* * * *}, 3$ & .82 & .07 & .11 & $.10, .11$ & .80 \\
3 & (LMX+Team)/POS/PsyS & $1,408.51^{* * *}, 272$ & $+906.84^{* * * *}, 3$ & .79 & .11 & .12 & $.11, .12$ & .77 \\
4 & LMX/(Team+POS)/PsyS & $1,167.13^{* * *}, 272$ & $+665.46^{* * * *}, 3$ & .83 & .08 & .10 & $.10, .11$ & .82 \\
5 & (LMX+Team+POS)/PsyS & $1,928.42^{* * *}, 274$ & $+925.08^{* * *}, 5$ & .69 & .10 & .14 & $.13, .14$ & .66 \\
6 & LMX/Team/(POS+PsyS) & $730.06^{* * *}, 272$ & $+228.39^{* * * *}, 3$ & .91 & .06 & .07 & $.07, .08$ & .91 \\
7 & LMX/POS/(Team+PsyS) & $947.96^{* * *}, 272$ & $+445.39^{* * *}, 3$ & .87 & .10 & .09 & $.08, .10$ & .86 \\
8 & Team/POS/(LMX+PsyS) & $849.81^{* * *}, 272$ & $+348.14^{* * *}, 3$ & .89 & .08 & .08 & $.08, .09$ & .88 \\
\hline
\end{tabular}

Note. $N=316$. Mod $=$ Model. $\chi^{2}=$ chi-square. $\mathrm{df}=$ degrees of freedom. $\Delta \chi^{2}=$ change in chisquare compared to Model $1 . \Delta \mathrm{df}=$ change in degrees of freedom compared to Model $1 . \mathrm{CFI}=$ comparative fit index. RMSEA = root mean square error of approximation. SRMR $=$ standardized root mean squared residual. TLI $=$ Tucker-Lewis index.

${ }^{* * *} \mathrm{p}<.001$

In addition, I conducted a CFA for the three measures used as dependent variables (i.e., voice behavior, innovative behavior, and learning behavior) since these items were indicators of change-oriented behaviors and were rated by the same respondent (i.e., leaders). The results indicate that the baseline model (i.e., Model 1, Table 5) has a significantly better fit model $\left(\chi^{2}=1,198.44, \mathrm{df}=296, \chi^{2} / \mathrm{df}=4.05, \mathrm{CFI}=.88, \mathrm{SRMR}=\right.$ $.06, \mathrm{RMSEA}=.09, \mathrm{RMSEA}[90 \% \mathrm{CI}]=[.09, .10], \mathrm{TLI}=.87)$ than the alternative models that combined two or more of the dependent variables into one structure (i.e., Models 2, 3, 4, and 5, Table 5), although some model fit indicators from the baseline model were below acceptable values.

Next, following Van Dyne, Ang and Botero's (2003) definition of voice as a multidimensional construct, Liang and colleagues (2012) suggest that voice behavior is composed of two subscales: promotive voice and prohibitive voice. Accordingly, I 
conducted CFAs to compare Model 1 with a model including a two-factor structure for voice behavior (i.e., Model 6, Table 5). As indicated in Table 5, the CFA results for Model 6 are within the acceptable values and the model fits the data well $\left(\chi^{2}=953.72\right.$, df $=293, \chi^{2} / \mathrm{df}=3.26, \mathrm{CFI}=.92, \mathrm{SRMR}=.06, \mathrm{RMSEA}=.08, \mathrm{RMSEA}[90 \% \mathrm{CI}]=[.08$, .09], TLI = .91) (Hu \& Bentler, 1999; Kline, 2016) and significantly better than Model 1.

Table 5

Confirmatory Factor Analysis for Dependent Variables

\begin{tabular}{clccccccc}
\hline Mod & Description & \multicolumn{1}{c}{$\chi^{2}, \mathrm{df}$} & $\Delta \chi^{2}, \Delta \mathrm{df}$ & $\mathrm{CFI}$ & SRMR & RMSEA & $90 \%$ CI & TLI \\
\hline 1 & $\mathrm{VB} / \mathrm{IB} / \mathrm{LB}$ & $1,198.44^{* * *}, 296$ & - & .88 & .06 & .09 & $.09, .10$ & .87 \\
2 & $(\mathrm{VB}+\mathrm{IB} / \mathrm{LB}$ & $1,975.29^{* * *}, 298$ & $776.85^{* * *}, 2$ & .80 & .08 & .12 & $.12, .13$ & .78 \\
3 & $(\mathrm{VB}+\mathrm{LB}) / \mathrm{IB}$ & $1,519.94^{* * *}, 298$ & $321.50^{* * *}, 2$ & .84 & .08 & .11 & $.10, .12$ & .83 \\
4 & $\mathrm{VB} / \mathrm{IB}+\mathrm{LB})$ & $1,401.63^{* * *}, 298$ & $203.19^{* * *}, 2$ & .86 & .07 & .10 & $.10, .11$ & .85 \\
5 & $(\mathrm{VB}+\mathrm{IB}+\mathrm{LB})$ & $2,072.88^{* * *}, 299$ & $874.44^{* * *}, 3$ & .77 & .09 & .13 & $.13, .14$ & .75 \\
\hline 6 & $\mathrm{VBm} / \mathrm{VBh} / \mathrm{IB} / \mathrm{LB}$ & $953.72^{* * *}, 293$ & $244.72^{* * *}, 3$ & .92 & .06 & .08 & $.08, .09$ & .91 \\
7 & $\mathrm{VB} / \mathrm{Ig} / \mathrm{Ip} / \mathrm{Ir} / \mathrm{LB}$ & $1,102.19^{* * *}, 289$ & $96.25^{* * *}, 7$ & .90 & .06 & .09 & $.09, .10$ & .88 \\
8 & $\mathrm{VBm} / \mathrm{VBh} / \mathrm{Ig} / \mathrm{Ip} / \mathrm{Ir} / \mathrm{LB}$ & $849.84^{* * *}, 284$ & $348.60^{* * *}, 12$ & .93 & .06 & .08 & $.07, .08$ & .92 \\
\hline
\end{tabular}

Note. $N=344 . \chi^{2}=$ chi-square. $\mathrm{df}=$ degrees of freedom. $\mathrm{CFI}=$ comparative fit index. RMSEA $=$ root mean square error of approximation. $\mathrm{SRMR}=$ standardized root mean squared residual. TLI $=$ Tucker-Lewis index. $\mathrm{VB}=$ voice behavior. $\mathrm{IB}=$ innovative behavior. $\mathrm{LB}=$ learning behavior. $\mathrm{VBm}=$ promotive voice behavior. $\mathrm{VBh}=$ prohibitive voice behavior. $\mathrm{Ig}=$ idea generation. $\mathrm{Ip}=$ idea promotion. Ir $=$ idea realization.

${ }^{* * * *} \mathrm{p}<.001$

Furthermore, using the stages of innovation proposed by Kanter (1988), Janssen (2000) modified Scott and Bruce's (1994) innovative behavior scale and proposed a multidimensional innovative behavior measure with three subscales: idea generation, idea promotion, and idea realization. Accordingly, I conducted a CFA to compare Model 1 with a model with the three-factor structure for innovative behavior (Model 7, Table 5). As indicated in Table 5, the CFA results for Model 7 are within the acceptable values $\left(\chi^{2}\right.$ $=1,102.19, \mathrm{df}=289, \chi^{2} / \mathrm{df}=3.81, \mathrm{CFI}=.90, \mathrm{SRMR}=.06, \mathrm{RMSEA}=.09, \mathrm{RMSEA}[90 \%$ $\mathrm{CI}]=[.09, .10], \mathrm{TLI}=.88)$ and fits the data better than Model 1. Lastly, I conducted a CFA for the model using the two-factor structure of the voice behavior measure, the 
three-factor structure of the innovative behavior measure, and the one-factor structure of the learning behavior measure (i.e., Model 8, Table 5). As indicated in Table 5, Model 8 fits the data well $\left(\chi^{2}=849.84, \mathrm{df}=284, \chi^{2} / \mathrm{df}=2.99, \mathrm{CFI}=.93\right.$, SRMR $=.06$, RMSEA $=$ .08 , RMSEA $[90 \% \mathrm{CI}]=[.07, .08], \mathrm{TLI}=.92)$ and significantly better than Model 1 . Thus, in addition to the analysis using Model 1 (as hypothesized), I retained the subscales of voice behavior and innovative behavior and conducted post-hoc analyses for promotive voice behavior, prohibitive voice behavior, idea generation, idea promotion, and idea realization.

Reliability of the scales. I tested the reliability of the scales by calculating the Cronbach's alpha coefficient for each scale used in this study. Cronbach's alpha coefficient values from all scales used in this study range from .79 to .97 (see Table 2), thus all scales have good reliabilities (Kline, 2016).

Descriptive statistics. I calculated the mean, standard deviation, and intercorrelation for each variable used in the model. Means and standard deviations were used to compare differences between the organizations' individual samples and differences between full respondents and partial respondents using t-test procedures, as described in the previous chapter. I performed bivariate correlation tests, using Pearson's $r$, to evaluate the strength and significance of the relationships between variables. Table 6 summarizes the descriptive statistics, including means, standard deviations, intercorrelations, and Cronbach's alpha coefficients (displayed on the diagonal) for each variable of the study. Leader-member exchange $(r=.59, p<.001)$, trust in team members $(r=.48, p<.001)$ and perceived organizational support $(r=.66, p<.001)$, the independent variables, are moderately correlated with psychological safety within the 
organization. All three independent variables are also correlated with learning behavior $(r$ $=.24, p<.01 ; r=.21, p<.01 ; r=.24, p<.01$, respectively), although the correlations are weak. Among the three independent variables, only leader-member exchange is correlated with voice behavior $(r=.18, p<.05)$. Trust in team members and perceived organizational support are not correlated with voice behavior $(r=.15$, n.s.; $r=.13$, n.s., respectively). None of the independent variables are correlated with innovative behavior $(r=.11, n s ; r=.13, n s ; r=.05, n s$, respectively). Psychological safety within the organization is correlated with learning behavior $(r=.22, p<.01)$, but not with voice $(r=$ $.15, n . s$.$) or innovative (r=.12, n . s$.$) behaviors. Among the control variables, age shows a$ negative and statistically significant correlation with innovative $(r=-.18, p<.05)$ and learning $(r=-.19, p<.05)$ behaviors. Education shows a positive and statistically significant correlation with learning behavior $(r=.17, p<.05)$. Tenure with supervisor $(r$ $=-.17, p<.05)$ and tenure with organization $(r=-.27, p<.001)$ show a negative and statistically significant correlation with learning behavior. Lastly, position level shows a positive and statistically significant correlation with voice $(r=.23, p<.01)$ and innovative $(r=.18, p<.05)$ behaviors. I also performed bivariate correlation tests to examine the strength of the relationships between moderators and the dependent variables. Innovative behavior is correlated with proactive personality $(r=.18, p<.05)$ and political skill $(r=.17, p<.05)$, and learning behavior is correlated with proactive personality $(r=.16, p<.05)$, political skill $(r=.16, p<.05)$, social integration $(r=.31, p$ $<.001)$, and procedural justice $(r=.18, p<.05)$. Lastly, I examined the correlations between the independent variables, and between psychological safety within the organization and the moderators, to assess potential collinearity issues, as discussed next. 
Table 6

Descriptive Statistics, Intercorrelations, and Reliabilities of Study Variables

\begin{tabular}{|c|c|c|c|c|c|c|c|c|c|c|c|c|c|c|}
\hline & & Mean & SD & 1 & 2 & 3 & 4 & 5 & 6 & 7 & 8 & 9 & 10 & 11 \\
\hline 1 & Leader-Member Exchange & 3.73 & 0.86 & $(.93)$ & & & & & & & & & & \\
\hline 2 & Trust in Team Members & 3.99 & 0.69 & $.41^{* * *}$ & $(.88)$ & & & & & & & & & \\
\hline 3 & P. Organizational Support & 5.19 & 1.27 & $.67^{* * *}$ & $.53^{* * *}$ & $(.93)$ & & & & & & & & \\
\hline 4 & Psychological Safety & 4.69 & 1.11 & $.59^{* * *}$ & $.48^{* * *}$ & $.66^{* * *}$ & $(.86)$ & & & & & & & \\
\hline 5 & Proactive Personality & 5.11 & 0.75 & .11 & .12 & .07 & $.18^{*}$ & $(.89)$ & & & & & & \\
\hline 6 & Political Skill & 5.47 & 0.69 & $.29^{* * *}$ & $.33^{* * *}$ & $.36^{* * *}$ & $.38^{* * *}$ & $.48^{* * *}$ & $(.91)$ & & & & & \\
\hline 7 & Team Social Integration & 5.19 & 0.95 & $.46^{* * *}$ & $.62^{* * *}$ & $.54^{* * *}$ & $.66^{* * *}$ & $.17^{*}$ & $.31^{* * *}$ & $(.88)$ & & & & \\
\hline 8 & Support for Innovation & 4.73 & 1.28 & $.55^{* * *}$ & $.37^{* * *}$ & $.67^{* * *}$ & $.74^{* * *}$ & $.20^{* *}$ & $.33^{* * *}$ & $.58^{* * *}$ & $(.96)$ & & & \\
\hline 9 & Distributive Justice & 2.87 & 1.24 & $.34^{* * *}$ & $.28^{* * *}$ & $.49^{* * *}$ & $.46^{* * *}$ & $.15^{*}$ & $.27^{* * *}$ & $.33^{* * *}$ & $.52^{* * *}$ & $(.95)$ & & \\
\hline 10 & Procedural Justice & 2.89 & 1.1 & $.54^{* * *}$ & $.36^{* * *}$ & $.57^{* * *}$ & $.61^{* * *}$ & $.25^{* *}$ & $.35^{* * *}$ & $.47^{* * *}$ & $.69^{* * *}$ & $.66^{* * *}$ & $(.93)$ & \\
\hline 11 & Voice Behavior & 3.99 & 0.59 & $.18^{*}$ & .15 & .13 & .15 & .07 & $.15^{*}$ & .12 & .05 & .12 & .13 & $(.92)$ \\
\hline 12 & Innovative Behavior & 4.57 & 1.34 & .11 & .13 & .05 & .12 & $.18^{*}$ & $.17^{*}$ & .15 & .09 & .07 & .13 & $.74^{* * * *}$ \\
\hline 13 & Learning Behavior & 3.65 & 0.54 & $.24^{* *}$ & $.21^{* *}$ & $.24^{* *}$ & $.22^{* *}$ & $.16^{*}$ & $.16^{*}$ & $.31^{* * * *}$ & .15 & .12 & $.18^{*}$ & $.50^{* * * *}$ \\
\hline 14 & Organization & 3.02 & 1.02 & $-.21^{* *}$ & $-.20^{* *}$ & $-.17^{*}$ & -.10 & -.05 & -.02 & -.08 & -.08 & -.04 & -.11 & -.06 \\
\hline 15 & Gender $_{F}$ & 0.51 & 0.5 & .04 & .14 & -.04 & .11 & $.25^{* *}$ & .04 & .13 & .09 & .13 & $.17^{*}$ & .09 \\
\hline 16 & $\operatorname{Age}_{F}$ & 44.00 & 11.1 & .06 & .01 & .05 & .02 & $-.19^{*}$ & -.10 & .03 & .00 & .07 & -.01 & -.07 \\
\hline 17 & Education $_{F}$ & 3.31 & 1.13 & .13 & .13 & $.21^{* *}$ & $.21^{* *}$ & $.15^{*}$ & $.29^{* * *}$ & $.19^{*}$ & $.20^{* *}$ & $.17^{*}$ & $.15^{*}$ & .04 \\
\hline 18 & Tenure $(\text { Organization })_{\mathrm{F}}$ & 8.26 & 6.97 & -.05 & -.06 & -.06 & -.10 & $-.16^{*}$ & -.07 & -.14 & -.12 & .00 & -.10 & .00 \\
\hline 19 & Position Level $_{F}$ & 2.01 & 1.05 & $.16^{*}$ & .08 & .14 & $.22^{* *}$ & .15 & $.22^{* *}$ & $.20^{* *}$ & $.21^{* *}$ & .14 & $.23^{* *}$ & $.23^{* *}$ \\
\hline 20 & Hispanic $_{\mathrm{F}}$ & 2.00 & 0.20 & .07 & -.13 & -.07 & .02 & .00 & -.10 & -.08 & .08 & -.08 & .00 & -.01 \\
\hline \multirow[t]{2}{*}{21} & Race $_{F}$ & 5.06 & 0.37 & -.11 & -.01 & -.14 & -.04 & .01 & -.07 & -.01 & -.10 & -.11 & -.08 & .02 \\
\hline & & 12 & 13 & 14 & 15 & 16 & 17 & 18 & 19 & 20 & & & & \\
\hline 12 & Innovative Behavior & (.97) & & & & & & & & & & & & \\
\hline 13 & Learning Behavior & $.66^{* * *}$ & $(.79)$ & & & & & & & & & & & \\
\hline 14 & Organization & .04 & -.11 & - & & & & & & & & & & \\
\hline 15 & Gender $_{F}$ & .08 & -.02 & -.07 & - & & & & & & & & & \\
\hline 16 & $\mathrm{Age}_{\mathrm{F}}$ & $-.18^{*}$ & $-.19^{*}$ & .07 & -.07 & - & & & & & & & & \\
\hline 17 & Education $_{F}$ & .12 & $.17^{*}$ & .08 & .01 & -.06 & - & & & & & & & \\
\hline 18 & Tenure $(\text { Organization })_{\mathrm{F}}$ & -.14 & - & $.18^{*}$ & .10 & $.43^{* * *}$ & $-.28^{* * *}$ & - & & & & & & \\
\hline 19 & Position Level ${ }_{F}$ & $.18^{*}$ & .11 & .10 & $.30^{* * *}$ & .13 & $.22^{* *}$ & $.22^{* *}$ & - & & & & & \\
\hline 20 & Hispanic $_{\mathrm{F}}$ & .02 & -.04 & .12 & .06 & -.02 & -.06 & -.01 & -.06 & - & & & & \\
\hline 21 & Race $_{\mathrm{F}}$ & .01 & .01 & .10 & .07 & .05 & -.02 & .04 & -.05 & $.25^{* *}$ & & & & \\
\hline
\end{tabular}

Note: $N_{F}=174$ ( $N_{F}=172$ for team social integration, distributive justice, and procedural justice $) .{ }^{* * *} \mathrm{p}<.001,{ }^{* *} \mathrm{p}<.01,{ }^{*} \mathrm{p}<.05(2$-tailed $)$. 
Multicollinearity. When two predictor variables are highly correlated (i.e., higher than .70), we may face the issue of multicollinearity. When multicollinearity is present, results from the analyses are not reliable. First, I evaluated the potential presence of multicollinearity among the three independent variables (i.e., leader member exchange, trust in team members, and perceived organizational support). I first looked at the strength of the correlations among these variables. Since all correlations are lower than .70 (see Table 6), multicollinearity is not likely to be present. For further support, I ran multiple regression analyses for psychological safety within the organization on the three independent variables and looked at the the collinearity statistics, where two values are given: tolerance and VIF (variance inflation factor). Tolerance values less than .10 and/or VIF values higher than 10 would indicate possible multicollinearity. Since the collinearity statistics are within the acceptable values for leader member exchange (tolerance $=.54, \mathrm{VIF}=1.86)$, trust in team members $($ tolerance $=.69, \mathrm{VIF}=1.46)$, and perceived organizational support (tolerance $=.45, \mathrm{VIF}=2.22$ ), these results present further support that multicollinearity is not likely an issue.

In addition, I evaluated the potential presence of multicollinearity among psychological safety within the organization and the second stage moderators. I performed bivariate correlation tests to examine the strength and significance of those relationships. Psychological safety within the organization is statistically correlated with proactive personality $(r=.18, p<.05)$, political skill $(r=.38, p<.001)$, perceived team social integration $(r=.66, p<.001)$, perceived support for innovation $(r=.74, p<.001)$, perceived distributive justice $(r=.46, p<.001)$, and perceived procedural justice $(r=.61$, $p<.001)$. With the exception of perceived support for innovation, all other moderators 
are correlated with psychological safety within the organization but with correlations lower than .70 , and thus multicollinearity is less likely to be present. However, since perceived support for innovation is highly correlated with psychological safety within the organization, I also ran multiple regression analyses using psychological safety within the organization and perceived support for innovation as predictors and looked at the the collinearity statistics. Since the collinearity statistics are within the acceptable values for perceived support for innovation (tolerance $=.44, \mathrm{VIF}=2.29$ ), multicollinearity is not likely to be present when using perceived support for innovation as a moderator.

Normality. I performed tests for skewness and kurtosis to examine normal data distribution of dependent variables. The variables tested were voice, innovative, and learning behaviors, and psychological safety within the organization. Psychological safety within the organization was tested for normality as it is treated as a dependable variable in some of the direct effect hypotheses testing. The test for skewness measures the symmetry of the data distribution (Kline, 2016). Data distribution with a negative skewness value is left-skewed, meaning that the left tail is longer and the scores are clustered on the right. Data distribution with a positive skewness value is right-skewed, meaning that the right tail is longer and the scores are clustered on the left. The test for kurtosis measures the peakness of the data distribution (Kline, 2016). Data distribution with a positive kurtosis value has an acute peak around the mean and fatter tails. Data distribution with a negative kurtosis value has a lower and wider peak around the mean and thinner tails. Table 7 presents the results for skewness statistic, kurtosis statistic and their respective standard errors. Scholars have suggested that absolute values of skewness and kurtosis statistics less than 0.5 is approximately symmetric and that absolute values 
of skewness and kurtosis statistics between 0.5 and 1.0 is acceptable, although there is not a clear consensus on the acceptable ranges (Bulmer, 1979; DeCarlo, 1997; Kline, 2005, 2016; West, Finch, \& Curran, 1995). Accordingly, our results indicate that psychological safety within the organization, voice behavior, innovative behavior, and learning behavior present a slightly negative skewness (i.e., scores are heavier on the higher end of the scale). Innovative behavior also presents a lightly negative kurtosis (i.e., data distribution has a lower and wider peak around the mean). However, all variables tested have acceptable or above acceptable skewness and kurtosis values. Therefore, the assumption of normality is supported, and data transformation is not needed prior to the testing of the hypotheses.

Table 7

Skewness and Kurtosis Statistics of Psychological Safety Within the Organization, Voice Behavior, Innovative Behavior, and Learning Behavior

\begin{tabular}{lcccc}
\hline & $\begin{array}{c}\text { Skewness } \\
\text { Statistic }\end{array}$ & $\begin{array}{c}\text { Skewness } \\
\text { Standard Error }\end{array}$ & $\begin{array}{c}\text { Kurtosis } \\
\text { Statistic }\end{array}$ & $\begin{array}{c}\text { Kurtosis } \\
\text { Standard Error }\end{array}$ \\
\hline Psychological Safety & -0.46 & 0.18 & 0.23 & 0.37 \\
Voice Behavior & -0.51 & 0.18 & 0.14 & 0.37 \\
Innovative Behavior & -0.28 & 0.18 & -0.74 & 0.37 \\
Learning Behavior & -0.07 & 0.18 & 0.55 & 0.37 \\
\hline
\end{tabular}

Note: $N=174$.

Outliers. I checked for the presence of outliers among the mediator and dependent variables in two ways. First, I compared the 5\% trimmed mean with the mean, which is provided by SPSS when running the descriptive statistics, for each variable in the study. The 5\% trimmed mean and the mean are the same at the first decimal level for all mediator and dependent variables in the study. Second, I examined the boxplot for each mediator and dependent variable in the study to identify possible scores that were considered outliers by SPSS. No extreme outliers, which are indicated by SPSS with an 
asterisk, were found among the mediator and dependent variables, and no outliers, which are indicated by SPSS with little circles and ID numbers attached to them, were identified for innovative behavior. The other variables tested have one or more outliers (although, as mentioned before, none of them were extreme outliers). I examined each outlier to look for errors or other evidence of non-genuine scores (e.g., when participants give the same rating to all the questions, etc.). I did not find any reason to eliminate the outliers indicated by SPSS based on this investigation and I decided to keep all the scores in the hypotheses' analyses.

Independence of responses. Considering the nested nature of the data (i.e., followers nested under leaders), I calculated the intraclass correlation (ICC(1)) for the mediator and dependent variables to assess the level of independence of the responses and evaluate the need to use multilevel analyses when testing my hypotheses (Burke, Landis, \& Burke, 2016). ICC(1) values indicate the level of variance due to the group level (i.e., leaders) rather than the individual level (i.e., followers) (Bliese, 2000) and scholars have suggested that an ICC(1) value equal or higher than .10 indicates nonindependence of responses and the need to use multilevel analyses. ICC(1) is calculated using the following Bartko equation:

$$
\operatorname{ICC}(1)=(\operatorname{MSB}-\mathrm{MSW}) /(\operatorname{MSB}+(\mathrm{n}-1) \times \mathrm{MSW})
$$

MSB stands for the between-group mean square, MSW stands for the withingroup mean square, and $\mathrm{n}$ is the average number of members within groups. I obtained the values of MSB and MSW by conducting ANOVA using SPSS Statistics v20.

Results from the analyses reveal ICC(1) values of .15 (psychological safety within the organization), .34 (voice behavior), .64 (innovative behavior), and .62 (learning 
behavior), indicating the need to use multilevel analyses since at least one of these values is equal or higher than .10 (Bliese, 2000).

\section{Hypotheses Testing}

Based on the results from the test of independence, I used multilevel analyses to test all hypotheses (i.e., direct effect, indirect effect, and conditional indirect effect hypotheses) using Mplus v8 (Muthen \& Muthen, 2017). I used two-level random and maximum likelihood, with random intercepts and fixed slopes. I entered the following controls in all hypotheses' tests: gender, age, education, tenure with organization, and position level. Since the data were collected from four organizations, a dummy-code for the organization was initially intended to be used as a control. However, when entered in the analyses it showed no variation and thus it was eliminated from the hypotheses testing.

Direct effects. Table 8 summarizes the results for the combined direct effects of leader-member exchange, trust in team members, and perceived organizational support on psychological safety within the organization (Hypotheses 1a-1c). Table 9 summarizes the results for the direct effects of psychological safety within the organization on voice behavior, innovative behavior, and learning behavior (Hypotheses 2, 4, and 6).

Table 8 indicates that the direct effects of leader-member exchange $(b=.34, S E=$ $.10, p<.01)$ and perceived organizational support $(\mathrm{b}=.34, S E=.08, p<.001)$ on psychological safety within the organization are positive and statistically significant. Hypotheses 1a and 1c are supported. Conversely, the direct effect of trust in team members $(\mathrm{b}=.02, S E=.10$, n.s. $)$ on psychological safety within the organization is not statistically significant. Hypothesis $1 \mathrm{~b}$ is not supported. 
Table 9 shows that the direct effects of psychological safety within the organization on voice behavior $(\mathrm{b}=.09, S E=.06$, n.s. $)$, and innovative behavior $(\mathrm{b}=.16$, $S E=.11, n . s$.$) are not statistically significant. Thus, hypotheses 2$, and 4 are not supported. However, the direct effect of psychological safety within the organization on learning behavior $(\mathrm{b}=.09, S E=.04, p<.05)$ is positive and statistically significant.

Hypotheses 6 is supported.

Table 8

Direct Effects of Leader-Member Exchange, Trust in Team Members, and Perceived Organizational Support on Psychological Safety Within the Organization

Mediator:

Psychological Safety

Controls Controls and IVs

b (S.E.)

b (S.E.)

\begin{tabular}{lrr}
\hline Controls & & \\
Gender & $.60^{* *}(.20)$ & $.43^{* *}(.16)$ \\
Age & $.01(.01)$ & $.01(.01)$ \\
Education & $.07(.08)$ & $.04(.06)$ \\
Tenure with the organization & $-.02(.01)$ & $-.00(.01)$ \\
Position level & $.17(.09)$ & $.08(.07)$ \\
\hline Independent Variables & & $.34^{* *}(.10)$ \\
Leader member exchange & & $.02(.10)$ \\
Trust in team members & & $.34^{* * *}(.08)$ \\
Perceived organizational support & & \\
\hline
\end{tabular}

Note. $N_{F}=174$ (followers), $N_{L}=85$ (leaders); $\mathrm{b}=$ unstandardized regression coefficient; S.E. $=$ standard errors. Gender: $0=$ female $; 1=$ male . Position level: 1 = nonsupervisory; 2 = front-line management 3 = middle management $; 4$ = top management .

*** $\mathrm{p}<.001$ ${ }^{* *} \mathrm{p}<.01$

Indirect effects. I tested the hypotheses for the indirect effects (i.e., mediation)

(Hypotheses 3, 5, and 7) with a 95\% confidence interval using Mplus v8.1 and the Mplus code created by Stride, Gardner, Catley, and Thomas (2015). Tables 10 to 12 summarize the results for the mediation hypotheses, including the indirect effects, direct effects, and total effects. 
Table 9

Direct Effects of Psychological Safety Within the Organization on Voice Behavior, Innovative Behavior, and Learning Behavior

\begin{tabular}{|c|c|c|c|c|c|c|}
\hline & \multicolumn{2}{|c|}{ Voice Behavior } & \multicolumn{2}{|c|}{ Innovative Behavior } & \multicolumn{2}{|c|}{ Learning Behavior } \\
\hline & $\begin{array}{l}\text { Controls } \\
\text { b (S.E.) }\end{array}$ & $\begin{array}{c}\text { Controls/ } \\
\text { Mediator } \\
\text { b (S.E.) }\end{array}$ & $\begin{array}{l}\text { Controls } \\
\text { b (S.E.) }\end{array}$ & $\begin{array}{l}\text { Controls/ } \\
\text { Mediator } \\
\text { b (S.E.) }\end{array}$ & $\begin{array}{l}\text { Controls } \\
\text { b (S.E.) }\end{array}$ & $\begin{array}{c}\text { Controls/ } \\
\text { Mediator } \\
\text { b (S.E.) }\end{array}$ \\
\hline \multicolumn{7}{|l|}{ Controls } \\
\hline Gender & $-.05(.16)$ & $-.10(.17)$ & $-.10(.28)$ & $-.20(.29)$ & $-.02(.11)$ & $-.08(.11)$ \\
\hline Age & $-.01(.01)$ & $-.01(.01)$ & $-.02^{*}(.01)$ & $-.02^{*}(.01)$ & $-.01(.00)$ & $-.01(.00)$ \\
\hline Education & $-.08(.06)$ & $-.08(.06)$ & $.02(.11)$ & $-.03(.11)$ & $-.01(.04)$ & $-.02(.04)$ \\
\hline Tenure (organization) & $.00(.01)$ & $.00(.01)$ & $-.01(.02)$ & $-.01(.02)$ & $-.01(.01)$ & $-.01(.01)$ \\
\hline Position level & $.09(.07)$ & $.07(.07)$ & $.15(.13)$ & $.12(.13)$ & $.03(.05)$ & $.02(.05)$ \\
\hline \multicolumn{7}{|l|}{ Independent Variable } \\
\hline Psychological Safety & & $.09(.06)$ & & $.16(.11)$ & & $.09^{*}(.04)$ \\
\hline
\end{tabular}

Note. $N_{F}=174$ (followers), $N_{L}=85$ (leaders). $\mathrm{b}=$ unstandardized regression coefficient; S.E. $=$ standard errors. Gender: $0=$ female $; 1=$ male. Position level: 1 = nonsupervisory; 2 =front-line management 3 = middle management; $4=$ top management. ${ }^{*} \mathrm{p}<.05$

Table 10

Indirect Effects of Leader-Member Exchange, Trust in Team Members, and Perceived Organizational Support on Voice Behavior via Psychological Safety Within the

Organization

\begin{tabular}{lcccccccr}
\hline & \multicolumn{3}{c}{ Decomposed Effects } & & \multicolumn{3}{c}{ Indirect Effects } \\
\cline { 2 - 4 } \cline { 7 - 8 } $\begin{array}{l}\text { Independent } \\
\text { Variable }\end{array}$ & $a$ & $b$ & $c$ & $c^{\prime}$ & & $a b$ & \\
& $\mathrm{~b}$ (S.E.) & $\mathrm{b}($ S.E. $)$ & $\mathrm{b}$ (S.E.) & $\mathrm{b}$ (S.E.) & & $\mathrm{b}$ (S.E.) & L CI & U CI \\
\hline LMX & $.34^{* *}(.10)$ & $.04(.08)$ & $.13(.11)$ & $.12(.11)$ & & $.02(.03)$ & -.04 & .07 \\
TTM & $.02(.10)$ & $.04(.08)$ & $.02(.11)$ & $.02(.11)$ & & $.00(.01)$ & -.01 & .01 \\
POS & $.34^{* * *}(.08)$ & $.04(.08)$ & $.00(.08)$ & $-.01(.08)$ & & $.02(.03)$ & -.04 & .07 \\
\hline
\end{tabular}

Note. $N_{F}=174$ (followers), $N_{L}=85$ (leaders). LMX = leader-member exchange, TTM = trust in team members, $\mathrm{POS}=$ perceived organizational support. $\mathrm{a}=$ first stage effect of the independent variable on the mediator; $b=$ second stage effect of the mediator on the dependent variable; $c=$ total effect of the independent variable on the dependent variable; $c^{\prime}=$ direct effect of the independent variable on the dependent variable. $\mathrm{b}=$ unstandardized regression coefficients; S.E. $=$ standard error. $\mathrm{ab}=$ indirect effect. $\mathrm{L}$ $\mathrm{CI}$ and $\mathrm{U} \mathrm{CI}=$ Bias-corrected lower and upper values of $95 \%$ confidence intervals.

*** $\mathrm{p}<.001$

** $\mathrm{p}<.01$

Confidence intervals with zero between low and high values (see Table 10)

indicate that psychological safety within the organization does not mediate the relationships between leader-member exchange $(\mathrm{b}=.02, \mathrm{SE}=.03,95 \% \mathrm{CI}[-.04, .07])$, trust in team members $(\mathrm{b}=.00, \mathrm{SE}=.01,95 \% \mathrm{CI}[-.01, .01])$, and perceived 
organizational support $(\mathrm{b}=.02, \mathrm{SE}=.03,95 \% \mathrm{CI}[-.04, .07])$, and voice behavior.

Hypothesis $3 \mathrm{a}, 3 \mathrm{~b}$, and $3 \mathrm{c}$ are not supported.

Table 11

Indirect Effects of Leader-Member Exchange, Trust in Team Members, and Perceived Organizational Support on Innovative Behavior via Psychological Safety Within the Organization

\begin{tabular}{|c|c|c|c|c|c|c|c|}
\hline \multirow{3}{*}{$\begin{array}{c}\text { Independent } \\
\text { Variable }\end{array}$} & \multicolumn{4}{|c|}{ Decomposed Effects } & \multicolumn{3}{|c|}{ Indirect Effects } \\
\hline & $a$ & $b$ & $c$ & $c^{\prime}$ & & $a b$ & \\
\hline & b (S.E.) & b (S.E.) & b (S.E.) & b (S.E.) & b (S.E.) & $\mathrm{L} \mathrm{CI}$ & $\mathrm{UCI}$ \\
\hline LMX & $.34^{* *}(.10)$ & $.11(.14)$ & $.27(.18)$ & $.23(.19)$ & $.04(.05)$ & -.06 & .13 \\
\hline TTM & $.02(.10)$ & $.11(.14)$ & $.05(.18)$ & $.05(.18)$ & $.00(.01)$ & -.02 & .03 \\
\hline POS & $.34^{* * *}(.08)$ & $.11(.14)$ & $-.04(.14)$ & $-.08(.14)$ & $.04(.05)$ & -.05 & .13 \\
\hline
\end{tabular}

Note. $N_{F}=174$ (followers), $N_{L}=85$ (leaders). LMX = leader-member exchange, TTM = trust in team members, $\mathrm{POS}=$ perceived organizational support. $\mathrm{a}=$ first stage effect of the independent variable on the mediator; $\mathrm{b}=$ second stage effect of the mediator on the dependent variable; $\mathrm{c}=$ total effect of the independent variable on the dependent variable; $\mathrm{c}^{\prime}=$ direct effect of the independent variable on the dependent variable. $\mathrm{b}=$ unstandardized regression coefficients; S.E. $=$ standard error. $\mathrm{ab}=$ indirect effect. $\mathrm{L}$ $\mathrm{CI}$ and $\mathrm{U} \mathrm{CI}=$ Bias-corrected lower and upper values of $95 \%$ confidence intervals.

${ }^{* * * *} \mathrm{p}<.001$

${ }^{* *} \mathrm{p}<.01$

Table 12

Indirect Effects of Leader-Member Exchange, Trust in Team Members, and Perceived Organizational Support on Learning Behavior via Psychological Safety Within the Organization

\begin{tabular}{|c|c|c|c|c|c|c|c|}
\hline \multirow{3}{*}{$\begin{array}{l}\text { Independent } \\
\text { Variable }\end{array}$} & \multicolumn{4}{|c|}{ Decomposed Effects } & \multicolumn{3}{|c|}{ Indirect Effects } \\
\hline & $a$ & $b$ & $c$ & $c^{\prime}$ & & $a b$ & \\
\hline & b (S.E.) & b (S.E.) & b (S.E.) & b (S.E.) & $\mathrm{b}$ (S.E.) & $\mathrm{LCI}$ & U CI \\
\hline LMX & $.34^{* *}(.10)$ & $.06(.05)$ & $.10(.07)$ & $.08(.07)$ & $.02(.03)$ & -.02 & .06 \\
\hline TTM & $.02(.10)$ & $.06(.05)$ & $-.04(.07)$ & $-.05(.07)$ & $.00(.01)$ & -.01 & .01 \\
\hline POS & $.34^{* * *}(.08)$ & $.06(.05)$ & $.04(.05)$ & $.02(.05)$ & $.02(.02)$ & -.02 & .06 \\
\hline
\end{tabular}

Note. $N_{F}=174$ (followers), $N_{L}=85$ (leaders). LMX = leader-member exchange, TTM = trust in team members, $\mathrm{POS}=$ perceived organizational support. $\mathrm{a}=$ first stage effect of the independent variable on the mediator; $\mathrm{b}=$ second stage effect of the mediator on the dependent variable; $\mathrm{c}=$ total effect of the independent variable on the dependent variable; $\mathrm{c}^{\prime}=$ direct effect of the independent variable on the dependent variable. $\mathrm{b}=$ unstandardized regression coefficients; S.E. $=$ standard error. $\mathrm{ab}=$ indirect effect. $\mathrm{L}$ $\mathrm{CI}$ and $\mathrm{U} \mathrm{CI}=$ Bias-corrected lower and upper values of $95 \%$ confidence intervals .

${ }^{* * * *} \mathrm{p}<.001$

${ }^{* *} \mathrm{p}<.01$

Confidence intervals with zero between low and high values (see Table 11) also indicate that psychological safety within the organization does not mediate the 
relationships between leader-member exchange $(\mathrm{b}=.04, \mathrm{SE}=.05,95 \% \mathrm{CI}[-.06, .13])$, trust in team members $(\mathrm{b}=.00, \mathrm{SE}=.01,95 \% \mathrm{CI}[-.02, .03])$, and perceived organizational support $(\mathrm{b}=.04, \mathrm{SE}=.05,95 \% \mathrm{CI}[-.05, .13])$, and innovative behavior. Hypothesis 5a, 5b, and 5c are not supported.

Confidence intervals with zero between low and high values (see Table 12) also indicate that psychological safety within the organization does not mediate the relationships between leader-member exchange $(\mathrm{b}=.02, \mathrm{SE}=.03,95 \% \mathrm{CI}[-.02, .06])$, trust in team members $(\mathrm{b}=.00, \mathrm{SE}=.01,95 \% \mathrm{CI}[-.01, .01])$, and perceived organizational support $(\mathrm{b}=.02, \mathrm{SE}=.02,95 \% \mathrm{CI}[-.02, .06])$, and learning behavior. Hypothesis 7a, 7b, and 7c are not supported.

Conditional indirect effects. I tested the hypotheses for the conditional indirect effects of the proposed model (i.e., moderated mediation) (hypotheses 8 to 25) by conducting a series of path analysis tests (Hayes, 2009). I used the Mplus code developed by Stride and colleagues (2015) and followed the moderated path analytic procedures proposed by Edwards and Lambert (2007). This method allowed me to test whether the hypothesized direct and indirect effects are conditional on the different values of the proposed moderators, and tested the conditional indirect effects at lower (-1SD from the mean) and higher (+1SD from the mean) levels of the moderator. Tables 13 to 18 summarize the results for the moderated mediation hypotheses.

None of the six proposed moderators (i.e., proactive personality, political skill, perceived team social integration, perceived support for innovation, perceived distributive justice, and perceived procedural justice) moderated the indirect effects hypothesized in this study, as can be confirmed by the presence of a zero between the low 
and high values of the confidence intervals for the conditional indirect effects tested, and/or by the non-significance of the interaction coefficient. Although the confidence intervals for the moderation of perceived support for innovation on the relationship between leader-member exchange and learning behavior, and between perceived organizational support and learning behavior do not contain zero, the coefficients for these interactions are not significant. Thus, Hypotheses 8 to 25 are not supported.

As a robustness test, all the hypotheses were also tested without the controls. The results from the analyses of the direct effects, indirect effects, and conditional indirect effects remained the same (i.e., supported or not supported) when they were also tested without the control variables.

Table 13

Conditional Indirect Effects of Leader-Member Exchange, Trust in Team Members, and Perceived Organizational Support on Voice Behavior, Innovative Behavior, and Learning Behavior via Psychological Safety Within the Organization X Proactive Personality

\begin{tabular}{|c|c|c|c|c|c|c|}
\hline \multirow{3}{*}{$\begin{array}{l}\text { Independent } \\
\text { Variables }\end{array}$} & \multicolumn{6}{|c|}{ Dependent Variables } \\
\hline & \multicolumn{2}{|c|}{ Voice Behavior } & \multicolumn{2}{|c|}{ Innovative Behavior } & \multicolumn{2}{|c|}{ Learning Behavior } \\
\hline & Index (S.E.) & $95 \% \mathrm{CI}$ & Index (S.E.) & $95 \% \mathrm{CI}$ & Index (S.E.) & $95 \% \mathrm{CI}$ \\
\hline \multicolumn{7}{|c|}{ Leader-member exchange } \\
\hline Low & $.01(.03)$ & {$[-.06, .07]$} & $.06(.06)$ & {$[-.06, .18]$} & $.02(.02)$ & {$[-.03, .07]$} \\
\hline High & .02(.04) & {$[-.05, .09]$} & $-.00(.06)$ & {$[-.13, .12]$} & $.01(.02)$ & {$[-.03, .06]$} \\
\hline \multicolumn{7}{|c|}{ Trust in team members } \\
\hline Low & .00 (.00) & {$[-.01, .01]$} & $.00(.02)$ & {$[-.03, .04]$} & $.00(.01)$ & {$[-.01, .01]$} \\
\hline High & $.00(.01)$ & {$[-.01, .01]$} & $.00(.00)$ & {$[-.01, .01]$} & $.00(.00)$ & {$[-.01, .01]$} \\
\hline \multicolumn{7}{|c|}{ Perceived organizational support } \\
\hline Low & $.01(.03)$ & {$[-.06, .07]$} & $.06(.06)$ & {$[-.06, .18]$} & $.02(.02)$ & {$[-.02, .07]$} \\
\hline High & $.02(.04)$ & {$[-.05, .09]$} & $-.00(.06)$ & {$[-.13, .12]$} & $.01(.02)$ & {$[-.03, .06]$} \\
\hline
\end{tabular}

Note. $N_{F}=174$ (followers), $N_{L}=85$ (leaders). S.E. $=$ standard error. $95 \% \mathrm{CI}=95 \%$ confidence intervals. Low $=-1 \mathrm{SD}$ from the moderator's mean. High $=+1 \mathrm{SD}$ from the moderator's mean. 
Table 14

Conditional Indirect Effects of Leader-Member Exchange, Trust in Team Members, and Perceived Organizational Support on Voice Behavior, Innovative Behavior, and Learning Behavior via Psychological Safety Within the Organization X Political Skill

\begin{tabular}{|c|c|c|c|c|c|c|}
\hline \multirow{3}{*}{$\begin{array}{l}\text { Independent } \\
\text { Variables }\end{array}$} & \multicolumn{6}{|c|}{ Dependent Variables } \\
\hline & \multicolumn{2}{|c|}{ Voice Behavior } & \multicolumn{2}{|c|}{ Innovative Behavior } & \multicolumn{2}{|c|}{ Learning Behavior } \\
\hline & Index (S.E.) & $95 \% \mathrm{CI}$ & Index (S.E.) & $95 \% \mathrm{CI}$ & Index (S.E.) & $95 \% \mathrm{CI}$ \\
\hline \multicolumn{7}{|c|}{ Leader-member exchange } \\
\hline Low & $.01(.03)$ & {$[-.06, .07]$} & $.04(.06)$ & {$[-.08, .15]$} & $.02(.02)$ & {$[-.03, .06]$} \\
\hline High & $.01(.03)$ & {$[-.05, .08]$} & $.01(.06)$ & {$[-.10, .12]$} & $.02(.02)$ & {$[-.03, .06]$} \\
\hline \multicolumn{7}{|c|}{ Trust in team members } \\
\hline Low & $.00(.00)$ & {$[-.01, .01]$} & $.00(.01)$ & {$[-.02, .03]$} & $.00(.01)$ & {$[-.01, .01]$} \\
\hline High & $.00(.00)$ & {$[-.01 . .01]$} & $.00(.01)$ & {$[-.01, .01]$} & $.00(.01)$ & {$[-.01, .01]$} \\
\hline \multicolumn{7}{|c|}{ Perceived organizational support } \\
\hline Low & $.01(.03)$ & {$[-.06, .07]$} & $.04(.06)$ & {$[-.07, .15]$} & $.02(.02)$ & {$[-.03, .06]$} \\
\hline High & $.01(.03)$ & {$[-.05, .08]$} & $.01(.06)$ & {$[-.10, .12]$} & $.02(.02)$ & {$[-.03, .06]$} \\
\hline
\end{tabular}

Note. $N_{F}=174$ (followers), $N_{L}=85$ (leaders). S.E. $=$ standard error. $95 \% \mathrm{CI}=95 \%$ confidence intervals.

Low $=-1 \mathrm{SD}$ from the moderator's mean. High $=+1 \mathrm{SD}$ from the moderator's mean.

Table 15

Conditional Indirect Effects of Leader-Member Exchange, Trust in Team Members, and Perceived Organizational Support on Voice Behavior, Innovative Behavior, and Learning Behavior via Psychological Safety Within the Organization X Perceived Team Social Integration

\begin{tabular}{|c|c|c|c|c|c|c|}
\hline \multirow{3}{*}{$\begin{array}{l}\text { Independent } \\
\text { Variables }\end{array}$} & \multicolumn{6}{|c|}{ Dependent Variables } \\
\hline & \multicolumn{2}{|c|}{ Voice Behavior } & \multicolumn{2}{|c|}{ Innovative Behavior } & \multicolumn{2}{|c|}{ Learning Behavior } \\
\hline & Index (S.E.) & $95 \% \mathrm{CI}$ & Index (S.E.) & $95 \% \mathrm{CI}$ & Index (S.E.) & $95 \% \mathrm{CI}$ \\
\hline \multicolumn{7}{|c|}{ Leader-member exchange } \\
\hline Low & $.02(.04)$ & {$[-.05, .09]$} & $.05(.06)$ & {$[-.08, .17]$} & $.03(.03)$ & {$[-.02, .08]$} \\
\hline High & $.02(.04)$ & {$[-.06, .09]$} & $.07(.07)$ & {$[-.06, .20]$} & $.02(.03)$ & {$[-.03, .07]$} \\
\hline \multicolumn{7}{|c|}{ Trust in team members } \\
\hline Low & $.00(.01)$ & {$[-.01, .01]$} & $.00(.01)$ & {$[-.02, .03]$} & $.00(.01)$ & {$[-.02, .02]$} \\
\hline High & $.00(.01)$ & {$[-.01, .01]$} & $.01(.02)$ & {$[-.04, .05]$} & $.00(.01)$ & {$[-.01, .01]$} \\
\hline \multicolumn{7}{|c|}{ Perceived organizational support } \\
\hline Low & $.02(.03)$ & {$[-.05, .08]$} & $.05(.06)$ & {$[-.08, .16]$} & $.03(.02)$ & {$[-.02, .08]$} \\
\hline High & $.02(.04)$ & {$[-.06, .09]$} & $.07(.07)$ & {$[-.06, .20]$} & $.02(.02)$ & {$[-.03, .07]$} \\
\hline
\end{tabular}

Note. $N_{F}=172$ (followers), $N_{L}=85$ (leaders). S.E. $=$ standard error. $95 \% \mathrm{CI}=95 \%$ confidence intervals.

Low $=-1 \mathrm{SD}$ from the moderator's mean. High $=+1 \mathrm{SD}$ from the moderator's mean. 
Table 16

Conditional Indirect Effects of Leader-Member Exchange, Trust in Team Members, and Perceived Organizational Support on Voice Behavior, Innovative Behavior, and Learning Behavior via Psychological Safety Within the Organization X Perceived Support for Innovation

\begin{tabular}{|c|c|c|c|c|c|c|}
\hline \multirow{3}{*}{$\begin{array}{l}\text { Independent } \\
\text { Variables }\end{array}$} & \multicolumn{6}{|c|}{ Dependent Variables } \\
\hline & \multicolumn{2}{|c|}{ Voice Behavior } & \multicolumn{2}{|c|}{ Innovative Behavior } & \multicolumn{2}{|c|}{ Learning Behavior } \\
\hline & Index (S.E.) & $95 \% \mathrm{CI}$ & Index (S.E.) & $95 \% \mathrm{CI}$ & Index (S.E.) & $95 \% \mathrm{CI}$ \\
\hline \multicolumn{7}{|c|}{ Leader-member exchange } \\
\hline Low & $.05(.04)$ & {$[-.02, .12]$} & $.11(.06)$ & {$[-.02, .23]$} & $.05(.03)$ & {$[.00, .10]$} \\
\hline High & $.03(.04)$ & {$[-.04, .10]$} & $.10(.07)$ & {$[-.03, .24]$} & $.03(.03)$ & {$[-.02, .08]$} \\
\hline \multicolumn{7}{|c|}{ Trust in team members } \\
\hline Low & $.00(.01)$ & {$[-.03, .03]$} & $.01(.03)$ & {$[-.06, .07]$} & $.00(.02)$ & {$[-.03, .03]$} \\
\hline High & $.00(.01)$ & {$[-.02, .02]$} & $.01(.03)$ & {$[-.05, .07]$} & $.00(.01)$ & {$[-.02, .02]$} \\
\hline \multicolumn{7}{|c|}{ Perceived organizational support } \\
\hline Low & $.05(.03)$ & {$[-.02, .11]$} & $.11(.06)$ & {$[-.01, .22]$} & $.05(.02)$ & {$[.01, .10]$} \\
\hline High & $.03(.04)$ & {$[-.04, .10]$} & $.10(.07)$ & {$[-.03, .23]$} & $.03(.02)$ & {$[-.02, .08]$} \\
\hline
\end{tabular}

Note. $N_{F}=174$ (followers), $N_{L}=85$ (leaders). S.E. $=$ standard error. $95 \% \mathrm{CI}=95 \%$ confidence intervals. Low $=-1 \mathrm{SD}$ from the moderator's mean. High $=+1 \mathrm{SD}$ from the moderator's mean.

Table 17

Conditional Indirect Effects of Leader-Member Exchange, Trust in Team Members, and Perceived Organizational Support on Voice Behavior, Innovative Behavior, and Learning Behavior via Psychological Safety Within the Organization X Perceived Distributive Justice

\begin{tabular}{|c|c|c|c|c|c|c|}
\hline \multirow{3}{*}{$\begin{array}{l}\text { Independent } \\
\text { Variables }\end{array}$} & \multicolumn{6}{|c|}{ Dependent Variables } \\
\hline & \multicolumn{2}{|c|}{ Voice Behavior } & \multicolumn{2}{|c|}{ Innovative Behavior } & \multicolumn{2}{|c|}{ Learning Behavior } \\
\hline & Index (S.E.) & $95 \% \mathrm{CI}$ & Index (S.E.) & $95 \% \mathrm{CI}$ & Index (S.E.) & $95 \% \mathrm{CI}$ \\
\hline \multicolumn{7}{|c|}{ Leader-member exchange } \\
\hline Low & $.02(.03)$ & {$[-.04, .08]$} & $.04(.06)$ & {$[-.07, .16]$} & $.04(.02)$ & {$[-.01, .08]$} \\
\hline High & $-.03(.03)$ & {$[-.09, .04]$} & $.01(.06)$ & {$[-.12, .13]$} & $-.01(.02)$ & {$[-.06, .04]$} \\
\hline \multicolumn{7}{|c|}{ Trust in team members } \\
\hline Low & $.00(.01)$ & {$[-.01, .01]$} & $.00(.01)$ & {$[-.02, .03]$} & $.00(.01)$ & {$[-.02, .02]$} \\
\hline High & $-.00(.01)$ & {$[-.02, .01]$} & $.00(.00)$ & {$[-.01, .01]$} & $.00(.00)$ & {$[-.01, .01]$} \\
\hline \multicolumn{7}{|c|}{ Perceived organizational support } \\
\hline Low & $.02(.03)$ & {$[-.04, .08]$} & $.04(.06)$ & {$[-.07, .15]$} & $.04(.02)$ & {$[-.01, .08]$} \\
\hline High & $-.03(.03)$ & {$[-.09, .04]$} & $.01(.06)$ & {$[-.11, .13]$} & $-.01(.02)$ & {$[-.06, .04]$} \\
\hline
\end{tabular}

Note. $N_{F}=172$ (followers), $N_{L}=85$ (leaders). S.E. $=$ standard error. $95 \% \mathrm{CI}=95 \%$ confidence intervals. Low $=-1 \mathrm{SD}$ from the moderator's mean. High $=+1 \mathrm{SD}$ from the moderator's mean. 
Table 18

Conditional Indirect Effects of Leader-Member Exchange, Trust in Team Members, and Perceived Organizational Support on Voice Behavior, Innovative Behavior, and Learning Behavior via Psychological Safety Within the Organization X Perceived Procedural Justice

\begin{tabular}{|c|c|c|c|c|c|c|}
\hline \multirow{3}{*}{$\begin{array}{l}\text { Independent } \\
\text { Variables }\end{array}$} & \multicolumn{6}{|c|}{ Dependent Variables } \\
\hline & \multicolumn{2}{|c|}{ Voice Behavior } & \multicolumn{2}{|c|}{ Innovative Behavior } & \multicolumn{2}{|c|}{ Learning Behavior } \\
\hline & Index (S.E.) & $95 \% \mathrm{CI}$ & Index (S.E.) & $95 \% \mathrm{CI}$ & Index (S.E.) & $95 \% \mathrm{CI}$ \\
\hline \multicolumn{7}{|c|}{ Leader-member exchange } \\
\hline Low & $.01(.03)$ & {$[-.06, .07]$} & $.02(.06)$ & {$[-.09, .12]$} & $.03(.02)$ & {$[-.02, .07]$} \\
\hline High & $-.01(.04)$ & {$[-.08, .06]$} & $.00(.06)$ & {$[-.12, .13]$} & $-.01(.02)$ & {$[-.06, .04]$} \\
\hline \multicolumn{7}{|c|}{ Trust in team members } \\
\hline Low & $.00(.00)$ & {$[-.00, .00]$} & $.00(.01)$ & {$[-.01, .01]$} & $.00(.01)$ & {$[-.02, .02]$} \\
\hline High & $.00(.00)$ & {$[-.01, .01]$} & $.00(.00)$ & {$[-.01, .01]$} & $-.00(.00)$ & {$[-.01, .01]$} \\
\hline \multicolumn{7}{|c|}{ Perceived organizational support } \\
\hline Low & $.01(.03)$ & {$[-.06, .07]$} & $.02(.06)$ & {$[-.09, .12]$} & $.03(.02)$ & {$[-.01, .07]$} \\
\hline High & $-.01(.04)$ & {$[-.08, .06]$} & $.00(.06)$ & {$[-.12, .13]$} & $-.01(.02)$ & {$[-.06, .04]$} \\
\hline
\end{tabular}

Note. $N_{F}=172$ (followers), $N_{L}=85$ (leaders). S.E. $=$ standard error. $95 \% \mathrm{CI}=95 \%$ confidence intervals. Low $=-1 \mathrm{SD}$ from the moderator's mean. High $=+1 \mathrm{SD}$ from the moderator's mean.

\section{Post-Hoc Analyses}

Promotive and prohibitive voice behaviors. I conducted three post-hoc analyses. First, based on the results from CFA, voice behavior was confirmed to be composed of two distinct constructs: promotive voice behavior and prohibitive voice behavior. Accordingly, I examined the direct effects, indirect effects, and conditional indirect effects of leader-member exchange, trust in team members, and perceived organizational support on promotive voice behavior and prohibitive voice behavior. Tables 19 to 21 present the results from the post-hoc analyses.

Results from the regression analyses (see Table 19) indicate that psychological safety within the organization is not significantly related to followers' promotive voice behavior $(\mathrm{b}=.10, \mathrm{SE}=.06$, n.s. $)$ nor to followers' prohibitive voice behavior $(\mathrm{b}=.08, S E$ $=.06$, n.s.). 
Table 19

Direct Effects of Psychological Safety Within the Organization on Promotive Voice Behavior and Prohibitive Voice Behavior

\begin{tabular}{|c|c|c|c|c|}
\hline & \multicolumn{4}{|c|}{ Dependent Variables } \\
\hline & \multicolumn{2}{|c|}{ Promotive Voice Behavior } & \multicolumn{2}{|c|}{ Prohibitive Voice Behavior } \\
\hline & $\begin{array}{l}\text { Model } 1 \\
\text { b (S.E.) }\end{array}$ & $\begin{array}{c}\text { Model } 2 \\
\text { b (S.E.) }\end{array}$ & $\begin{array}{c}\text { Model } 3 \\
\text { b (S.E.) }\end{array}$ & $\begin{array}{c}\text { Model } 4 \\
\text { b (S.E.) }\end{array}$ \\
\hline \multicolumn{5}{|l|}{ Controls } \\
\hline Gender & $-.06(.16)$ & $-.12(.16)$ & $-.03(.16)$ & $-.08(.16)$ \\
\hline Age & $-.01(.01)$ & $-.01(.01)$ & $-.01(.01)$ & $-.01(.01)$ \\
\hline Education & $-.07(.06)$ & $-.07(.06)$ & $-.08(.06)$ & $-.09(.06)$ \\
\hline Tenure (organization) & $.00(.01)$ & $.00(.01)$ & $.00(.01)$ & $.01(.01)$ \\
\hline Position level & $.10(.07)$ & $.08(.07)$ & $.08(.07)$ & $.07(.07)$ \\
\hline \multicolumn{5}{|l|}{ Independent Variable } \\
\hline Psychological safety & & $.10(.06)$ & & $.08(.06)$ \\
\hline
\end{tabular}

Note. $N_{F}=174$ (followers), $N_{L}=85$ (leaders); $\mathrm{b}=$ unstandardized regression coefficient; S.E. $=$ standard errors. Gender: $0=$ female $; 1=$ male. Position level: $1=$ nonsupervisory; 2 = front-line management; 3 = middle management $; 4$ = top management .

Confidence intervals with zero between low and high values (see Table 20) indicate that psychological safety within the organization does not mediate the relationships between leader-member exchange, $(\mathrm{b}=.02, \mathrm{SE}=.03,95 \% \mathrm{CI}[-.04, .07])$, trust in team members $(\mathrm{b}=.00, \mathrm{SE}=.01,95 \% \mathrm{CI}[-.01, .01])$ and perceived organizational support $(\mathrm{b}=.02, \mathrm{SE}=.03,95 \% \mathrm{CI}[-.04, .07])$, and promotive voice behavior. In addition, the presence of a zero between the lower and higher values of the confidence interval indicates that psychological safety within the organization does not mediate the relationships between leader-member exchange $(b=.02, \mathrm{SE}=.03,95 \% \mathrm{CI}[-$ $.04, .07])$, trust in team members $(\mathrm{b}=.00, \mathrm{SE}=.01,95 \% \mathrm{CI}[-.01, .01])$, and perceived organizational support $(\mathrm{b}=.02, \mathrm{SE}=.03,95 \% \mathrm{CI}[-.04, .07])$, and prohibitive voice behavior. 
Table 20

Indirect Effects of Leader-Member Exchange, Trust in Team Members, and Perceived Organizational Support on Promotive Voice Behavior and Prohibitive Voice Behavior via Psychological Safety Within the Organization

\begin{tabular}{|c|c|c|c|c|c|c|c|}
\hline \multirow{3}{*}{$\begin{array}{l}\text { Independent } \\
\text { Variable }\end{array}$} & \multicolumn{4}{|c|}{ Decomposed Effects } & \multicolumn{3}{|c|}{ Indirect Effects } \\
\hline & $a$ & $b$ & $c$ & $c^{\prime}$ & & $a b$ & \\
\hline & b (S.E.) & b (S.E.) & b (S.E.) & b (S.E.) & b (S.E.) & $\mathrm{L} \mathrm{CI}$ & $\mathrm{H} \mathrm{CI}$ \\
\hline \multicolumn{8}{|c|}{ Promotive Voice Behavior } \\
\hline LMX & $.34(.10)^{* *}$ & $.04(.08)$ & $.15(.10)$ & $.14(.11)$ & $.02(.03)$ & -.04 & .07 \\
\hline TTM & $.02(.10)$ & $.04(.08)$ & $-.03(.10)$ & $-.03(.10)$ & $.00(.01)$ & -.01 & .01 \\
\hline POS & $.34(.08)^{* * *}$ & $.04(.08)$ & $.02(.08)$ & $.00(.08)$ & $.02(.03)$ & -.04 & .07 \\
\hline \multicolumn{8}{|c|}{ Prohibitive Voice Behavior } \\
\hline LMX & $.34(.10)^{* *}$ & $.05(.08)$ & $.12(.10)$ & $.10(.11)$ & $.02(.03)$ & -.04 & .07 \\
\hline TTM & $.02(.10)$ & $.05(.08)$ & $.07(.10)$ & $.07(.10)$ & $.00(.01)$ & -.01 & .01 \\
\hline POS & $.34(.08)^{* * *}$ & $.05(.08)$ & $-.01(.08)$ & $-.03(.08)$ & $.02(.03)$ & -.04 & .07 \\
\hline
\end{tabular}

Note. $N_{F}=174$ (followers), $N_{L}=85$ (leaders). LMX = leader-member exchange, TTM = trust in team members, $\mathrm{POS}=$ perceived organizational support. $\mathrm{a}=$ first stage effect of the independent variable on the mediator; $b=$ second stage effect of the mediator on the dependent variable; $c=$ total effect of the independent variable on the dependent variable; $c^{\prime}=$ direct effect of the independent variable on the dependent variable. $\mathrm{b}=$ unstandardized regression coefficients; S.E. $=$ standard error. $\mathrm{ab}=$ indirect effect. $\mathrm{L}$ $\mathrm{CI}$ and $\mathrm{H} \mathrm{CI}=$ Lower and higher values of $95 \%$ confidence intervals.

${ }^{* * * *} \mathrm{p}<.001$

${ }^{* *} \mathrm{p}<.01$

Lastly, none of the six proposed moderators (i.e., proactive personality, political skill, perceived team social integration, perceived support for innovation, perceived distributive justice, and perceived procedural justice) moderate the indirect relationships between leader-member exchange, trust in team members, and perceived organizational support, and promotive voice behavior and prohibitive voice behavior, as can be confirmed by the presence of a zero between the low and high values of the confidence intervals of the conditional indirect effects tested (see Table 21).

Idea generation, idea promotion, and idea realization. Second, based on the results from CFA, innovative behavior was confirmed to be composed of three distinct constructs: idea generation, idea promotion, and idea realization. Accordingly, I examined the direct effects, indirect effects, and conditional indirect effects of leader- 
member exchange, trust in team members, and perceived organizational support on these three subscales. Tables 22 to 24 present the results from the post-hoc analyses.

Results from the regression analyses (see Table 22) indicate that psychological safety within the organization is not significantly related to followers' idea generation (b $=.08, \mathrm{SE}=.18$, n.s. $)$, idea promotion $(\mathrm{b}=.11, S E=.18, n . s$.$) , nor idea realization (\mathrm{b}=$ $.16, S E=.20, n . s)$.

Confidence intervals with zero between low and high values (see Table 23) indicate that psychological safety within the organization does not mediate the relationships between leader-member exchange, $(\mathrm{b}=.03, \mathrm{SE}=.06,95 \% \mathrm{CI}[-.10, .15])$, trust in team members $(\mathrm{b}=.00, \mathrm{SE}=.01,95 \% \mathrm{CI}[-.02, .02])$ and perceived organizational support $(\mathrm{b}=.03, \mathrm{SE}=.06,95 \% \mathrm{CI}[-.10, .15])$, and followers' idea generation. In addition, the presence of a zero between the lower and higher values of the confidence interval indicates that psychological safety within the organization does not mediate the relationships between leader-member exchange $(\mathrm{b}=.04, \mathrm{SE}=.06,95 \% \mathrm{CI}[$ $.08, .16])$, trust in team members $(\mathrm{b}=.00, \mathrm{SE}=.01,95 \% \mathrm{CI}[-.02, .03])$, and perceived organizational support $(\mathrm{b}=.04, \mathrm{SE}=.06,95 \% \mathrm{CI}[-.08, .16])$, and followers' idea promotion. Furthermore, the presence of a zero between the lower and higher values of the confidence interval indicates that psychological safety within the organization does not mediate the relationships between leader-member exchange $(b=.05, \mathrm{SE}=.07,95 \%$ $\mathrm{CI}[-.08, .19])$, trust in team members $(\mathrm{b}=.00, \mathrm{SE}=.02,95 \% \mathrm{CI}[-.03, .04])$, and perceived organizational support $(\mathrm{b}=.05, \mathrm{SE}=.07,95 \% \mathrm{CI}[-.08, .19])$, and followers' idea realization. 
Table 21

Conditional Indirect Effects of Leader-Member Exchange, Trust in Team Members, and Perceived Organizational Support on Promotive Voice Behavior and Prohibitive Voice Behavior via Psychological Safety Within the Organization

\begin{tabular}{|c|c|c|c|c|c|c|}
\hline & & & Voice Behav & (Promotive) & Voice Beha & Prohibitive \\
\hline & & & Index (SE) & $95 \% \mathrm{CI}$ & Index (SE) & $95 \% \mathrm{CI}$ \\
\hline & LMX & $\mathrm{L}$ & $.01(.03)$ & {$[-.06, .08]$} & $.01(.03)$ & {$[-.06, .08]$} \\
\hline & & $\mathrm{H}$ & $.01(.04)$ & {$[-.06, .08]$} & $.02(.04)$ & {$[-.05, .09]$} \\
\hline$\geq=$ & TTM & $\mathrm{L}$ & $.00(.00)$ & {$[-.01, .01]$} & $.00(.00)$ & {$[-.01, .01]$} \\
\hline o & & $\mathrm{H}$ & $.00(.00)$ & {$[-.01, .01]$} & $.00(.01)$ & {$[-.01, .01]$} \\
\hline & POS & $\mathrm{L}$ & $.01(.03)$ & {$[-.06, .08]$} & $.01(.03)$ & {$[-.06, .08]$} \\
\hline & & $\mathrm{H}$ & $.01(.04)$ & {$[-.06, .08]$} & $.02(.04)$ & {$[-.05, .09]$} \\
\hline & LMX & $\mathrm{L}$ & $.00(.03)$ & {$[-.06, .07]$} & $.01(.03)$ & {$[-.06, .07]$} \\
\hline & & $\mathrm{H}$ & $.01(.03)$ & {$[-.06, .08]$} & $.01(.03)$ & {$[-.05, .08]$} \\
\hline.$\stackrel{\Xi}{\Xi} \equiv$ & TTM & $\mathrm{L}$ & $.00(.00)$ & {$[-.00, .01]$} & $.00(.00)$ & {$[-.01, .01]$} \\
\hline$\overline{0}$ & & $\mathrm{H}$ & $.00(.00)$ & {$[-.01, .01]$} & $.00(.00)$ & {$[-.01, .01]$} \\
\hline & POS & $\mathrm{L}$ & $.00(.03)$ & {$[-.06, .07]$} & $.01(.02)$ & {$[-.06, .07]$} \\
\hline & & $\mathrm{H}$ & $.01(.03)$ & {$[-.06, .08]$} & $.01(.03)$ & {$[-.05, .08]$} \\
\hline & LMX & $\mathrm{L}$ & $.01(.04)$ & {$[-.05, .08]$} & $.02(.04)$ & {$[-.05, .09]$} \\
\hline$\cdot \overline{\frac{\pi}{0}}$ 。ี & & $\mathrm{H}$ & $.03(.04)$ & {$[-.05, .10]$} & $.01(.04)$ & {$[-.06, .08]$} \\
\hline ڤ & TTM & $\mathrm{L}$ & $.00(.00)$ & {$[-.01, .01]$} & $.00(.01)$ & {$[-.01, .01]$} \\
\hline & & $\mathrm{H}$ & .00(.01) & {$[-.01, .02]$} & $.00(.00)$ & {$[-.01, .01]$} \\
\hline & POS & $\mathrm{L}$ & .01 (.04) & {$[-.05, .08]$} & $.02(.04)$ & {$[-.05, .08]$} \\
\hline & & $\mathrm{H}$ & $.03(.04)$ & {$[-.05, .10]$} & $.01(.04)$ & {$[-.06, .08]$} \\
\hline & LMX & $\mathrm{L}$ & .04 (.03) & {$[-.03, .11]$} & $.05(.04)$ & {$[-.02, .12]$} \\
\hline & & $\mathrm{H}$ & .04 (.04) & {$[-.04, .11]$} & $.03(.04)$ & {$[-.05, .10]$} \\
\hline & TTM & $\mathrm{L}$ & $.00(.01)$ & {$[-.02, .03]$} & $.00(.02)$ & {$[-.03, .03]$} \\
\hline$\cong$ & & $\mathrm{H}$ & $.00(.01)$ & {$[-.02, .03]$} & $.00(.01)$ & {$[-.01, .02]$} \\
\hline & POS & $\mathrm{L}$ & $.04(.03)$ & {$[-.03, .11]$} & $.05(.03)$ & {$[-.02, .12]$} \\
\hline & & $\mathrm{H}$ & $.04(.04)$ & {$[-.04, .11]$} & $.03(.04)$ & {$[-.05, .10]$} \\
\hline & LMX & $\mathrm{L}$ & $.01(.03)$ & {$[-.05, .07]$} & $.02(.03)$ & {$[-.04, .08]$} \\
\hline & & $\mathrm{H}$ & $-.02(.04)$ & {$[-.09, .05]$} & $-.02(.04)$ & {$[-.09, .05]$} \\
\hline ق. & TTM & $\mathrm{L}$ & $.00(.00)$ & {$[-.01, .01]$} & $.00(.01)$ & {$[-.01, .01]$} \\
\hline & & $\mathrm{H}$ & $-.00(.01)$ & {$[-.02, .01]$} & $-.00(.01)$ & {$[-.01, .01]$} \\
\hline & POS & $\mathrm{L}$ & $.01(.03)$ & {$[-.05, .07]$} & $.02(.03)$ & {$[-.04, .08]$} \\
\hline & & $\mathrm{H}$ & $-.02(.03)$ & {$[-.09, .05]$} & $-.02(.04)$ & {$[-.09, .05]$} \\
\hline & LMX & $\mathrm{L}$ & .01 (.03) & {$[-.05, .07]$} & $.01(.03)$ & {$[-.05, .07]$} \\
\hline & & $\mathrm{H}$ & $-.01(.04)$ & {$[-.08, .06]$} & $-.01(.04)$ & {$[-.08, .06]$} \\
\hline & TTM & $\mathrm{L}$ & .00 (.00) & {$[-.00, .01]$} & $.00(.00)$ & {$[-.01, .01]$} \\
\hline & & $\mathrm{H}$ & $-.00(.00)$ & {$[-.01, .01]$} & $.00(.00)$ & {$[-.01, .01]$} \\
\hline & POS & $\mathrm{L}$ & .01 (.03) & {$[-.05, .07]$} & $.01(.03)$ & {$[-.05, .07]$} \\
\hline & & $\mathrm{H}$ & $-.01(.04)$ & {$[-.08, .06]$} & $-.01(.04)$ & {$[-.08, .06]$} \\
\hline
\end{tabular}

Note. $N=174$ ( $N=172$ for distributive justice, procedural justice, and team social integration). LMX = leader-member exchange, TTM = trust in team members, POS = perceived organizational support. $\mathrm{SE}=$ standard error. $95 \% \mathrm{CI}=95 \%$ confidence intervals. $\mathrm{L}=-1 \mathrm{SD}$ from the moderator's mean. $\mathrm{H}=+1 \mathrm{SD}$ from the moderator's mean. 
Table 22

Direct Effects of Psychological Safety Within the Organization on Idea Generation, Idea Promotion, and Idea Realization

\begin{tabular}{|c|c|c|c|c|c|c|}
\hline & \multicolumn{2}{|c|}{ Idea Generation } & \multicolumn{2}{|c|}{ Idea Promotion } & \multicolumn{2}{|c|}{ Idea Realization } \\
\hline & $\begin{array}{l}\text { Controls } \\
\text { b (S.E.) }\end{array}$ & $\begin{array}{c}\text { Controls/ } \\
\text { Mediator } \\
\text { b (S.E.) }\end{array}$ & $\begin{array}{l}\text { Controls } \\
\text { b (S.E.) }\end{array}$ & $\begin{array}{l}\text { Controls/ } \\
\text { Mediator } \\
\text { b (S.E.) }\end{array}$ & $\begin{array}{l}\text { Controls } \\
\text { b (S.E.) }\end{array}$ & $\begin{array}{c}\text { Controls/ } \\
\text { Mediator } \\
\text { b (S.E.) }\end{array}$ \\
\hline \multicolumn{7}{|l|}{ Controls } \\
\hline Gender & $.00(.37)$ & $-.12(.38)$ & $-.17(.37)$ & $-.31(.38)$ & $-.14(.41)$ & $-.30(.42)$ \\
\hline Age & $-.02(.01)$ & $-.03(.02)$ & $-.03(.01)$ & $-.03^{*}(.01)$ & $-.02(.02)$ & $-.02(.02)$ \\
\hline Education & $-.04(.14)$ & $-.01(.15)$ & $-.05(.14)$ & $-.04(.15)$ & $.04(.16)$ & $.05(.16)$ \\
\hline Tenure (organization) & $-.02(.03)$ & $-.01(.03)$ & $-.02(.03)$ & $-.01(.03)$ & $-.00(.03)$ & $.00(.03)$ \\
\hline Position level & $.13(.17)$ & $.11(.17)$ & $.12(.17)$ & $.09(.17)$ & $.20(.19)$ & $.17(.19)$ \\
\hline \multicolumn{7}{|l|}{ Independent Variable } \\
\hline Psychological Safety & & $.08(.18)$ & & . $11(.18)$ & & $.16(.20)$ \\
\hline
\end{tabular}

Note. $N_{F}=174$ (followers), $N_{L}=85$ (leaders). $\mathrm{b}=$ unstandardized regression coefficient; S.E. $=$ standard errors. Gender: $0=$ female $; 1=$ male. Position level: 1 = nonsupervisory; 2 front-line management $; 3=$ middle management; $4=$ top management. ${ }^{*} \mathrm{p}<.05$

Table 23

Indirect Effects of Leader-Member Exchange, Trust in Team Members, and Perceived Organizational Support on Idea Generation, Idea Promotion, and Idea Realization, via Psychological Safety Within the Organization

\begin{tabular}{|c|c|c|c|c|c|c|c|}
\hline \multirow{3}{*}{$\begin{array}{c}\text { Independent } \\
\text { Variable }\end{array}$} & \multicolumn{4}{|c|}{ Decomposed Effects } & \multicolumn{3}{|c|}{ Indirect Effects } \\
\hline & $a$ & $b$ & $c$ & $c^{\prime}$ & & $a b$ & \\
\hline & b (S.E.) & b (S.E.) & b (S.E.) & b (S.E.) & b (S.E.) & $\mathrm{LCI}$ & $\mathrm{H} \mathrm{CI}$ \\
\hline \multicolumn{8}{|c|}{ Idea Generation } \\
\hline LMX & $.34(.10)^{* *}$ & $.08(.18)$ & $.31(.25)$ & $.31(.25)$ & $.03(.06)$ & -.10 & .15 \\
\hline TTM & $.02(.10)$ & $.08(.18)$ & $-.09(.24)$ & $-.09(.24)$ & $.00(.01)$ & -.02 & .02 \\
\hline POS & $.34(.08)^{* * * *}$ & $.08(.18)$ & $-.05(.19)$ & $-.05(.19)$ & $.03(.06)$ & -.10 & .15 \\
\hline \multicolumn{8}{|c|}{ Idea Promotion } \\
\hline LMX & $.34(.10)^{* * *}$ & $.11(.18)$ & $.20(.25)$ & $.20(.25)$ & $.04(.06)$ & -.08 & .16 \\
\hline TTM & $.02(.10)$ & $.11(.18)$ & $.07(.24)$ & $.07(.24)$ & $.00(.01)$ & -.02 & .03 \\
\hline POS & $.34(.08)^{* * *}$ & $.11(.18)$ & $-.06(.19)$ & $-.06(.19)$ & $.04(.06)$ & -.08 & .16 \\
\hline \multicolumn{8}{|c|}{ Idea Realization } \\
\hline LMX & $.34(.10)^{* *}$ & $.16(.20)$ & $.18(.28)$ & $.18(.28)$ & $.05(.07)$ & -.08 & .19 \\
\hline TTM & $.02(.10)$ & $.16(.20)$ & $.16(.27)$ & $.16(.27)$ & $.00(.02)$ & -.03 & .04 \\
\hline POS & $.34(.08)^{* * *}$ & $.16(.20)$ & $-.14(.21)$ & $-.14(.21)$ & $.05(.07)$ & -.08 & .19 \\
\hline
\end{tabular}

Note. $N_{F}=174$ (followers), $N_{L}=85$ (leaders). LMX = leader-member exchange, TTM = trust in team members, $\mathrm{POS}=$ perceived organizational support. $\mathrm{a}=$ first stage effect of the independent variable on the mediator; $\mathrm{b}=$ second stage effect of the mediator on the dependent variable; $\mathrm{c}=$ total effect of the independent variable on the dependent variable; $\mathrm{c}^{\prime}=$ direct effect of the independent variable on the dependent variable. $\mathrm{b}=$ unstandardized regression coefficients; S.E. $=$ standard error. $\mathrm{ab}=$ indirect effect. $\mathrm{L}$ $\mathrm{CI}$ and $\mathrm{H} \mathrm{CI}=$ Lower and higher values of $95 \%$ confidence intervals.

${ }^{* * *} \mathrm{p}<.001,{ }^{* *} \mathrm{p}<.01$ 
Lastly, none of the six proposed moderators (i.e., proactive personality, political skill, perceived team social integration, perceived support for innovation, perceived distributive justice, and perceived procedural justice) moderate the indirect relationships between leader-member exchange, trust in team members, and perceived organizational support, and followers' idea generation, idea promotion, and idea realization, as can be confirmed by the presence of a zero between the low and high values of the confidence intervals of the conditional indirect effects tested (see Table 24). A summary of all the hypotheses is presented on Table 25 .

Power analyses. I also conducted a post-hoc power analysis, using G*Power v. 3.1.9.2 (Erdfelder, Faul, \& Buchner, 1996), to examine whether my sample size of 174 dyads provided enough statistical power for my analyses. A low statistical power increases the probability of a Type II error (i.e., a false negative). According to Cohen (1988), to determine the statistical power of an analysis, we must have the information on four different parameters: significance criterion $(\alpha)$, effect size $(\beta)$, number of predictors, and sample size $(\mathrm{N})$. The basic parameters for this dissertation were: significance criterion $(\alpha)=.05$ and total sample size $(N)=174$. The effect size, number of tested predictors, and total number of predictors varied with the hypotheses being tested.

For the direct effect hypotheses between the independent variables and the mediator the number of tested predictors was three and the total number of predictors was eight (i.e., three tested predictors plus five control variables). To achieve at least $80 \%$ statistical power (Cohen, 1988) when using these parameters, effect sizes should be at least .07. Two hypotheses resulted in an effect size larger than .07 (see Table 8), which are the relationships between leader-member exchange $(b=.34)$ and perceived 
Table 24

Conditional Indirect Effects of Leader-Member Exchange, Trust in Team Members, and Perceived Organizational Support on Idea Generation, Idea Promotion, and Idea Realization, via Psychological Safety Within the Organization

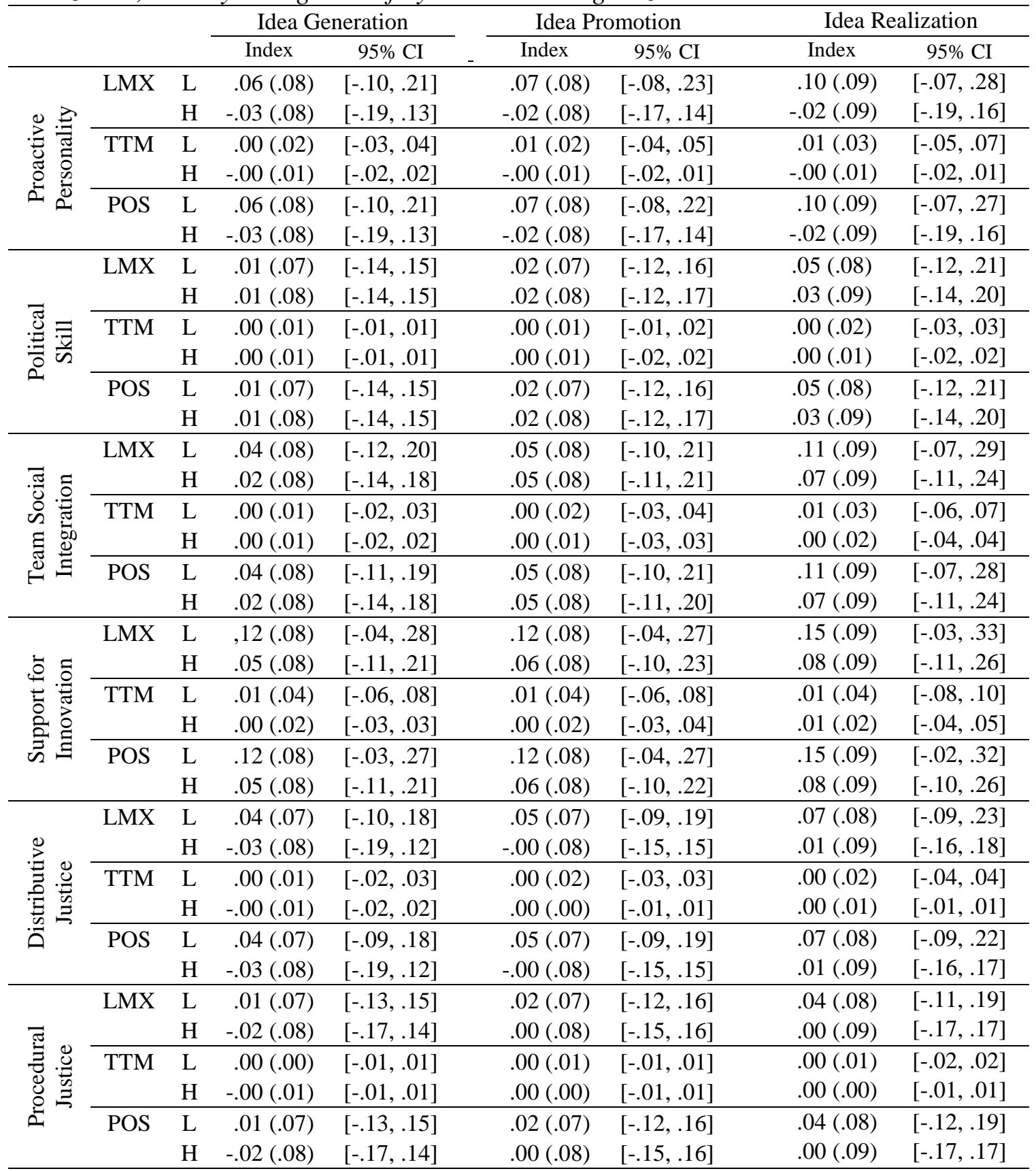

Note. $N=174$ ( $N=172$ for distributive justice, procedural justice, and team social integration). LMX = leader-member exchange, TTM = trust in team members, POS = perceived organizational support. $\mathrm{SE}=$ standard error. $95 \% \mathrm{CI}=95 \%$ confidence intervals. $\mathrm{L}=-1 \mathrm{SD}$ from the moderator's mean. $\mathrm{H}=+1 \mathrm{SD}$ from the moderator's mean. 
organizational support $(\mathrm{b}=.34)$, and psychological safety within the organization, resulting in a statistical power of $80 \%$ or above. For the relationship between trust in team members and psychological safety within the organization $(b=.02)$, the statistical power is lower than $80 \%$ and we would require a sample larger than 174 dyads to achieve at least $80 \%$ statistical power.

For the direct effect hypotheses between the mediator and the dependent variables, the number of predictor variables was one and the total number of predictors was six (i.e., one predictor variable and five control variables). To achieve at least $80 \%$ statistical power when using these parameters, effect sizes should be at least .05 . All three hypotheses resulted in an effect size larger than .05 , that is, the relationships between psychological safety within the organization and voice behavior $(b=.09)$, innovative behavior $(b=.16)$, and learning behavior $(b=.09)$, resulting in a statistical power of $80 \%$ or above for each relationship tested.

For the indirect effect hypotheses, the number of tested predictors was four and the total number of predictors was nine. To achieve at least $80 \%$ statistical power when using these parameters, indirect effect sizes should be at least .07. All hypotheses resulted in an indirect effect size smaller than .07 (see Tables 10 to 12), with indirect effect sizes ranging from .00 (5\% statistical power) to .04 (52\% statistical power). To achieve a statistical power of at least $80 \%$, we would require a sample size of at least 304 dyads to test some of these indirect effects.

For the conditional indirect effect hypotheses, the number of tested predictors was six (including the interaction term) and the total number of predictors was eleven. To achieve at least $80 \%$ statistical power when using these parameters, conditional indirect 
effect sizes should be at least .08. Only two hypotheses related to the moderation analyses of perceived support for innovation on innovative behavior achieved the recommended statistical power of $80 \%$ (see Table 16). For small effect sizes (i.e., .02) we would need a sample size of 1,369 dyads to reach $80 \%$ statistical power, using the same parameters determined above. Overall, the power analysis results indicate that there is a possibility of Type II error (i.e., a false negative) for the relationships with less than $80 \%$ statistical power, such as for the mediation and most of the moderated mediation models.

Table 25

Summary of the Hypotheses

\begin{tabular}{|c|c|}
\hline Hypotheses & Results \\
\hline $\begin{array}{l}\text { Hypothesis 1a. Leader-member exchange is positively related to followers' } \\
\text { psychological safety within the organization. }\end{array}$ & Supported \\
\hline $\begin{array}{l}\text { Hypothesis } 1 \mathrm{~b} \text {. Trust in team members is positively related to followers' } \\
\text { psychological safety within the organization. }\end{array}$ & Not supported \\
\hline $\begin{array}{l}\text { Hypothesis 1c. Perceived organizational support is positively related to } \\
\text { followers' psychological safety within the organization. }\end{array}$ & Supported \\
\hline $\begin{array}{l}\text { Hypothesis } 2 \text {. Psychological safety within the organization is positively } \\
\text { related to followers' voice behavior. }\end{array}$ & Not st \\
\hline $\begin{array}{l}\text { Hypothesis } 3 \text {. The relationships between (a) leader-member exchange, (b) } \\
\text { trust in team members, (c) perceived organizational support and voice } \\
\text { behavior are mediated by psychological safety within the organization. }\end{array}$ & Not supported \\
\hline $\begin{array}{l}\text { Hypothesis } 4 \text {. Psychological safety within the organization is positively } \\
\text { related to followers' innovative behavior. }\end{array}$ & Not supported \\
\hline $\begin{array}{l}\text { Hypothesis 5. The relationships between (a) leader-member exchange, (b) } \\
\text { trust in team members, (c) perceived organizational support and innovative } \\
\text { behavior are mediated by psychological safety within the organization. }\end{array}$ & Not supported \\
\hline $\begin{array}{l}\text { Hypothesis 6. Psychological safety within the organization is positively } \\
\text { related to followers' learning behavior. }\end{array}$ & Supported \\
\hline $\begin{array}{l}\text { Hypothesis } 7 \text {. The relationships between (a) leader-member exchange, (b) } \\
\text { trust in team members, (c) perceived organizational support and learning } \\
\text { behavior are mediated by psychological safety within the organization. }\end{array}$ & Not supported \\
\hline $\begin{array}{l}\text { Hypothesis } 8 \text {. The relationships between (a) leader-member exchange, (b) } \\
\text { trust in team members, (c) perceived organizational support and voice } \\
\text { behavior occur indirectly through psychological safety within the } \\
\text { organization such that the positive indirect effects on voice behavior are } \\
\text { weaker (stronger) for followers with stronger (weaker) proactive personality }\end{array}$ & Not supported \\
\hline
\end{tabular}




\begin{tabular}{|c|c|}
\hline $\begin{array}{l}\text { Hypothesis 9. The relationships between (a) leader-member exchange, (b) } \\
\text { trust in team members, (c) perceived organizational support and innovative } \\
\text { behavior occur indirectly through psychological safety within the } \\
\text { organization such that the positive indirect effects on innovative behavior are } \\
\text { weaker (stronger) for followers with stronger (weaker) proactive personality. }\end{array}$ & Not supported \\
\hline $\begin{array}{l}\text { Hypothesis } 10 \text {. The relationships between (a) leader-member exchange, (b) } \\
\text { trust in team members, (c) perceived organizational support and learning } \\
\text { behavior occur indirectly through psychological safety within the } \\
\text { organization such that the positive indirect effects on learning behavior are } \\
\text { weaker (stronger) for followers with stronger (weaker) proactive personality. }\end{array}$ & Not supported \\
\hline $\begin{array}{l}\text { Hypothesis 11. The relationships between (a) leader-member exchange, (b) } \\
\text { trust in team members, (c) perceived organizational support and voice } \\
\text { behavior occur indirectly through psychological safety within the } \\
\text { organization such that the positive indirect effects on voice behavior are } \\
\text { weaker (stronger) for followers with stronger (weaker) political skill. }\end{array}$ & Not supported \\
\hline $\begin{array}{l}\text { Hypothesis 12. The relationships between (a) leader-member exchange, (b) } \\
\text { trust in team members, (c) perceived organizational support and innovative } \\
\text { behavior occur indirectly through psychological safety within the } \\
\text { organization such that the positive indirect effects on innovative behavior are } \\
\text { weaker (stronger) for followers with stronger (weaker) political skill. }\end{array}$ & Not supported \\
\hline $\begin{array}{l}\text { Hypothesis 13. The relationships between (a) leader-member exchange, (b) } \\
\text { trust in team members, (c) perceived organizational support and learning } \\
\text { behavior occur indirectly through psychological safety within the } \\
\text { organization such that the positive indirect effects on learning behavior are } \\
\text { weaker (stronger) for followers with stronger (weaker) political skill. }\end{array}$ & Not supported \\
\hline $\begin{array}{l}\text { Hypothesis 14. The relationships between (a) leader-member exchange, (b) } \\
\text { trust in team members, (c) perceived organizational support and voice } \\
\text { behavior occur indirectly through psychological safety within the } \\
\text { organization such that the positive indirect effects on voice behavior are } \\
\text { weaker (stronger) for followers who feel more (less) socially integrated with } \\
\text { their work groups. }\end{array}$ & Not supported \\
\hline $\begin{array}{l}\text { Hypothesis } 15 \text {. The relationships between (a) leader-member exchange, (b) } \\
\text { trust in team members, (c) perceived organizational support and innovative } \\
\text { behavior occur indirectly through psychological safety within the } \\
\text { organization such that the positive indirect effects on innovative behavior are } \\
\text { weaker (stronger) for followers who feel more (less) socially integrated with } \\
\text { their work groups. }\end{array}$ & Not supported \\
\hline $\begin{array}{l}\text { Hypothesis } 16 \text {. The relationships between (a) leader-member exchange, (b) } \\
\text { trust in team members, (c) perceived organizational support and learning } \\
\text { behavior occur indirectly through psychological safety within the } \\
\text { organization such that the positive indirect effects on learning behavior are } \\
\text { weaker (stronger) for followers who feel more (less) socially integrated with } \\
\text { their work groups. }\end{array}$ & Not supported \\
\hline $\begin{array}{l}\text { Hypothesis } 17 \text {. The relationships between (a) leader-member exchange, (b) } \\
\text { trust in team members, (c) perceived organizational support and voice } \\
\text { behavior occur indirectly through psychological safety within the } \\
\text { organization such that the positive indirect effects on voice behavior are } \\
\text { weaker (stronger) for followers with higher (lower) perceived support for } \\
\text { innovation. }\end{array}$ & Not supported \\
\hline
\end{tabular}




\begin{tabular}{|c|c|}
\hline $\begin{array}{l}\text { Hypothesis } 18 \text {. The relationships between (a) leader-member exchange, (b) } \\
\text { trust in team members, (c) perceived organizational support and innovative } \\
\text { behavior occur indirectly through psychological safety within the } \\
\text { organization such that the positive indirect effects on innovative behavior are } \\
\text { weaker (stronger) for followers with higher (lower) perceived support for } \\
\text { innovation. }\end{array}$ & Not supported \\
\hline $\begin{array}{l}\text { Hypothesis 19. The relationships between (a) leader-member exchange, (b) } \\
\text { trust in team members, (c) perceived organizational support and learning } \\
\text { behavior occur indirectly through psychological safety within the } \\
\text { organization such that the positive indirect effects on learning behavior are } \\
\text { weaker (stronger) for followers with higher (lower) perceived support for } \\
\text { innovation. }\end{array}$ & Not supported \\
\hline $\begin{array}{l}\text { Hypothesis 20. The relationships between (a) leader-member exchange, (b) } \\
\text { trust in team members, (c) perceived organizational support and voice } \\
\text { behavior occur indirectly through psychological safety within the } \\
\text { organization such that the positive indirect effects on voice behavior are } \\
\text { weaker (stronger) for followers with higher (lower) distributive justice. }\end{array}$ & Not supported \\
\hline $\begin{array}{l}\text { Hypothesis } 21 \text {. The relationships between (a) leader-member exchange, (b) } \\
\text { trust in team members, (c) perceived organizational support and innovative } \\
\text { behavior occur indirectly through psychological safety within the } \\
\text { organization such that the positive indirect effects on innovative behavior are } \\
\text { weaker (stronger) for followers with higher (lower) distributive justice. }\end{array}$ & Not supported \\
\hline $\begin{array}{l}\text { Hypothesis } 22 \text {. The relationships between (a) leader-member exchange, (b) } \\
\text { trust in team members, (c) perceived organizational support and learning } \\
\text { behavior occur indirectly through psychological safety within the } \\
\text { organization such that the positive indirect effects on learning behavior are } \\
\text { weaker (stronger) for followers with higher (lower) distributive justice. }\end{array}$ & Not \\
\hline $\begin{array}{l}\text { Hypothesis } 23 \text {. The relationships between (a) leader-member exchange, (b) } \\
\text { trust in team members, (c) perceived organizational support and voice } \\
\text { behavior occur indirectly through psychological safety within the } \\
\text { organization such that the positive indirect effects on voice behavior are } \\
\text { weaker (stronger) for followers with higher (lower) procedural justice. }\end{array}$ & Not \\
\hline $\begin{array}{l}\text { Hypothesis } 24 \text {. The relationships between (a) leader-member exchange, (b) } \\
\text { trust in team members, (c) perceived organizational support and innovative } \\
\text { behavior occur indirectly through psychological safety within the } \\
\text { organization such that the positive indirect effects on innovative behavior are } \\
\text { weaker (stronger) for followers with higher (lower) procedural justice. }\end{array}$ & Not $\mathrm{s}$ \\
\hline $\begin{array}{l}\text { Hypothesis } 25 \text {. The relationships between (a) leader-member exchange, (b) } \\
\text { trust in team members, (c) perceived organizational support and learning } \\
\text { behavior occur indirectly through psychological safety within the } \\
\text { organization such that the positive indirect effects on learning behavior are } \\
\text { weaker (stronger) for followers with higher (lower) procedural justice. }\end{array}$ & Not supported \\
\hline
\end{tabular}




\section{CHAPTER V \\ DISCUSSION}

Chapter five includes an overview of the study and a discussion on the theoretical and practical implications of the hypotheses tested (i.e., supported and non-supported hypotheses). This chapter also contains sections about the limitations of this study, suggestions for future research, and conclusion.

\section{Study Overview}

This dissertation provides some insights regarding the role of social exchanges and psychological safety within the organization on behaviors that lead to change. It is important to understand the drivers of change-oriented behaviors due to the dynamic nature of the business world and the increasing competitiveness among organizations. Multiple social exchanges exist simultaneously in an organization, yet research that looks at the role of social exchanges on individual outcomes usually focuses on only one social exchange at a time. This study looks at three types of social exchanges, that is, leadermember exchange, trust in team members, and perceived organizational support, and examines the combined effects of three predictors in leading to change-oriented behaviors and the mechanisms through which these relationships occur. Furthermore, the context where these relationships happen varies and it is important to understand the boundary conditions that may affect these relationships. Thus, this study also examines how the relationships between social exchanges and change-oriented behaviors via psychological safety within the organization are conditional to followers' proactive personality, political skill, perceived team social integration, perceived support for innovation, and perceived organizational justice. 
Building on social exchange theory (Blau, 1964) and using a sample of 174 dyads (174 followers and 85 leaders), I proposed and tested a moderated mediation model where leader-member exchange, trust in team members, and perceived organizational support lead to voice, innovative, and learning behaviors via psychological safety within the organization, and where the second stage relationships are moderated by proactive personality, political skill, perceived team social integration, perceived support for innovation, and perceived organizational justice. From a review of the literature, I selected previously validated survey instruments, and the results from the Cronbach's alpha test and confirmatory factor analyses indicated that most constructs have acceptable reliability and validity values. The CFA results for voice behavior were below acceptable standards, but this will be discussed later in this chapter. Overall, the findings of this study provide support to some of the direct effect hypotheses (i.e., hypotheses $1 \mathrm{a}, 1 \mathrm{c}$, and 6); however, none of the mediation or moderated mediation hypotheses were supported.

\section{Implications for Theory and Practice}

Supported hypotheses. When testing for the combined direct effects of leadermember exchange, trust in team members, and perceived organizational support on psychological safety within the organization, the three predictors were entered in the model at the same time. Results show that individuals feel psychologically safe when they perceive to be supported by their organization. This finding is consistent with and supports the theoretical underpinning developed by Edmondson (2004), who suggests that individuals feel psychologically safe in a supportive organizational context. Likewise, results also show that when followers perceive to have a high-quality relationship with their leaders, they feel psychologically safe. This result is not surprising 
and is consistent with the literature which states that when followers are in a high-quality relationship with their leaders, they perceive a higher level of interpersonal trust (Blau, 1964); and trust is a characteristic of psychological safety (Edmondson, 1999).

Furthermore, as several scholars have suggested (Coyle-Shapiro \& Shore, 2007;

Eisenberger, Stinglhamber, Vandenberghe, Sucharski, \& Rhoades, 2002), followers may see their leaders as representatives or agents of the organization, and thus it is not surprising that when followers have a high-quality relationship with their leaders, they may perceive the organization to be psychologically safe. Conversely, when LMX is low, followers may feel psychologically unsafe within the organization.

It is remarkable that the effects of leader-member exchange and perceived organizational support on psychological safety within the organization are significant even when all three predictors are entered in the model altogether. When combined, the three predictors account for 31.79 percent of the variance in psychological safety within the organization. Results from this study suggest that both leader-member exchange and perceived organizational support matter for employee psychological safety within the organization. Although trust in team members is not significantly related to psychological safety within the organization, supplemental analyses indicate that trust in team members may still be important for psychological safety, and it will be discussed further in the next section. In addition to reciprocation, trust and respect, social exchange is also characterized by an environment of psychological safety; that is, when followers perceive to have a good relationship with and receive support from their leaders and their organization, they feel safe to express themselves without the fear of negative consequences. 
Furthermore, followers who perceive the environment to be psychologically safe are more likely to engage in learning behaviors. It is noteworthy that this relationship is supported even when psychological safety within the organization and learning behavior are rated by different individuals, that is, followers and leaders, respectively. Psychological safety within the organization accounts for 9.29 percent of the variance in learning behavior. This relationship also supports and complements initial studies on the relationship between psychological safety and learning behavior. For example, Edmondson (1999) found that team psychological safety led to team learning behavior. A few years later, Edmondson (2004) suggested that organizational learning could also be driven by psychological safety within the organization. And Carmeli, Brueller and Dutton (2009) found a significant relationship between feelings of psychological safety and learning among students. This dissertation supports these findings in an organizational setting; that is, when individuals feel psychologically safe within the organization, they are more likely to engage in learning behaviors such as asking questions, taking risks, seeking feedback, and discussing unexpected outcomes (Edmondson, 1999).

For managers and organizational leaders, these results have some practical implications. Organizations should invest in leadership training and create practices that develop high-quality relationships between leaders and followers. Furthermore, managers should create an environment that encourages followers to ask questions, take risks, propose new ideas, and expresses themselves. This is particularly important for organizations that want to remain competitive as they will foster a learning environment that will enable their employees to engage in behaviors that are likely to lead to change. 
Hypotheses not supported. This study also resulted in several relationships that were not found to be significant. First, trust in team members failed to predict psychological safety within the organization when the variable was entered in the model with leader-member exchange and perceived organizational support, even though the correlation between trust in team members and psychological safety within the organization is moderate and significant $(r=.48, p<.001)$; the correlation suggests that these two constructs are related. Furthermore, a post-hoc analysis indicates that when the relationship between trust in team members and psychological safety within the organization is tested without the two other predictors (i.e., leader-member exchange and perceived organizational support), the relationship is strong and significant $(b=.45, \mathrm{SE}=$ $.11, \mathrm{p}<.001)$, even when controlled for gender, age, education, tenure with organization, and position level. However, the relationship becomes no longer significant when leadermember exchange and perceived organizational support are entered in the model (see Table 9).

One theoretical explanation for this result could be that for followers to feel safe in the organization, it is more important that they perceive support from their organizational and leaders, as discussed above, than from their co-workers. Trust in team members may be more important for team psychological safety while perceived support from the organization and high-quality relationships with leaders are more important for psychological safety within the organization. In other words, when followers have a good relationship with their leaders and/or perceive the organization to be supportive, they may still feel psychologically safe in the organization and their trust (or lack of) in their team members will not matter. 
Furthermore, the non-significant result for the relationship between trust in team members and psychological safety within the organization may have been due to the different types of teams included in the sample. For example, Barrick, Bradley, KristofBrown, and Colbert (2007) found that team interdependence moderated the relationship between cohesiveness and team performance as such that the relationship was stronger for teams with high interdependence. Other researchers also found that several team relationships that had been previously examined were conditional to team size, team composition, types of teams, and/or other team characteristics (e.g., Beal, Cohen, Burke, \& McLendon, 2003; De Dreu \& Weingart, 2003). Thus, it is possible that the relationship between trust in team members and psychological safety within the organization is conditional to the types of teams studied in this dissertation, which may also explain the non-significant result observed for this relationship.

An alternative explanation for this non-significant relationship could be the high mean (3.99 out of 5.00) and small variation (ranging from $3.3-4.7$ out of 5.0) of the trust in team members variable. In fact, a frequency analysis showed that $80 \%$ of the followers rated trust in team members as 4.0 or higher (out of 5.0). Furthermore, a power analysis for this relationship using the current study parameters $(\mathrm{N}=174 ; \alpha=.05)$, indicates that the effect size of trust in team members on psychological safety within the organization $(b=.02)$ is not large enough to achieve $80 \%$ statistical power (Cohen, 1988, 1992), and thus there is a possibility of Type II error, that is, of a false negative finding (Scherbaum $\&$ Ferreter, 2009). In fact, with the current parameters, this test only achieves $46 \%$ statistical power. Thus, the overall results suggest that trust in team members may still be important for individuals' psychological safety within the organization, and there may be 
some other explanations for the non-significant result of the relationship between trust in team members and psychological safety within the organization when the other two predictors are present in the model.

Psychological safety within the organization has a positive and significant relationship with learning behavior, yet it failed to predict voice behavior and innovative behavior. Post-hoc power analyses indicate that the statistical power of the tests for the direct effects of psychological safety within the organization on innovative and voice behaviors are at least $80 \%$, the recommended threshold to decrease the chances of Type II error. Despite not reaching the threshold of $p<.05$, the direct effects of psychological safety within the organization on innovative behavior and voice behavior are considered large $(\mathrm{b}=.16, n . s$.$) and medium (\mathrm{b}=.09$, n.s. $)$, respectively, in strength; both direct effects are also in the direction hypothesized. Results from confirmatory factor analysis show that the one-factor voice construct does not show satisfactory results, while the twofactor construct shows satisfactory results (see Table 6). Thus, I tested the relationships between psychological safety within the organization and promotive and prohibitive voice behaviors, yet results show that these relationships are not significant (see Table 20).

One potential explanation for the lack of support for the relationships between psychological safety within the organization and voice and innovative behaviors is the mere-measurement effect. Morwitz, Johnson, and Schmittlein (1993) found that the effect of merely asking individuals' intention questions increases the likelihood of respondents behaving according to the question asked, a phenomenon they called mere-measurement effect. Although Time 1 and Time 2 surveys do not include intention questions, the same 
effect may happen when the questions asked give clues to followers of what behaviors their leaders and the organization expect from them. For example, when followers were asked in Time 2 if "employees in this organization feel comfortable bringing up problems and tough issues" (psychological safety within the organization), they may have felt more inclined to engage in prohibitive voice behavior in the month prior to the Time 3 survey. When followers were asked if they "excel at identifying opportunities" (proactive personality) or if "in this organization, we take the time needed to develop new ideas" (perceived support for innovation), they may have felt more prone to engage in idea generation behavior (i.e., a component of innovative behavior) prior to the Time 3 survey. As a result, followers may have been rated more favorably on voice and innovative behaviors by their leaders even when followers perceived the organization to be psychologically unsafe. Indeed, the mean of voice behavior was above 3.99 and most of the respondents reported very high scores for voice behavior; that is, over $85 \%$ of the followers received a voice behavior rating of 4.0 or higher.

Another alternative explanation for the non-significant results of the relationships between psychological safety within the organization and voice and innovative behaviors is that respondents may have interpreted the referent (i.e., the person that the statement refers to) in the psychological safety measure statements differently; that it, instead of rating the statements on how they apply to them individually, respondents may have rated the statements on how they apply to all employees in the organization in general. For example, followers may have given a different rate to the alternate statement "I feel comfortable bringing up problems and though issues in this organization" compared to the original statement "Employees in this organization feel comfortable bringing up 
problems and though issues in this organization," or to the alternate statement "I feel safe to take a risk in this organization" compared to the original statement "It is safe to take a risk in this organization." Future studies may consider modifying the original statements of the measure to better assess respondents' individual perceptions of psychological safety within the organization.

Furthermore, in a longitudinal study conducted by Schulte, Cohen, and Klein (2012), researchers measured team psychological safety in three different points in time separated by 5 months each and found that team members' perceptions of psychological safety changed over time. Likewise, there is a possibility that psychological safety within the organization is also an unstable construct and that followers' perceptions of psychological safety within the organization changed over the four weeks before the change-oriented behaviors and after the social exchange variables were measured. This instability of followers' perceptions of psychological safety within the organization may explain some of the non-significant results in this study (i.e., between trust in team members and psychological safety, and between psychological safety and voice and innovative behaviors).

Even though leader-member exchange and perceived organizational support predicted psychological safety within the organization, and the latter predicted followers' learning behaviors, no mediation effects of psychological safety within the organization were found. Furthermore, none of the moderated mediation hypotheses were supported. Low statistical power may have contributed to the lack of support for some of these relationships, particularly the ones that have significant direct effect results. Range 
restriction and extreme values, as discussed above, could also have contributed to some of the lack of significance in the mediation and moderated mediation analyses.

\section{Limitations and Future Research}

This study has several strengths (e.g., sample from four organizations to increase generalizability, data collected from leaders and followers and at three points in time to mitigate issues related to common method bias, multilevel analyses to address issues of non-independence, previously validated scales to increase reliability of results), but it also has some limitations, which will be discussed next.

First, although the sample is consisted of 174 dyads, the sample is not large enough to avoid potential issues related to Type II error for several of the relationships tested, particularly for the mediation and moderated mediation hypotheses analyses. This limitation restricts the ability to draw conclusions for many of the hypotheses tested, as some of these relationships could have been significant if they were tested with a larger sample; future research could examine these relationships using a larger sample. For example, in order to reach $80 \%$ statistical power, the sample should be of at least 304 dyads for the indirect effect analyses and more than 1,000 for the conditional indirect effect analyses. Such sample sizes would be large enough to detect small, but non-trivial, effects at the recommended study parameters (i.e., 95\% alpha reliability, and $80 \%$ statistical power) (Cohen, 1988, 1992).

Second, as previously discussed, some of the variables in this study have small variability and high means (e.g., trust in team members, political skill, voice behavior). This limitation may explain the non-significant results for the relationships that included one or more of these variables. 
Third, although the sample was collected from four organizations to increase generalizability, all four organizations are in the same industry. Future research could collect data from organizations across different industries to increase external validity. Furthermore, future research could also investigate similar relationships in organizations that are naturally driven to change and innovation or for employees in R\&D facilities.

Fourth, although the study was designed to avoid common method bias by using data collected from different sources and at different points in times, it is still crosssectional in nature and, consequently, the study does not support causal inferences. For example, it could be that followers have a good relationship with their leaders and/or perceive the organization to be supportive because they feel psychologically safe within the organization. Future research should consider a longitudinal or experimental design to test some of the relationships proposed in this study and examine the potential presence of reverse causality.

Fifth, although in this study I examined several proposed relationships, there are several other extensions that should be considered in future research. For example, how do these relationships change depending on the followers' position level? How would these relationships change in organizations that are driven by continuous change, such as tech firms? In addition, this study may also open the door to the investigation of other mediators that may lead social exchanges to change-oriented behaviors (e.g., team psychological safety), other moderators that may reduce the negative effects of low psychological safety within the organization and/or low-quality social exchanges, and other behaviors that lead to organizational change. 


\section{Conclusion}

Change-oriented behaviors are essential for business survival. In this dissertation, I draw from social exchange theory to examine the mechanisms that lead to changeoriented behaviors. I propose and test a moderated mediation model to investigate the roles of three social exchanges as predictors of change-oriented behaviors via psychological safety within the organization, and of five individual and contextual moderators of these relationships. As predicted, this study reveals that leader-member exchange and perceived organizational support predict followers' psychological safety within the organization, and that psychological safety within the organization predicts followers' learning behaviors. However, trust in team members was not found to be a significant predictor of psychological safety within the organization, and psychological safety within the organization was not found to be a significant predictor of voice and innovative behaviors. In addition, the five proposed moderators did not moderate the second stage relationships. This study also provides recommendations for future research to address some of the limitations and non-significant findings. All things considered, this study contributes to the literature on social exchange, psychological safety, and changeoriented behavior. 


\section{REFERENCES}

Adams, J. S. (1965). Inequity in social exchange. In L. Berkowitz (Ed.), Advances in experimental social psychology (Vol. 2, pp. 267-299). New York, NY: Academic Press.

Ahearn, K. K., Ferris, G. R., Hochwarter, W. A., Douglas, C., \& Ammeter, A. P. (2004). Leader political skill and team performance. Journal of Management, 30(3), 309327.

Alge, B. J., Wiethoff, C., \& Klein, H. J. (2003). When does the medium matter? Knowledge-building experiences and opportunities in decision-making teams. Organizational Behavior and Human Decision Processes, 91(1), 26-37.

Amabile, T. M., Conti, R., Coon, H., Lazenby, J., \& Herron, M. (1996). Assessing the work environment for creativity. Academy of Management Journal, 39(5), 11541184.

Anderson, J. C., \& Gerbing, D. W. (1988). Structural equation modeling in practice: A review and recommended two-step approach. Psychological Bulletin, 103(3), 411-423.

Anderson, N. R., \& West, M. A. (1998). Measuring climate for work group innovation: Development and validation of the team climate inventory. Journal of Organizational Behavior: The International Journal of Industrial, Occupational and Organizational Psychology and Behavior, 19(3), 235-258.

Anderson, N. R., Hardy, G., \& West, M. (1992). Management team innovation. Management Decision, 30(2), 17-21.

Aselage, J., \& Eisenberger, R. (2003). Perceived organizational support and psychological contracts: A theoretical integration. Journal of Organizational Behavior: The International Journal of Industrial, Occupational and Organizational Psychology and Behavior, 24(5), 491-509.

Baer, M. (2012). Putting creativity to work: The implementation of creative ideas in organizations. Academy of Management Journal, 55(5), 1102-1119.

Baer, M., \& Frese, M. (2003). Innovation is not enough: Climates for initiative and psychological safety, process innovations, and firm performance. Journal of Organizational Behavior: The International Journal of Industrial, Occupational and Organizational Psychology and Behavior, 24(1), 45-68.

Baer, M., Oldham, G. R., \& Cummings, A. (2003). Rewarding creativity: When does it really matter? The Leadership Quarterly, 14(4), 569-586. 
Bandura, A. (1977). Self-efficacy: Toward a unifying theory of behavioral change. Psychological Review, 84(2), 191-215.

Bandura, A. (1986). The explanatory and predictive scope of self-efficacy theory. Journal of Social and Clinical Psychology, 4(3), 359-373.

Banks, G. C., Batchelor, J. H., Seers, A., O'Boyle, E. H., Pollack, J. M., \& Gower, K. (2014). What does team-member exchange bring to the party? A meta-analytic review of team and leader social exchange. Journal of Organizational Behavior, 35(2), 273-295.

Barczak, G., Lassk, F., \& Mulki, J. (2010). Antecedents of team creativity: An examination of team emotional intelligence, team trust and collaborative culture. Creativity and Innovation Management, 19(4), 332-345.

Barrick, M. R., Bradley, B. H., Kristof-Brown, A. L., \& Colbert, A. E. (2007). The moderating role of top management team interdependence: Implications for real teams and working groups. Academy of Management Journal, 50(3), 544-557.

Bateman, T. S., \& Crant, J. M. (1993). The proactive component of organizational behavior: A measure and correlates. Journal of Organizational Behavior, 14(2), 103-118.

Beal, D. J., Cohen, R. R., Burke, M. J., \& McLendon, C. L. (2003). Cohesion and performance in groups: A meta-analytic clarification of construct relations. Journal of Applied Psychology, 88(6), 989-1004.

Bessant, J., \& Tidd, J. (2009). Inovação e empreendedorismo: Administração. Bookman Editora.

Blader, S. L., \& Tyler, T. R. (2009). Testing and extending the group engagement model: Linkages between social identity, procedural justice, economic outcomes, and extrarole behavior. Journal of Applied Psychology, 94(2), 445-464.

Blau, P. M. (1964). Exchange and power in social life. New York, NY: John Wiley \& Sons.

Bliese, P. D. (2000). Within-Group Agreement, Non-Independence, and Reliability: Implications for Data Aggregation and Analysis. In K. J. Klein, \& S. W. J. Kozlowski (Eds.), Multilevel Theory, Research, and Methods in Organizations. Foundations, Extensions, and New Directions (pp. 249-381). San Francisco: Jossey-Bass.

Bond-Barnard, T. J., Fletcher, L., \& Steyn, H. (2018). Linking trust and collaboration in project teams to project management success. International Journal of Managing Projects in Business, 11(2), 432-457. 
Bosman, J. \& de la Merced, M. J. (Feb 16, 2011). Borders' Bankruptcy Shakes Industry. The New York Times. Retrieved from https://www.nytimes.com/2011/02/17/business/media/17borders.html

Bresman, H., \& Zellmer-Bruhn, M. (2013). The structural context of team learning: Effects of organizational and team structure on internal and external learning. Organization Science, 24(4), 1120-1139.

Brown, J. S., \& Duguid, P. (1991). Organizational learning and communities-of-practice: Toward a unified view of working, learning, and innovation. Organization Science, 2(1), 40-57.

Bulmer, M. G. (1979). Principles of statistics. New York, NY: Dover Publications.

Bunderson, J. S., \& Boumgarden, P. (2010). Structure and learning in self-managed teams: Why "bureaucratic" teams can be better learners. Organization Science, 21(3), 609-624.

Burke, M. I., Landis, R. S., \& Burke, M. J. (2017). Estimating group-level relationships: General recommendations and considerations for the use of intraclass correlation coefficients. Journal of Business and Psychology, 32(6), 611-626.

Burris, E. R., Detert, J. R., \& Chiaburu, D. S. (2008). Quitting before leaving: The mediating effects of psychological attachment and detachment on voice. Journal of Applied Psychology, 93(4), 912-922.

Calton, J. M., \& Lad, L. J. (1995). Social contracting as a trust-building process of network governance. Business Ethics Quarterly, 5(2), 271-295.

Carmeli, A., \& Gittell, J. H. (2009). High-quality relationships, psychological safety, and learning from failures in work organizations. Journal of Organizational Behavior, 30(6), 709-729.

Carmeli, A., \& Spreitzer, G. M. (2009). Trust, connectivity, and thriving: Implications for innovative behaviors at work. The Journal of Creative Behavior, 43(3), 169-191.

Carmeli, A., \& Zisu, M. (2009). The relational underpinnings of quality internal auditing in medical clinics in Israel. Social Science \& Medicine, 68(5), 894-902.

Carmeli, A., Meitar, R., \& Weisberg, J. (2006). Self-leadership skills and innovative behavior at work. International Journal of Manpower, 27(1), 75-90.

Carmeli, A., Reiter-Palmon, R., \& Ziv, E. (2010). Inclusive leadership and employee involvement in creative tasks in the workplace: The mediating role of psychological safety. Creativity Research Journal, 22(3), 250-260. 
Carmeli, A., Tishler, A., \& Edmondson, A. C. (2012). CEO relational leadership and strategic decision quality in top management teams: The role of team trust and learning from failure. Strategic Organization, 10(1), 31-54.

Carson, JB, Tesluk, PE, \& Marrone, JA (2007) Shared leadership in teams: An investigation of antecedent conditions and performance. Academy of Management Journal, 50(5), 1217-1234.

Cauwelier, P., Ribière, V. M., \& Bennet, A. (2016). Team psychological safety and team learning: a cultural perspective. The Learning Organization, 23(6), 458-468.

Chamberlin, M., Newton, D. W., \& Lepine, J. A. (2016). A meta-analysis of voice and its promotive and prohibitive forms: Identification of key associations, distinctions, and future research directions. Personnel Psychology, 70(1), 11-71

Chen, T., Li, F., \& Leung, K. (2016). When does supervisor support encourage innovative behavior? Opposite moderating effects of general self-efficacy and internal locus of control. Personnel Psychology, 69(1), 123-158.

Chughtai, A. A., \& Buckley, F. (2013). Exploring the impact of trust on research scientists' work engagement: Evidence from Irish science research centres. Personnel Review, 42(4), 396-421.

Chung, Y., \& Jackson, S. E. (2011). Co-worker trust and knowledge creation: A multilevel analysis. Journal of Trust Research, 1(1), 65-83.

Cohen, J. (1988). Statistical power analysis for the behavioral sciences. (2nd edn). Hilldale, NJ: Lawrence Erlbaum Associates.

Cohen, J. (1992). A power primer. Psychological Bulletin, 112(1), 155-159.

Cohen-Charash, Y., \& Spector, P. E. (2001). The role of justice in organizations: A metaanalysis. Organizational Behavior and Human Decision Processes, 86(2), 278321.

Cole, M. S., Bernerth, J. B., Walter, F., \& Holt, D. T. (2010). Organizational justice and individuals' withdrawal: Unlocking the influence of emotional exhaustion. Journal of Management Studies, 47(3), 367-390.

Colquitt, J. A. (2001). On the dimensionality of organizational justice: A construct validation of a measure. Journal of Applied Psychology, 86(3), 386-400.

Colquitt, J. A., Conlon, D. E., Wesson, M. J., Porter, C. O., \& Ng, K. Y. (2001). Justice at the millennium: A meta-analytic review of 25 years of organizational justice research. Journal of Applied Psychology, 86(3), 425-445. 
Colquitt, J. A., Scott, B. A., Rodell, J. B., Long, D. M., Zapata, C. P., Conlon, D. E., \& Wesson, M. J. (2013). Justice at the millennium, a decade later: A meta-analytic test of social exchange and affect-based perspectives. Journal of Applied Psychology, 98(2), 199-236.

Cook, K. S. (1990). Linking actors and structures: An exchange network perspective. In C. Calhoun, M.W. Meyer, and W.R. Scott (Eds.), Structures of power and constraint (pp. 113-128). Cambridge, MA: Cambridge University Press.

Costa, A. C. (2003). Work team trust and effectiveness. Personnel Review, 32(5), 605622.

Costa, A. C., Roe, R. A., \& Taillieu, T. (2001). Trust within teams: The relation with performance effectiveness. European Journal of Work and Organizational Psychology, 10(3), 225-244.

Coyle-Shapiro, J. A., \& Shore, L. M. (2007). The employee-organization relationship: Where do we go from here? Human Resource Management Review, 17(2), 166179 .

Crant, J. M. (2000). Proactive behavior in organizations. Journal of Management, 26(3), $435-462$.

Cronbach, L. J. (1951). Coefficient alpha and the internal structure of tests. Psychometrika, 16(3), 297-334.

Cropanzano, R., \& Mitchell, M. S. (2005). Social exchange theory: An interdisciplinary review. Journal of Management, 31(6), 874-900.

Dansereau, F., Graen, G., \& Haga, W. J. (1975). A vertical dyad linkage approach to leadership within formal organizations: A longitudinal investigation of the role making process. Organizational Behavior and Human Performance, 13(1), 46-78.

De Dreu, C. K., \& Weingart, L. R. (2003). Task versus relationship conflict, team performance, and team member satisfaction: a meta-analysis. Journal of Applied Psychology, 88(4), 741-749.

De Jong, B. A., \& Elfring, T. (2010). How does trust affect the performance of ongoing teams? The mediating role of reflexivity, monitoring, and effort. Academy of Management Journal, 53(3), 535-549.

De Jong, B. A., Bijlsma-Frankema, K. M., \& Cardinal, L. B. (2014). Stronger than the sum of its parts? The performance implications of peer control combinations in teams. Organization Science, 25(6), 1703-1721. 
de la Merced, M. J. (Sept. 23, 2010). Blockbuster, hoping to reinvent itself, files for bankruptcy. The New York Times. Retrieved from https://www.nytimes.com/2010/09/24/business/24blockbuster.html

DeCarlo, L. T. (1997). On the meaning and use of kurtosis. Psychological Methods, 2(3), 292-307.

DeChurch, L. A., \& Mesmer-Magnus, J. R. (2010). The cognitive underpinnings of effective teamwork: A meta-analysis. Journal of Applied Psychology, 95(1), 3253.

DeOrtentiis, P., K. Summers, J., P. Ammeter, A., Douglas, C., \& R. Ferris, G. (2013). Cohesion and satisfaction as mediators of the team trust-team effectiveness relationship: An interdependence theory perspective. Career Development International, 18(5), 521-543.

Detert, J. R., \& Burris, E. R. (2007). Leadership behavior and employee voice: Is the door really open? Academy of Management Journal, 50(4), 869-884.

Dienesch, R. M., \& Liden, R. C. (1986). Leader-member exchange model of leadership: A critique and further development. Academy of Management Review, 11(3), 618634.

Dillman, D. A. (2000). Mail and internet surveys: The tailored design method. New York, NY: John Wiley \& Sons.

Duhigg, C. (2016, February 25). What Google learned from its quest to build the perfect team. The New York Times Magazine. Retrieved from https://www.nytimes.com/2016/02/28/magazine/what-google-learned-from-itsquest-to-build-the-perfect-team.html?_r=0

Dulebohn, J. H., Bommer, W. H., Liden, R. C., Brouer, R. L., \& Ferris, G. R. (2012). A meta-analysis of antecedents and consequences of leader-member exchange: Integrating the past with an eye toward the future. Journal of Management, 38(6), 1715-1759.

Dyne, L. V., Ang, S., \& Botero, I. C. (2003). Conceptualizing employee silence and employee voice as multidimensional constructs. Journal of Management Studies, 40(6), 1359-1392.

Edmondson, A. C. (1996). Learning from mistakes is easier said than done: Group and organizational influences on the detection and correction of human error. The Journal of Applied Behavioral Science, 32(1), 5-28.

Edmondson, A. C. (1999). Psychological safety and learning behavior in work teams. Administrative Science Quarterly, 44(2), 350-383. 
Edmondson, A. C. (2003). Speaking up in the operating room: How team leaders promote learning in interdisciplinary action teams. Journal of Management Studies, 40(6), 1419-1452.

Edmondson, A. C. (2004). Learning from failure in health care: Frequent opportunities, pervasive barriers. Quality and Safety in Health Care, 13(suppl 2), ii3-ii9.

Edmondson, A. C., Bohmer, R. M., \& Pisano, G. P. (2001). Disrupted routines: Team learning and new technology implementation in hospitals. Administrative Science Quarterly, 46(4), 685-716.

Edwards, J. R., \& Lambert, L. S. (2007). Methods for integrating moderation and mediation: A general analytical framework using moderated path analysis. Psychological Methods, 12(1), 1-22.

Eisenberger, R., Armeli, S., Rexwinkel, B., Lynch, P. D., \& Rhoades, L. (2001). Reciprocation of perceived organizational support. Journal of Applied Psychology, 86(1), 42-51.

Eisenberger, R., Fasolo, P., \& Davis-LaMastro, V . (1990). Perceived organizational support and employee diligence, commitment, and innovation. Journal of Applied Psychology, 75(1), 51-59.

Eisenberger, R., Huntington, R., Hutchison, S., \& Sowa, D. (1986). Perceived organizational support. Journal of Applied Psychology, 71(3), 500-507.

Eisenberger, R., Stinglhamber, F., Vandenberghe, C., Sucharski, I. L., \& Rhoades, L. (2002). Perceived supervisor support: Contributions to perceived organizational support and employee retention. Journal of Applied Psychology, 87(3), 565-573.

Emerson, R. M. (1976). Social exchange theory. Annual Review of Sociology, 2(1), 335362.

Epitropaki, O., Kapoutsis, I., Ellen, B. P., Ferris, G. R., Drivas, K., \& Ntotsi, A. (2016). Navigating uneven terrain: The roles of political skill and LMX differentiation in prediction of work relationship quality and work outcomes. Journal of Organizational Behavior, 37(7), 1078-1103.

Erdfelder, E., Faul, F., \& Buchner, A. (1996). GPOWER: A general power analysis program. Behavior Research Methods, Instruments, \& Computers, 28(1), 1-11.

Erdogan, B., \& Liden, R. C. (2002). Social exchanges in the workplace: A review of recent developments and future research directions in leader-member exchange theory. In L. L. Neider, \& C. A. Schriesheim (Eds), Leadership (pp. 65-114). Greenwich, CT: Information Age. 
Erdogan, B., Kraimer, M. L., \& Liden, R. C. (2004). Work value congruence and intrinsic career success: The compensatory roles of leader-member exchange and perceived organizational support. Personnel Psychology, 57(2), 305-332.

Ferres, N., Connell, J., \& Travaglione, A. (2004). Co-worker trust as a social catalyst for constructive employee attitudes. Journal of Managerial Psychology, 19(6), 608622 .

Ferris, G. R., Treadway, D. C., Brouer, R. L., \& Munyon, T. P. (2012). Political skill in the organizational sciences. In G. R. Ferris, \& D. C. Treadway (Eds.), Politics in organizations: Theory and research considerations (pp. 487-528). New York, NY: Routledge/Taylor \& Francis Group.

Ferris, G. R., Treadway, D. C., Kolodinsky, R. W., Hochwarter, W. A., Kacmar, C. J., Douglas, C., \& Frink, D. D. (2005). Development and validation of the political skill inventory. Journal of Management, 31(1), 126-152.

Ferris, G. R., Treadway, D. C., Perrewé, P. L., Brouer, R. L., Douglas, C., \& Lux, S. (2007). Political skill in organizations. Journal of Management, 33(3), 290-320.

Ford, C. M. (1996). A theory of individual creative action in multiple social domains. Academy of Management Review, 21(4), 1112-1142.

Frazier, M. L., Fainshmidt, S., Klinger, R. L., Pezeshkan, A., \& Vracheva, V. (2017). Psychological safety: A meta-analytic review and extension. Personnel Psychology, 70(1), 113-165.

French, W. (1964, December). The nature and problems of organizational justice. In Academy of Management Proceedings (Vol. 1964, No. 1, pp. 102-109). Academy of Management.

Fuller, B., \& Marler, L. E. (2009). Change driven by nature: A meta-analytic review of the proactive personality literature. Journal of Vocational Behavior, 75(3), 329345.

Gerstner, C. R., \& Day, D. V. (1997). Meta-Analytic review of leader-member exchange theory: Correlates and construct issues. Journal of Applied Psychology, 82(6), $827-844$.

Gherardi, S., Nicolini, D., \& Odella, F. (1998). Toward a social understanding of how people learn in organizations: The notion of situated curriculum. Management Learning, 29(3), 273-297.

Gilson, L. L., Lim, H. S., D'Innocenzo, L., \& Moye, N. (2012). One size does not fit all: Managing radical and incremental creativity. The Journal of Creative Behavior, 46(3), 168-191. 
Gong, Y., Cheung, S. Y., Wang, M., \& Huang, J. C. (2012). Unfolding the proactive process for creativity: Integration of the employee proactivity, information exchange, and psychological safety perspectives. Journal of Management, 38(5), 1611-1633.

Gouldner, A. W. (1960). The norm of reciprocity: A preliminary statement. American Sociological Review, 161-178.

Graen, G. B., \& Scandura, T. A. (1987). Toward a psychology of dyadic organizing. Research in Organizational Behavior, 9, 175-208.

Graen, G. B., \& Uhl-Bien, M. (1995). Relationship-based approach to leadership: Development of leader-member exchange (LMX) theory of leadership over 25 years: Applying a multi-level multi-domain perspective. The Leadership Quarterly, 6(2), 219-247.

Greenberg, J. (1987). A taxonomy of organizational justice theories. Academy of Management Review, 12(1), 9-22.

Guchait, P., Lee, C., Wang, C. Y., \& Abbott, J. L. (2016). Impact of error management practices on service recovery performance and helping behaviors in the hospitality industry: The mediating effects of psychological safety and learning behaviors. Journal of Human Resources in Hospitality \& Tourism, 15(1), 1-28.

Gump, B. B., \& Kulik, J. A. (1997). Stress, affiliation, and emotional contagion. Journal of Personality and Social Psychology, 72(2), 305-319.

Hayes, A. F. (2009). Beyond Baron and Kenny: Statistical mediation analysis in the new millennium. Communication Monographs, 76(4), 408-420.

Hayes, A. F. (2013). Introduction to mediation, moderation, and conditional process analysis: A regression-based approach. New York, NY: Guilford Press.

Hiller, N. J., DeChurch, L. A., Murase, T., \& Doty, D. (2011). Searching for outcomes of leadership: A 25-year review. Journal of Management, 37(4), 1137-1177.

Hirst, G., Van Knippenberg, D., \& Zhou, J. (2009). A cross-level perspective on employee creativity: Goal orientation, team learning behavior, and individual creativity. Academy of Management Journal, 52(2), 280-293.

Holmstrom, B. (1989). Agency costs and innovation. Journal of Economic Behavior \& Organization, 12(3), 305-327.

Homans, G. C. (1958). Social behavior as exchange. American Journal of Sociology, 63(6), 597-606. 
Howell, J. M., \& Avolio, B. J. (1993). Transformational leadership, transactional leadership, locus of control, and support for innovation: Key predictors of consolidated-business-unit performance. Journal of Applied Psychology, 78(6), 891-902.

Hsiao, H., Chang, J., \& Chen, S. (2014). The influence of support for innovation on organizational innovation: Taking organizational learning as a mediator. The Asia-Pacific Education Researcher, 23(3), 463-472.

Hu, L. T., \& Bentler, P. M. (1999). Cutoff criteria for fit indexes in covariance structure analysis: Conventional criteria versus new alternatives. Structural Equation Modeling: A Multidisciplinary Journal, 6(1), 1-55.

Huang, L., Krasikova, D. V., \& Liu, D. (2016). I can do it, so can you: The role of leader creative self-efficacy in facilitating follower creativity. Organizational Behavior and Human Decision Processes, 132, 49-62.

Hunt, T. J. (2014). Leader-member exchange relationships in health information management. Perspectives in Health Information Management, 11(Spring), 1-8.

Ibarra, H. (1993). Network centrality, power, and innovation involvement: Determinants of technical and administrative roles. Academy of Management Journal, 36(3), 471-501.

Idris, M. A., Dollard, M. F., Coward, J., \& Dormann, C. (2012). Psychosocial safety climate: Conceptual distinctiveness and effect on job demands and worker psychological health. Safety Science, 50(1), 19-28.

Ilies, R., Nahrgang, J. D., \& Morgeson, F. P. (2007). Leader-member exchange and citizenship behaviors: A meta-analysis. Journal of Applied Psychology, 92(1), 269-277.

Jacobs, K. (November 10, 2008). Circuit City files for bankruptcy protection. Reuters. Retrieved from https://www.reuters.com/article/us-circuitcity/circuit-city-filesfor-bankruptcy-protection-idUSTRE4A936V20081110

Janssen, O. (2000). Job demands, perceptions of effort-reward fairness and innovative work behaviour. Journal of Occupational and Organizational Psychology, 73(3), 287-302.

Janssen, O. (2004). How fairness perceptions make innovative behavior more or less stressful. Journal of Organizational Behavior, 25(2), 201-215.

Janssen, O., \& Van Yperen, N. W. (2004). Employees' goal orientations, the quality of leader-member exchange, and the outcomes of job performance and job satisfaction. Academy of Management Journal, 47(3), 368-384. 
Johnson, R. E., Selenta, C., \& Lord, R. G. (2006). When organizational justice and the self-concept meet: Consequences for the organization and its members. Organizational Behavior and Human Decision Processes, 99(2), 175-201.

Jones, G. R., \& George, J. M. (1998). The experience and evolution of trust: Implications for cooperation and teamwork. Academy of Management Review, 23(3), 531-546.

Kahn, W. A. (1990). Psychological conditions of personal engagement and disengagement at work. Academy of Management Journal, 33(4), 692-724.

Kakkar, H., Tangirala, S., Srivastava, N. K., \& Kamdar, D. (2016). The dispositional antecedents of promotive and prohibitive voice. Journal of Applied Psychology, 101(9), 1342-1351.

Kang, J. H., Solomon, G. T., \& Choi, D. Y. (2015). CEOs' leadership styles and managers' innovative behaviour: Investigation of intervening effects in an entrepreneurial context. Journal of Management Studies, 52(4), 531-554.

Kanter, R. M. (1988). Three tiers for innovation research. Communication Research, 15(5), 509-523.

Kark, R., \& Carmeli, A. (2009). Alive and creating: The mediating role of vitality and aliveness in the relationship between psychological safety and creative work involvement. Journal of Organizational Behavior, 30(6), 785-804.

Karriker, J. H., \& Williams, M. L. (2009). Organizational justice and organizational citizenship behavior: A mediated multifoci model. Journal of Management, 35(1), 112-135.

Katz, D., \& Kahn, R. L. (1978). The social psychology of organizations (Vol. 2). New York, NY: Wiley.

Keltner, D., \& Haidt, J. (1999). Social functions of emotions at four levels of analysis. Cognition \& Emotion, 13(5), 505-521.

Kline, R. B. (2005). Principles and practice of structural equation modeling. New York, NY: The Guilford Press.

Kline, R. B. (2016). Principles and practice of structural equation modeling. New York, NY: The Guilford Press.

Knight, A. P., \& Eisenkraft, N. (2015). Positive is usually good, negative is not always bad: The effects of group affect on social integration and task performance. Journal of Applied Psychology, 100(4), 1214-1227.

Koys, D. J., \& DeCotiis, T. A. (1991). Inductive measures of psychological climate. Human Relations, 44(3), 265-285. 
Kwon Choi, B., Koo Moon, H., \& Ko, W. (2013). An organization's ethical climate, innovation, and performance: Effects of support for innovation and performance evaluation. Management Decision, 51(6), 1250-1275.

Ladebo, O. J. (2006). Perceptions of trust and employees' attitudes: A look at Nigeria's agricultural extension workers. Journal of Business and Psychology, 20(3), 409427.

Larson, C. E., Larson, C., \& LaFasto, F. M. (1989). Teamwork: What must go right/what can go wrong (Vol. 10). Sage.

LePine, J. A., \& Van Dyne, L. (1998). Predicting voice behavior in work groups. Journal of Applied Psychology, 83(6), 853-868.

Leung, K., Deng, H., Wang, J., \& Zhou, F. (2015). Beyond risk-taking: Effects of psychological safety on cooperative goal interdependence and prosocial behavior. Group \& Organization Management, 40(1), 88-115.

Leventhal, G. S. (1980). What should be done with equity theory? New approaches to the study of fairness in social relationships. In K. J. Gergen, M. S. Greenberg, \& R. H. Willis (Eds.), Social exchange (pp. 27-55). New York, NY: Springer.

Levinson, H. (1965). Reciprocation: The relationship between man and organization. Administrative Science Quarterly, 370-390.

Li, A. N., \& Tan, H. H. (2013). What happens when you trust your supervisor? Mediators of individual performance in trust relationships. Journal of Organizational Behavior, 34(3), 407-425.

Liang, J., Farh, C. I., \& Farh, J. L. (2012). Psychological antecedents of promotive and prohibitive voice: A two-wave examination. Academy of Management Journal, 55(1), 71-92.

Liao, H., \& Rupp, D. E. (2005). The impact of justice climate and justice orientation on work outcomes: a cross-level multifoci framework. Journal of Applied Psychology, 90(2), 242-256.

Liden, R. C., \& Graen, G. (1980). Generalizability of the vertical dyad linkage model of leadership. Academy of Management Journal, 23(3), 451-465.

Liden, R. C., Sparrowe, R. T., \& Wayne, S. J. (1997). Leader-member exchange theory: The past and potential for the future. Research in Personnel and Human Resources Management, 15, 47-120.

Liden, R. C., Wayne, S. J., \& Sparrowe, R. T. (2000). An examination of the mediating role of psychological empowerment on the relations between the job, 
interpersonal relationships, and work outcomes. Journal of Applied Psychology, 85(3), 407-416.

Liu, W., Tangirala, S., Lam, W., Chen, Z., Jia, R. T., \& Huang, X. (2015). How and when peers' positive mood influences employees' voice. Journal of Applied Psychology, 100(3), 976-989.

Loi, R., Ao, O. K., \& Xu, A. J. (2014). Perceived organizational support and coworker support as antecedents of foreign workers' voice and psychological stress. International Journal of Hospitality Management, 36, 23-30.

Lu, L., Zhou, F., \& Leung, K. (2011). Effects of task and relationship conflicts on individual work behaviors. International Journal of Conflict Management, 22(2), 131-150.

Lubart, T. I. (2001). Models of the creative process: Past, present and future. Creativity Research Journal, 13(3-4), 295-308.

Madlock, P. E., Martin, M. M., Bogdan, L., \& Ervin, M. (2007). The impact of communication traits on leader-member exchange. Human Communication, 10(4), 451-464.

Martin, R., Guillaume, Y., Thomas, G., Lee, A., \& Epitropaki, O. (2016). LeaderMember exchange (LMX) and performance: A Meta-Analytic review. Personnel Psychology, 69(1), 67-121.

Maurer, T. J., \& Tarulli, B. A. (1994). Investigation of perceived environment, perceived outcome, and person variables in relationship to voluntary development activity by employees. Journal of Applied Psychology, 79(1), 3-14.

Mayer, R. C., Davis, J. H., \& Schoorman, F. D. (1995). An integrative model of organizational trust. Academy of Management Review, 20(3), 709-734.

Mayfield, C. O., Tombaugh, J. R., \& Lee, M. (2016). Psychological collectivism and team effectiveness: Moderating effects of trust and psychological safety. Journal of Organizational Culture, Communications \& Conflict, 20(1), 78-94.

McAllister, D. J. (1995). Affect-and cognition-based trust as foundations for interpersonal cooperation in organizations. Academy of Management Journal, $38(1), 24-59$.

McCarty, D. \& Jinks, B. (January 19, 2012). Kodak files for bankruptcy as digital era spells end to film. BloombergBusiness. Retrieved from https://www.bloomberg.com/news/articles/2012-01-19/kodak-photographypioneer-files-for-bankruptcy-protection-1- 
Meng, H., Cheng, Z. C., \& Guo, T. C. (2016). Positive team atmosphere mediates the impact of authentic leadership on subordinate creativity. Social Behavior and Personality, 44(3), 355-368.

Mitchell, M. S., Vogel, R. M., \& Folger, R. (2015). Third parties' reactions to the abusive supervision of coworkers. Journal of Applied Psychology, 100(4), 1040-1055.

Montani, F., Battistelli, A., \& Odoardi, C. (2017). Proactive goal generation and innovative work behavior: The moderating role of affective commitment, production ownership and leader support for innovation. The Journal of Creative Behavior, 51(2), 107-127.

Moorman, R. H. (1991). Relationship between organizational justice and organizational citizenship behaviors: Do fairness perceptions influence employee citizenship? Journal of Applied Psychology, 76(6), 845-855.

Morrison, E. W., \& Milliken, F. J. (2000). Organizational silence: A barrier to change and development in a pluralistic world. Academy of Management Review, 25(4), 706-725.

Morwitz, V. G., Johnson, E., \& Schmittlein, D. (1993). Does measuring intent change behavior? Journal of Consumer Research, 20(1), 46-61.

Munyon, T. P., Summers, J. K., Thompson, K. M., \& Ferris, G. R. (2015). Political skill and work outcomes: A theoretical extension, meta-analytic investigation, and agenda for the future. Personnel Psychology, 68(1), 143-184.

Muthén, L. K., \& Muthen, B. O. (2017). Mplus. Los Angeles: Muthen \& Muthen.

Nembhard, I. M., \& Edmondson, A. C. (2006). Making it safe: The effects of leader inclusiveness and professional status on psychological safety and improvement efforts in health care teams. Journal of Organizational Behavior, 27(7), 941-966.

Newman, A., Donohue, R., \& Eva, N. (2017). Psychological safety: A systematic review of the literature. Human Resource Management Review, 27(3), 521-535.

Ng, T. W., \& Feldman, D. C. (2010). The impact of job embeddedness on innovationrelated behaviors. Human Resource Management, 49(6), 1067-1087.

Ng, T. W., Feldman, D. C., \& Butts, M. M. (2014). Psychological contract breaches and employee voice behaviour: The moderating effects of changes in social relationships. European Journal of Work and Organizational Psychology, 23(4), 537-553.

Nunnally, J. C. (1978). Psychometric theory. New York, NY: McGraw-Hill International Book Co. 
Oeij, P. R., Dhondt, S., Gaspersz, J. B., \& Vroome, E. M. D. (2016). Can teams benefit from using a mindful infrastructure when defensive behaviour threatens complex innovation projects? International Journal of Project Organisation and Management, 8(3), 241-258.

Oldham, G. R., \& Cummings, A. (1996). Employee creativity: Personal and contextual factors at work. Academy of Management Journal, 39(3), 607-634.

O'Reilly III, C. A., Caldwell, D. F., \& Barnett, W. P. (1989). Work group demography, social integration, and turnover. Administrative Science Quarterly, 34(1), 21-37.

Ostroff, C., Kinicki, A. J., \& Clark, M. A. (2002). Substantive and operational issues of response bias across levels of analysis: An example of climate-satisfaction relationships. Journal of Applied Psychology, 87(2), 355-368.

Palanski, M. E., Kahai, S. S., \& Yammarino, F. J. (2011). Team virtues and performance: An examination of transparency, behavioral integrity, and trust. Journal of Business Ethics, 99(2), 201-216.

Paustian-Underdahl, S. C., \& Halbesleben, J. R. (2014). Examining the influence of climate, supervisor guidance, and behavioral integrity on work-family conflict: A demands and resources approach. Journal of Organizational Behavior, 35(4), 447-463.

Perrewé, P. L., Zellars, K. L., Ferris, G. R., Rossi, A. M., Kacmar, C. J., \& Ralston, D. A. (2004). Neutralizing job stressors: Political skill as an antidote to the dysfunctional consequences of role conflict. Academy of Management Journal, 47(1), 141-152.

Pfeffer, J. (1992). Managing with power: Politics and influence in organizations. Boston, MA: Harvard Business Press.

Podsakoff, P. M., MacKenzie, S. B., Lee, J. Y., \& Podsakoff, N. P. (2003). Common method biases in behavioral research: A critical review of the literature and recommended remedies. Journal of Applied Psychology, 88(5), 879-903.

Raemdonck, I., Tillema, H., de Grip, A., Valcke, M., \& Segers, M. (2012). Does selfdirectedness in learning and careers predict the employability of low-qualified employees? Vocations and Learning, 5(2), 137-151.

Raemdonck, I., van der Leeden, R., Valcke, M., Segers, M., \& Thijssen, J. (2012). Predictors of self-directed learning for low-qualified employees: a multi-level analysis. European Journal of Training and Development, 36(6), 572-591.

Rhoades, L., \& Eisenberger, R. (2002). Perceived organizational support: A review of the literature. Journal of Applied Psychology, 87(4), 698-714. 
Rhoades, L., Eisenberger, R., \& Armeli, S. (2001). Affective commitment to the organization: The contribution of perceived organizational support. Journal of Applied Psychology, 86(5), 825-836.

Riggle, R. J., Edmondson, D. R., \& Hansen, J. D. (2009). A meta-analysis of the relationship between perceived organizational support and job outcomes: 20 years of research. Journal of Business Research, 62(10), 1027-1030.

Rizzo, L. \& Fitzgerald, P. (March 8, 2017). Radio Shack files for bankruptcy protection, again. The Wall Street Journal. Retrieved from https://www.wsj.com/articles/radio-shack-files-for-bankruptcy-protection-again1489025346

Rockstuhl, T., Dulebohn, J. H., Ang, S., \& Shore, L. M. (2012). Leader-member exchange (LMX) and culture: A meta-analysis of correlates of LMX across 23 countries. Journal of Applied Psychology, 97(6), 1097-1130.

Rousseau, D. M., Sitkin, S. B., Burt, R. S., \& Camerer, C. (1998). Not so different after all: A cross-discipline view of trust. Academy of Management Review, 23(3), 393404.

Runhaar, P., Konermann, J., \& Sanders, K. (2013). Teachers' organizational citizenship behaviour: Considering the roles of their work engagement, autonomy and leadermember exchange. Teaching and Teacher Education, 30, 99-108.

Scherbaum, C. A., \& Ferreter, J. M. (2009). Estimating statistical power and required sample sizes for organizational research using multilevel modeling. Organizational Research Methods, 12(2), 347-367.

Schermuly, C. C., Meyer, B., \& Dämmer, L. (2013). Leader-member exchange and innovative behavior. Journal of Personnel Psychology, 12(3), 132-142.

Schiller, S. Z., Mennecke, B. E., Nah, F. F. H., \& Luse, A. (2014). Institutional boundaries and trust of virtual teams in collaborative design: An experimental study in a virtual world environment. Computers in Human Behavior, 35, 565577.

Schriesheim, C. A., Castro, S. L., \& Cogliser, C. C. (1999). Leader-member exchange (LMX) research: A comprehensive review of theory, measurement, and dataanalytic practices. The Leadership Quarterly, 10(1), 63-113.

Schulte, M., Cohen, N. A., \& Klein, K. J. (2012). The coevolution of network ties and perceptions of team psychological safety. Organization Science, 23(2), 564-581.

Scott, S. G., \& Bruce, R. A. (1994). Determinants of innovative behavior: A path model of individual innovation in the workplace. Academy of Management Journal, 37(3), 580-607. 
Seibert, S. E., Crant, J. M., \& Kraimer, M. L. (1999). Proactive personality and career success. Journal of Applied Psychology, 84(3), 416-427.

Seibert, S. E., Kraimer, M. L., \& Crant, J. M. (2001). What do proactive people do? A longitudinal model linking proactive personality and career success. Personnel Psychology, 54(4), 845-874.

Sin, H. P., Nahrgang, J. D., \& Morgeson, F. P. (2009). Understanding why they don't see eye to eye: An examination of leader-member exchange (LMX) agreement. Journal of Applied Psychology, 94(4), 1048-1057.

Singh, B., Shaffer, M. A., \& Selvarajan, T. T. (2018). Antecedents of organizational and community embeddedness: The roles of support, psychological safety, and need to belong. Journal of Organizational Behavior, 39(3), 339-354.

Smith, J. B., \& Barclay, D. W. (1997). The effects of organizational differences and trust on the effectiveness of selling partner relationships. The Journal of Marketing, 321.

Smith, K. G., Smith, K. A., Olian, J. D., Sims Jr, H. P., O'Bannon, D. P., \& Scully, J. A. (1994). Top management team demography and process: The role of social integration and communication. Administrative Science Quarterly, 39(3), 412438.

Smothers, J. E. J. (2012). Reinventing the wheel: Examining the antecedents, moderators, and outcomes of the innovation process (Doctoral dissertation). Retrieved from ABI/INFORM Collection; ProQuest Dissertations \& Theses A\&I; ProQuest Dissertations \& Theses Global. (1284889213).

Spitzmuller, M., Sin, H. P., Howe, M., \& Fatimah, S. (2015). Investigating the uniqueness and usefulness of proactive personality in organizational research: A meta-analytic review. Human Performance, 28(4), 351-379.

Stamper, C. L., \& Van Dyne, L. (2001). Work status and organizational citizenship behavior: A field study of restaurant employees. Journal of Organizational Behavior, 22(5), 517-536.

Stern, Z., Katz-Navon, T., \& Naveh, E. (2008). The influence of situational learning orientation, autonomy, and voice on error making: The case of resident physicians. Management Science, 54(9), 1553-1564.

Stride, C. B., Gardner, S., Catley, N., \& Thomas, F. (2015). Mplus code for the mediation, moderation, and moderated mediation model templates from Andrew Hayes. PROCESS analysis examples. Retrieved from http://www. offbeat. group. shef. ac. uk/FIO/mplusmedmod. htm. 
Strutton, D., Pelton, L. E., \& Lumpkin, J. R. (1993). The relationship between psychological climate and salesperson-sales manager trust in sales organizations. Journal of Personal Selling \& Sales Management, 13(4), 1-14.

Sun, S., \& van Emmerik, H. I. (2015). Are proactive personalities always beneficial? Political skill as a moderator. Journal of Applied Psychology, 100(3), 966-975.

Takeuchi, R., Chen, Z., \& Cheung, S. Y. (2012). Applying uncertainty management theory to employee voice behavior: An integrative investigation. Personnel Psychology, 65(2), 283-323.

Tangirala, S., Kamdar, D., Venkataramani, V., \& Parke, M. R. (2013). Doing right versus getting ahead: The effects of duty and achievement orientations on employees' voice. Journal of Applied Psychology, 98(6), 1040-1050.

Thibaut, J. W., \& Kelley, H. H. (1959). The social psychology of groups. New York, NY: Wiley.

Thibaut, J. W., \& Walker, L. (1975). Procedural justice: A psychological analysis. Hillsdale, NJ: Lawrence Erlbaum Associates.

Tierney, P., Farmer, S. M., \& Graen, G. B. (1999). An examination of leadership and employee creativity: The relevance of traits and relationships. Personnel Psychology, 52(3), 591-620.

Tornau, K., \& Frese, M. (2013). Construct clean-up in proactivity research: A metaanalysis on the nomological net of work-related proactivity concepts and their incremental validities. Applied Psychology, 62(1), 44-96.

van den Berg, P. T. (2010). Stimulating knowledge sharing by error management and leader-member exchange: Psychological safety as a mediator. Psychology of Human Resources Journal, 8(2), 42-52.

van der Vegt, G. S., Bunderson, S., \& Kuipers, B. (2010). Why turnover matters in selfmanaging work teams: Learning, social integration, and task flexibility. Journal of Management, 36(5), 1168-1191.

Van Dyne, L., \& LePine, J. A. (1998). Helping and voice extra-role behaviors: Evidence of construct and predictive validity. Academy of Management Journal, 41(1), 108-119.

Van Dyne, L., Kamdar, D., \& Joireman, J. (2008). In-role perceptions buffer the negative impact of low LMX on helping and enhance the positive impact of high LMX on voice. Journal of Applied Psychology, 93(6), 1195-1207. 
Viswesvaran, C., \& Ones, D. S. (2002). Examining the construct of organizational justice: A meta-analytic evaluation of relations with work attitudes and behaviors. Journal of Business Ethics, 38(3), 193-203.

Waldman, D. A., \& Avolio, B. J. (1986). A meta-analysis of age differences in job performance. Journal of Applied Psychology, 71(1), 33-38.

Walumbwa, F. O., Cropanzano, R., \& Hartnell, C. A. (2009). Organizational justice, voluntary learning behavior, and job performance: A test of the mediating effects of identification and leader-member exchange. Journal of Organizational Behavior, 30(8), 1103-1126.

Wang, D., Gan, C., \& Wu, C. (2016). LMX and employee voice: A moderated mediation model of psychological empowerment and role clarity. Personnel Review, 45(3), 605-615.

Wang, X. H. F., Fang, Y., Qureshi, I., \& Janssen, O. (2015). Understanding employee innovative behavior: Integrating the social network and leader-member exchange perspectives. Journal of Organizational Behavior, 36(3), 403-420.

Wayne, S. J., Shore, L. M., \& Liden, R. C. (1997). Perceived organizational support and leader-member exchange: A social exchange perspective. Academy of Management Journal, 40(1), 82-111.

Wayne, S. J., Shore, L. M., Bommer, W. H., \& Tetrick, L. E. (2002). The role of fair treatment and rewards in perceptions of organizational support and leadermember exchange. Journal of Applied Psychology, 87(3), 590-598.

Wei, L. Q., Chiang, F. F., \& Wu, L. Z. (2012). Developing and utilizing network resources: Roles of political skill. Journal of Management Studies, 49(2), 381402.

Wei, X., Zhang, Z. X., \& Chen, X. P. (2015). I will speak up if my voice is socially desirable: A moderated mediating process of promotive versus prohibitive voice. Journal of Applied Psychology, 100(5), 1641-1652.

Wenger, E. (1998). Communities of practice: Learning as a social system. Systems Thinker, 9(5), 2-3.

West, M. A. (1990). The social psychology of innovation in groups. In M. A. West \& J. L. Farr (Eds.), Innovation and creativity at work: Psychological and organizational strategies (pp. 309-333). Oxford, England: John Wiley \& Sons.

West, M. A., \& Farr, J. L. (1989). Innovation at work: Psychological perspectives. Social Behaviour, 4(1), 15-30. 
West, S. G., Finch, J. F., \& Curran, P. J. (1995). Structural equation models with nonnormal variables: Problems and remedies. In R. H. Hoyle (Ed.), Structural equation modeling: Concepts, issues, and applications (pp. 56-75). Thousand Oaks, CA, US: Sage Publications, Inc.

Wiersema, M. F., \& Bantel, K. A. (1992). Top management team demography and corporate strategic change. Academy of Management Journal, 35(1), 91-121.

Wilson, K. S., Sin, H. P., \& Conlon, D. E. (2010). What about the leader in leadermember exchange? The impact of resource exchanges and substitutability on the leader. Academy of Management Review, 35(3), 358-372.

Yuan, F., \& Woodman, R. W. (2010). Innovative behavior in the workplace: The role of performance and image outcome expectations. Academy of Management Journal, 53(2), 323-342.

Zhao, B., \& Olivera, F. (2006). Error reporting in organizations. Academy of Management Review, 31(4), 1012-1030. 


\section{APPENDIX A. EMAIL TO SURVEY PARTICIPANTS}

Dear $\$\{$ e://Field/Org $\}$ Employee,

With the permission of the $\$\{$ e://Field/Org $\}$ administration, we cordially invite you to participate in a research study conducted by Florida International University (FIU). The purpose of this study is to investigate several work behaviors and attitudes and we would appreciate your assistance in answering three surveys, which will be administered separately within a two-month period.

Participation in this study is voluntary but it will be really appreciated. No identifiable information will be collected throughout the administration of any of these surveys. We will only ask you to enter a code to link the three surveys to one another. Your organization (or members of your organization) will not have any access to your individual responses, which will be gathered and collected by researchers from FIU. Confidentiality of your information is guaranteed under the supervision of the Institutional Review Board (IRB) of FIU.

If you have any questions about this study, you can contact Cynthia Halliday (xxx@ fiu.edu; xxx-xxx-xxxx) or Dr. Hock-Peng Sin (xxx@ fiu.edu; xxx-xxx-xxxx) at FIU. If you have questions about your rights as a participant, you can contact the FIU Office of Research Integrity (xxx@fiu.edu; xxx-xxx-xxxx).

Your assistance is greatly appreciated! Please be assured that all your individual responses will be kept confidential.

If you agree to participate in this study, click on the link below and enter the 5-digit code $\$\{\mathbf{e}: / /$ Field/Code $\}$ to complete your first survey.

\section{Follow this link to the Survey:}

$\$\{1: / /$ SurveyLink?d=Take the Survey $\}$

Or copy and paste the URL below into your internet browser:

$$
\$\{1: / / \text { SurveyURL }\}
$$

Sincerely,

Cynthia Halliday

Florida International University

Follow the link to opt out of future emails:

$\$\{1: / / O p t O u t L i n k ? d=$ Click here to unsubscribe $\}$ 


\section{APPENDIX B. SURVEY ITEMS (TIME 1)}

\section{SURVEY 1.}

Rater: Leader

\section{Leader Characteristics}

Instructions: The following questions are intended to gather information in aggregate terms (for example, percentage of female respondents, average age of participants, etc.) and no individual responses are reported. Please select the statement that best describes you.

What is your gender?

1. Male

2. Female

Please select your age from the following drop-down menu.

What is your highest degree earned?

1. Not a high school graduate

2. High school graduate (or equivalent)

3. Associate's degree (including occupational or academic degrees)

4. Bachelor's degree (BA, BS, AB, etc.)

5. Master's degree (MA, MS, MENG, MSW, etc.)

6. Professional degree (MD, DDC, JD, etc.)

7. Doctorate degree $(\mathrm{PhD}, \mathrm{EdD}$, etc.)

Please select the number of years you have worked for your current supervisor.

Please select the number of years you have worked for your current organization.

What is your current employment status?

1. Part-time (under 40 hours per week)

2. Full-time (40 hours or more per week)

Which of the following best describes your position?

1. Nonsupervisory

2. First-line management

3. Middle management

4. Top management

Are you of Hispanic, Latino, or Spanish origin?

1. Yes

2. No

3. Unknown 
Which category best describes your race?

1. American Indian or Alaska Native

2. Asian

3. Black or African-American

4. Native Hawaiian or Other Pacific Islander

5. White

6. Two or more races

7. Unknown

\section{SURVEY 2.}

Rater: Follower

\section{Leader-Member Exchange}

Source: Graen, G. B., \& Uhl-Bien, M. (1995). Relationship-based approach to leadership: Development of leader-member exchange (LMX) theory of leadership over 25 years: Applying a multi-level multi-domain perspective. The Leadership Quarterly, 6(2), 219-247.

Instructions: In this section, we ask you to consider the nature of your relationship with your direct supervisor. Please rate each statement according to its respective 5-point Likert type scale.

1. Do you know where you stand with your leader .. do you usually know how satisfied your leader is with what you do?

( 1 = Rarely, 2 = Occasionally, 3 = Sometimes, 4 = Fairly Often, $5=$ Very Often $)$

2. How well does your leader understand your job problems and needs?

( 1 = Not a Bit, 2 = A Little, 3 = A Fair Amount, $4=$ Quite a Bit, 5 = A Great Deal)

3. How well does your leader recognize your potential?

$(1=$ Not at All, $2=$ A Little, $3=$ Moderately, $4=$ Mostly, $5=$ Fully $)$

4. Regardless of how much formal authority he/she has built into his/her position, what are the chances that your leader would use his/her power to help you solve problems in your work?

$(1=$ None, $2=$ Small, $3=$ Moderate, $4=$ High, $5=$ Very High $)$

5. Again, regardless of the amount of formal authority your leader has, what are the chances that he/she would "bail you out," at his/her expense?

$(1=$ None, $2=$ Small, $3=$ Moderate, $4=$ High, $5=$ Very High $)$

6. I have enough confidence in my leader that I would defend and justify his/her decision if he/she were not present to do so.

( 1 = Strongly Disagree, $2=$ Disagree, $3=$ Neutral, $4=$ Agree, $5=$ Strongly Agree $)$

7. How would you characterize your working relationship with your leader?

$(1=$ Extremely Ineffective, $2=$ Worse Than Average, $3=$ Average, $4=$ Better

Than Average, 5 = Extremely Effective) 


\section{Perceived Organizational Support}

Source: Eisenberger, R., Huntington, R., Hutchison, S., \& Sowa, D. (1986). Perceived organizational support. Journal of Applied Psychology, 71(3), 500-507.

Instructions: Please indicate the degree to which you agree or disagree with the following statements.

Scale: 1 = strongly disagree, $2=$ disagree, $3=$ slightly disagree, $4=$ neither agree nor disagree, $5=$ slightly agree, $6=$ agree, $7=$ strongly agree

1. My organization takes pride in my accomplishments.

2. My organization really cares about my well-being.

3. My organization values my contributions to its well-being.

4. My organization strongly considers my goals and values.

5. My organization shows little concern for me (reverse-coded).

6. My organization is willing to help me if I need a special favor.

\section{Trust in Team Members}

Source: De Jong, B. A., \& Elfring, T. (2010). How does trust affect the performance of ongoing teams? The mediating role of reflexivity, monitoring, and effort. Academy of Management Journal, 53(3), 535-549.

Instructions: Please indicate the extent to which you agree or disagree with the following statements.

Scale: $1=$ strongly disagree, $2=$ disagree, $3=$ neither agree nor disagree, $4=$ agree, $5=$ strongly agree

1. I am able to count on my team members for help if I have difficulties with my job.

2. I am confident that my team members will take my interests into account when making work-related decisions.

3. I am confident that that my team members will keep me informed about issues that concern my work.

4. I can rely on my team members to keep their word.

5. I trust my team members.

\section{Follower Characteristics}

Instructions: The following questions are intended to gather information in aggregate terms (for example, percentage of female respondents, average age of participants, etc.) and no individual responses are reported. We assure you that your answers will not be linked to you and cannot be used to identify you. Please select the statement that best describes you.

What is your gender?

1. Male 


\section{Female}

Please select your age from the following drop-down menu.

What is your highest degree earned?

1. Not a high school graduate

2. High school graduate (or equivalent)

3. Associate's degree (including occupational or academic degrees)

4. Bachelor's degree (BA, BS, AB, etc.)

5. Master's degree (MA, MS, MENG, MSW, etc.)

6. Professional degree (MD, DDC, JD, etc.)

7. Doctorate degree $(\mathrm{PhD}, \mathrm{EdD}$, etc.)

Please select the number of years you have worked for your current supervisor.

Please select the number of years you have worked for your current organization.

What is your current employment status?

1. Part-time (under 40 hours per week)

2. Full-time (40 hours or more per week)

Which of the following best describes your position?

1. Nonsupervisory

2. First-line management

3. Middle management

4. Top management

Are you of Hispanic, Latino, or Spanish origin?
1. Yes
2. No
3. Unknown

Which category best describes your race?

1. American Indian or Alaska Native

2. Asian

3. Black or African-American

4. Native Hawaiian or Pacific Islander

5. White

6. Two or more races

7. Unknown 


\section{APPENDIX C. SURVEY ITEMS (TIME 2)}

\section{SURVEY 3.}

Rater: Follower

\section{Psychological Safety Within the Organization}

Source: Edmondson, A. (1999). Psychological safety and learning behavior in work teams. Administrative Science Quarterly, 44(2), 350-383.

Instructions: Please indicate the degree to which you agree or disagree with the following statements.

Scale: 1 = strongly disagree, $2=$ disagree, $3=$ slightly disagree, $4=$ neither agree nor disagree, $5=$ slightly agree, $6=$ agree, $7=$ strongly agree

1. If you make a mistake in this organization, it is often held against you (reversecoded).

2. Employees in this organization feel comfortable bringing up problems and tough issues.

3. Employees in this organization sometimes reject others for being different (reversecoded).

4. It is safe to take a risk in this organization.

5. It is difficult to ask other employees in this organization for help (reverse-coded).

6. No one in this organization would deliberately act in a way that undermines my efforts.

7. Working with employees of this organization, my unique skills and talents are valued and utilized.

Note. Items in italics were modified from original scale, which used members of teams, instead of employees of an organization.

\section{Perceived Organizational Justice}

Source: Colquitt, J. A. (2001). On the dimensionality of organizational justice: A construct validation of a measure. Journal of Applied Psychology, 86(3), 386-400.

Instructions: All items have the common stem: "To what extent" and the common response scale.

Scale: 1 = to a small extent; $2=$ to a small-moderate extent; $3=$ to a moderate extent; $4=$ to a moderate-large extent; $5=$ to a large extent.

Distributive Justice

This section includes questions about the payment and rewards you receive at work.

1. Do your pay and rewards reflect the effort you have put into your work?

2. Are your pay and rewards appropriate for the work you have completed? 
3. Do your pay and rewards reflect what you have contributed to the organization?

4. Are your pay and rewards justified, given your performance?

Procedural Justice

This section includes questions about the decision-making procedures used at work to make decisions about important outcomes affecting you.

1. Have you been able to express your views and feelings during those procedures?

2. Have you had influence over the payment and rewards arrived at by those procedures?

3. Have those procedures been applied consistently?

4. Have those procedures been free of bias?

5. Have those procedures been based on accurate information?

6. Have you been able to appeal the payment and rewards arrived at by those procedures?

7. Have those procedures upheld ethical and moral standards?

\section{Perceived Team Social Integration}

Source: Smith, K. G., Smith, K. A., Olian, J. D., Sims Jr, H. P., O'Bannon, D. P., \&

Scully, J. A. (1994). Top management team demography and process: The role of social integration and communication. Administrative Science Quarterly, 412438.

Instructions: Please indicate your level of agreement with the following statements.

Scale: $1=$ strongly disagree, $2=$ disagree, $3=$ slightly disagree, $4=$ neither agree nor disagree, $5=$ slightly agree, $6=$ agree, $7=$ strongly agree

1. The members of my team are quick to defend each other from criticism by outsiders.

2. The successes of other members of my team help me achieve my own objectives.

3. Everyone's input is incorporated into most important company decisions.

4. The members of my team get along together very well.

5. Relationships between members of my team are best described as "win-lose"; if he/she wins, I lose (reverse-coded).

6. The members of my team are always ready to cooperate and help each other.

7. When final decisions are reached, it is common for at least one member of my team to be unhappy with the decision (reverse-coded).

8. There is a great deal of competition between members of my team (reverse-coded).

9. The members of my team really stick together.

Note. Items in italics were modified from original scale, which used the TMG (top management group), instead of my team.

\section{Proactive Personality}

Source: Seibert, S. E., Crant, J. M., \& Kraimer, M. L. (1999). Proactive personality and career success. Journal of Applied Psychology, 84(3), 416-427. 
Instructions: Please indicate the extent to which you agree or disagree with the following statements.

Scale: 1 = strongly disagree, $2=$ disagree, $3=$ slightly disagree, $4=$ neither agree nor disagree, $5=$ slightly agree, $6=$ agree, $7=$ strongly agree

1. I am constantly on the lookout for new ways to improve my life.

2. Wherever I have been, I have been a powerful force for constructive change.

3. Nothing is more exciting than seeing my ideas turn into reality.

4. If I see something I don't like, I fix it.

5. No matter what the odds, if I believe in something I will make it happen.

6. I love being a champion for my ideas, even against others' opposition.

7. I excel at identifying opportunities.

8. I am always looking for better ways to do things.

9. If I believe in an idea, no obstacle will prevent me from making it happen.

10. I can spot a good opportunity long before others can.

Note. Original scale.

\section{Political Skill}

Source: Ferris, G. R., Treadway, D. C., Kolodinsky, R. W., Hochwarter, W. A., Kacmar, C. J., Douglas, C., \& Frink, D. D. (2005). Development and validation of the political skill inventory. Journal of Management, 31(1), 126-152.

Instructions: Please indicate your level of agreement with each of the following statements.

Scale: $1=$ strongly disagree, $2=$ disagree, $3=$ slightly disagree, $4=$ neither agree nor disagree, $5=$ slightly agree, $6=$ agree, $7=$ strongly agree

Networking Ability

1. I spend a lot of time and effort at work networking with others.

2. I am good at building relationships with influential people at work.

3. I have developed a large network of colleagues and associates at work whom I can call on for support when I really need to get things done.

4. At work, I know a lot of important people and am well connected.

5. I spend a lot of time at work developing connections with others.

6. I am good at using my connections and network to make things happen at work.

Interpersonal Influence

1. I am able to make most people feel comfortable and at ease around me. $\dagger$

2. I am able to communicate easily and effectively with others.

3. It is easy for me to develop good rapport with most people. $\dagger$

4. I am good at getting people to like me. 
Social Astuteness

1. I understand people very well. $\dagger$

2. I am particularly good at sensing the motivations and hidden agendas of others.

3. I have good intuition or savvy about how to present myself to others.

4. I always seem to instinctively know the right things to say or do to influence others.

5. I pay close attention to people's facial expressions.

Apparent Sincerity

1. When communicating with others, I try to be genuine in what I say and do.

2. It is important that people believe I am sincere in what I say and do.

3. I try to show a genuine interest in other people.

Note: Items marked with $\uparrow$ indicate the original six items developed by Ferris et al. (1999).

\section{Perceived Support for Innovation}

Source: Anderson, N. R., \& West, M. A. (1998). Measuring climate for work group innovation: development and validation of the team climate inventory. Journal of Organizational Behavior, 19(3), 235-258.

Instructions: Please indicate the degree to which you agree or disagree with the following statements.

Scale: 1 = strongly disagree, $2=$ disagree, $3=$ slightly disagree, $4=$ neither agree nor disagree, $5=$ slightly agree, $6=$ agree, $7=$ strongly agree

1. This organization is always moving toward the development of new answers.

2. Assistance in developing new ideas is readily available.

3. This organization is open and responsive to change.

4. People in this organization are always searching for fresh, new ways of looking at problems.

5. In this organization we take the time needed to develop new ideas.

6. People in the organization cooperate in order to help develop and apply new ideas.

7. Organization employees provide and share resources to help in the application of new ideas.

8. Organization employees provide practical support for new ideas and their application.

Note. Original scale. 


\section{APPENDIX D. SURVEY ITEMS (TIME 3)}

\section{SURVEY 4.}

Rater: Leader

\section{Voice Behavior}

Source: Liang, J., Farh, C. I., \& Farh, J. L. (2012). Psychological antecedents of promotive and prohibitive voice: A two-wave examination. Academy of Management Journal, 55(1), 71-92.

Instructions: Please indicate the degree to which you agree or disagree with the following statements regarding your employee.

Scale: $1=$ strongly disagree, $2=$ disagree, $3=$ neither agree nor disagree, $4=$ agree, $5=$ strongly agree

Promotive Voice

1. Proactively develop and makes suggestions for issues that may influence the unit.

2. Proactively suggest new projects which are beneficial to the work unit.

3. Raise suggestions to improve the unit's working procedure.

4. Proactively voice out constructive suggestions that help the unit reach its goals.

5. Make constructive suggestions to improve the unit's operations.

Prohibitive Voice

1. Advise other colleagues against undesirable behaviors that would hamper job performance.

2. Speak up honestly with problems that might cause serious loss to the work unit, even when/though dissenting opinions exist.

3. Dare to voice out opinions on things that might affect efficiency in the work unit, even if that would embarrass others.

4. Dare to point out problems when they appear in the unit, even if that would hamper relationships with other colleagues.

5. Proactively report coordination problems in the workplace to the management.

Note. Original scale.

\section{Innovative Behavior}

Source: Janssen, O. (2000). Job demands, perceptions of effort-reward fairness and innovative work behaviour. Journal of Occupational and Organizational Psychology, 73(3), 287-302.

Instructions: How often does your employee perform these innovative work behaviors in the workplace? 
Scale $: 1=$ never, $2=$ almost never, $3=$ occasionally, $4=$ fairly often, $5=$ often, $6=$ almost always, $7=$ always

1. Create new ideas for difficult issues.

2. Search out new working methods, techniques, or instruments.

3. Generate original solutions for problems.

4. Mobilize support for innovative ideas.

5. Acquire approval for innovative ideas.

6. Make important organizational members enthusiastic for innovative ideas.

7. Transform innovative ideas into useful applications.

8. Introduce innovative ideas into the work environment in a systematic way.

9. Evaluate the utility of innovative ideas.

Note. Items 1, 2, and 3 measure idea generation; items 4, 5, and 6 measure idea promotion; items 7,8 , and 9 measure idea realization.

\section{Learning Behavior}

Source: Edmondson, A. (1999). Psychological safety and learning behavior in work teams. Administrative Science Quarterly, 44(2), 350-383.

Instructions: Please indicate how often this employee engage in the following behaviors.

Scale: $1=$ never, $2=$ almost never, $3=$ occasionally, $4=$ almost always, $5=$ always

1. This employee asks his/her internal customers (those who receive or use his/her work) for feedback on his or her performance.

2. This employee relies on outdated information or ideas (reverse-coded).

3. This employee actively reviews his/her own progress and performance.

4. This employee does his/her work without stopping to consider all the information he/she has (reverse-coded).

5. This employee regularly takes time to figure out ways to improve his/her work performance.

6. This employee ignores feedback from others in the company (reverse-coded).

7. This employee asks for help from others in the company when something comes up that he/she doesn't know how to handle.

Note. Words in italics were modified from original scale, which used team instead of employee. 
VITA

\section{CYNTHIA SALDANHA HALLIDAY}

Born, Rio de Janeiro, Brazil

2014-2019

Doctoral Candidate / Graduate Assistant

Florida International University

Miami, Florida

\section{PUBLICATIONS AND PRESENTATIONS}

Halliday, C. S., Paustian-Underdahl, S., Ordonez, Z., Rogelberg, S., \& Zhang, H. (2018). Autonomy as a key resource for women in low gender egalitarian countries: A crosscultural examination. Human Resource Management, 52(2), 601-615.

Kim, K., Halliday, C. S., Zhao, Y., Wang, C., \& Von Glinow, M. A. (2018). Rewarding self-initiated expatriates: A skills-based approach. Thunderbird International Business Review, 60(1), 89-104.

Halliday, C. S., Sin, H.-P. (2019, April). Leadership or Personality? What Fosters Followers' Innovative Behavior. The $34^{\text {th }}$ Annual Conference of the Society for Industrial and Organizational Psychology, Washington D.C.

Halliday, C. S., \& Sin, H.-P. (2018, November). LMX and innovative behavior. 2018 Accepted to be presented at the Meeting of the Southern Management Association, Lexington, Kentucky.

Halliday, C. S., Paustian-Underdahl, S., \& Zhang, H. (2018, August). The role of supervisor support, psychological safety and national culture in retaining women in $R \& D$. 78th Annual Meeting of the Academy of Management, Chicago, Illinois.

Paustian-Underdahl, S.C., Sockbeson, C., Hall, A., \& Halliday, C. S. (2018, August). Gender and leadership styles: A meta-analysis of effects across contexts. 78th Annual Meeting of the Academy of Management Conference, Chicago, Illinois.

Halliday, C. S., Ponnapalli, A., Wang, C., Kim, K., \& Newburry, W. (2017, October). The role of sub-national institutions on the corporate social responsibility and corporate reputation relationship. 2017 Meeting of the Southern Management Association, St. Petersburg Beach, Florida.

Halliday, C. S., Paustian-Underdahl, S., Ordonez, Z., Rogelberg, S., \& Zhang, H. (2017, April). Autonomy: A resource for women in low gender egalitarian nations. The 32nd 
Annual Conference of the Society for Industrial and Organizational Psychology, Orlando, Florida.

Halliday, C. S., Paustian-Underdahl, S., \& Fainshmidt, S. (2016, August). Gender diversity on boards: A meta-analytic review. 76th Annual Meeting of the Academy of Management, Anaheim, California.

Halliday, C. S., Kim, K., Zhao, Y., \& Von Glinow, M. A. (2015, June). Multilevel analysis of non-traditional managers on international assignments. 2015 Academy of International Business Annual Meeting, Bangalore, India. 